\title{
Nanocrystal Bioassembly: \\ Asymmetry, Proximity, and Enzymatic Manipulation
}

\author{
Shelley Ann Claridge \\ Department of Chemistry \\ University of California, Berkeley \\ Berkeley, CA 94720 \\ and \\ Materials Sciences Division \\ Lawrence Berkeley National Laboratory \\ Berkeley, CA 94720
}

May 2008

This work was supported by the Director, Office of Science, Office of Basic Energy Sciences, of the U.S. Department of Energy under Contract No. DE-AC02-05CH11231. 
Nanocrystal Bioassembly:

Asymmetry, Proximity, and Enzymatic Manipulation

\section{By}

Shelley Ann Claridge

B.S. (Texas A\&M University) 1997

A dissertation submitted in partial satisfaction of the requirements for the degree of

Doctor of Philosophy

in

Chemistry

and the Designated Emphasis

in

Nanoscale Science and Engineering

in the

Graduate Division

of the

University of California, Berkeley

Committee in charge:

Professor A. Paul Alivisatos, Co-chair Professor Jean M.J. Fréchet, Co-chair

Professor Seung-Wuk Lee

Spring 2008 
The dissertation of Shelley Ann Claridge is approved:

Co-chair

Date

Co-chair

Date

Date

University of California, Berkeley

Spring 2008 
Nanocrystal Bioassembly:

Asymmetry, Proximity, and Enzymatic Manipulation

(C) 2008

by Shelley Ann Claridge 


\author{
Abstract \\ Nanocrystal Bioassembly: \\ Asymmetry, Proximity, and Enzymatic Manipulation \\ by \\ Shelley Ann Claridge \\ Doctor of Philosophy in Chemistry \\ University of California, Berkeley \\ Professor A. Paul Alivisatos, Co-chair \\ Professor Jean M.J. Fréchet, Co-chair
}

Research at the interface between biomolecules and inorganic nanocrystals has resulted in a great number of new discoveries. In part this arises from the synergistic duality of the system: biomolecules may act as self-assembly agents for organizing inorganic nanocrystals into functional materials; alternatively, nanocrystals may act as microscopic or spectroscopic labels for elucidating the behavior of complex biomolecular systems. However, success in either of these functions relies heavily upon the ability to control the conjugation and assembly processes.

In the work presented here, we first design a branched DNA scaffold which allows hybridization of DNA-nanocrystal monoconjugates to form discrete assemblies. Importantly, the asymmetry of the branched scaffold allows the formation of asymmetric 
assemblies of nanocrystals. In the context of a self-assembled device, this can be considered a step toward the ability to engineer functionally distinct inputs and outputs.

Next we develop an anion-exchange high performance liquid chromatography purification method which allows large gold nanocrystals attached to single strands of very short DNA to be purified. When two such complementary conjugates are hybridized, the large nanocrystals are brought into close proximity, allowing their plasmon resonances to couple. Such plasmon-coupled constructs are of interest both as optical interconnects for nanoscale devices and as 'plasmon ruler' biomolecular probes.

We then present an enzymatic ligation strategy for creating multi-nanoparticle building blocks for self-assembly. In constructing a nanoscale device, such a strategy would allow pre-assembly and purification of components; these constructs can also act as multi-label probes of single-stranded DNA conformational dynamics. Finally we demonstrate a simple proof-of-concept of a nanoparticle analog of the polymerase chain reaction.

Co-chair Date Date 


\section{Table of Contents}

Acknowledgements..................................................

Chapter 1 - Introduction..........................................1

Chapter 2 - Reactions of Nanocrystal Molecules............................4

Chapter 3 - Directed Assembly of Discrete Gold Nanoparticle Groupings

Using Branched DNA Scaffolds...........................15

Introduction................................................. 16

Results and Discussion.....................................19

Conclusion.......................................................

Materials and Methods.........................................31

References......................................................

Chapter 4 - Isolation of Discrete Nanoparticle-DNA Conjugates for Plasmonic

Applications...........................................41

Introduction................................................ 42

Results and Discussion...................................44

Conclusion.................................................52

Materials and Methods.........................................53

References..................................................57

Chapter 5 - Enzymatic Ligation Creates Discrete Multi-Nanoparticle

Building Blocks for Self-Assembly.....................60

Introduction...............................................61

Results and Discussion....................................63

Conclusion................................................ 75

Materials and Methods......................................76 
References............................................... 84

Appendix A - Supporting Materials for Chapter 3 ....................87

Appendix B - Supporting Materials for Chapter 4....................93

Appendix C - Supporting Materials for Chapter 5....................94 


\section{Acknowledgements}

"... they are ill discoverers that think there is no land when they can see nothing but sea."

- Francis Bacon

Journeys of exploration have always been fraught with hardship and periods of fruitless wandering; graduate school has been no exception. My ultimate success has been made possible by the help of many people, a few of whom I will mention here.

Thanks go first to my parents Karen and David, who started me on the path of learning early, and offered me their unequivocal support no matter which direction I chose. I also thank my brother Jonathan, one of my best and most lasting friends, for his tireless and cheerful editing, and for letting me finish my $\mathrm{PhD}$ before him.

My boyfriend David sustains me. He and his family, who have become my family as well, are a source of happiness and comfort in the sometimes rocky world of research.

In chemistry, poetically, people often refer to their advisor as their 'chemical father.' I have been fortunate to have two such remarkable figures in my life at Berkeley.

I thank Professor Jean Fréchet, who enthusiastically welcomed me into his group when there was no reason to believe I would succeed as a chemist. Without his endless encouragement in the first two years, I would not be writing this dissertation today. He has reminded me often that graduate school, while important, is merely a prelude to a career, and has constantly challenged me to better myself on all fronts. 
I thank Professor Paul Alivisatos for supporting me and my experiments in good times and bad. His zenlike patience and positive outlook have served as a reminder that there may, indeed, be land ahead no matter how long one has been at sea.

I would also like to acknowledge a third, equally important, influence in my development as a chemist: my undergraduate advisor Professor David Bergbreiter. His inimitable humor, candor, and joy in the practicality of chemistry are reflected in the following equation, which formed the basis for his discussion of saponification, and is one of my earliest memories of enjoying chemistry.

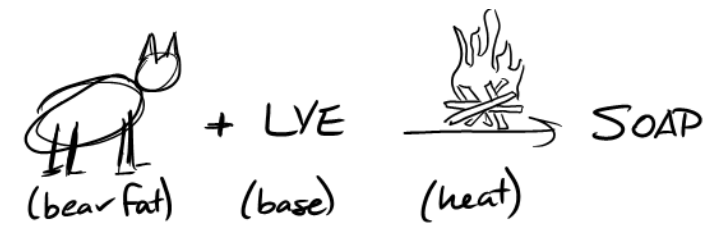




\section{Chapter 1 - Introduction}

Research at the interface between biomolecules and inorganic nanocrystals has resulted in a great number of new discoveries. In part this arises from the synergistic duality of the system: biomolecules may act as self-assembly agents for organizing inorganic nanocrystals into functional materials which may ultimately form the basis of nanoscale devices; alternatively, nanocrystals may act as microscopic or spectroscopic labels for elucidating the behavior of complex biomolecular systems. However, success in either of these functions relies heavily upon the ability to control the conjugation and assembly processes.

Although both proteins and DNA are promising as scaffolds and assembly agents for patterning inorganic nanocrystals, we have chosen DNA as a scaffold since its sequence-specific base pairing allows programmable self-assembly of several different components in a controlled way based on the sequences chosen. In Chapter 2, we discuss the feasibility of using DNA as the basis for a chemistry of 'nanocrystal molecule' reactions and outline synthetic goals which guide the research presented herein.

In Chapter 3, we design a branched DNA scaffold which allows hybridization of DNA-nanocrystal monoconjugates to form discrete assemblies. Importantly, the asymmetry of the branched scaffold allows the formation of asymmetric assemblies of nanocrystals. In the context of a self-assembled device, this can be considered a step toward the ability to engineer functionally distinct inputs and outputs. 
Chapter 4 discusses the development of an anion-exchange high performance liquid chromatography purification method which allows large gold nanocrystals attached to single strands of very short DNA to be purified from unconjugated gold as well as from nanocrystals functionalized with multiple strands of DNA. When two such complementary conjugates are hybridized, the large nanocrystals are brought into close proximity, allowing their plasmon resonances to couple. Shorter interparticle distances lead to stronger plasmon coupling. For devices, the ability to create plasmon-coupled assemblies would be important since plasmon coupling represents one of a very limited number of methods for directing light energy below the diffraction limit. As molecular probes, discrete self-assembled DNA-gold nanostructures are of interest as 'plasmon rulers' which can measure conformational changes of the DNA linker with subnanometer sensitivity, again due to plasmon coupling between the nanoparticles.

Chapter 5 presents an enzymatic ligation strategy for creating multi-nanoparticle building blocks for self-assembly. Such DNA-nanoparticle building blocks can be designed such that the nanocrystals are connected by single-stranded DNA. Thus, they retain the sequence-specific targeting ability of their DNA linker. In constructing a nanoscale device, such a strategy would allow pre-assembly and purification of components, which would likely lead to higher yields of fully assembled products when the components were combined. These constructs can also act as multi-label probes of single-stranded DNA conformational dynamics, which are of fundamental biological interest in understanding the physical chemistry of DNA. We also demonstrate that enzymatic ligation may be performed repeatedly in tandem with thermal cycling to 
exponentially amplify the amount of DNA-gold dimer product. This can be considered to be a simple demonstration of a nanoparticle analog of the polymerase chain reaction. 


\section{Chapter 2 - Reactions of Nanocrystal Molecules}

Recent materials research has found that it is possible to create nanocrystals of many different materials with controlled size, shape, and morphology. ${ }^{1}$ Physical properties of nanoparticles are often vastly different than those of the same materials in bulk, and can result in a wide array of remarkable functions such as tunable photoluminescence ${ }^{2}$ or dramatically increased catalytic activity. These properties may also be influenced in a distance-dependent manner by the proximity of other nanoparticles. For instance, linear and branched arrays of noble metal nanocrystals have been shown to be effective means of directing light energy below the diffraction limit, ${ }^{3}$ a property which could eventually be exploited to create nanoscale optical interconnects for devices. Both noble metal and semiconductor nanocrystals have been used as distancedependent Förster resonant energy transfer (FRET) probes in biomolecular detection noble metals can act as FRET quenchers, ${ }^{4}$ while semiconductor quantum dots and rods can act as non-bleaching FRET donors. ${ }^{5}$ Pairs of noble metal nanocrystals have also been developed as plasmonic rulers which can detect changes in interparticle distance with subnanometer sensitivity. ${ }^{6,7}$

Ultimately it may be possible to create libraries of advanced functional materials with tailored properties by controlling the relative placement of individual nanocrystals to tune the coupling of their physical properties. This can be considered analogous to the formation of molecules out of atoms, in which both the atomic composition and the relative spatial placement and bonding of atoms influence molecular function. 
In a 'nanocrystal molecule', ${ }^{8}$ in which individual nanocrystals are the 'atomic' building blocks, the symmetry, connectivity, and interparticle distances within the structure determine the properties of the assembly just as bonding and atomic connectivity determine the physical properties of a molecule. Thus in developing this new paradigm for materials science, it is crucial to understand the set of reactions that can be used to assemble nanocrystal building blocks into 'molecules'. This includes the set of nanocrystal 'atoms' available and how they may be connected, as well as the physical properties of the resulting assemblies.

Four requirements will be addressed for nanocrystal molecule reactions in analogy to traditional chemical synthesis. First is the requirement for scalability or parallel assembly. Many types of nanocrystal assemblies may be constructed in a serial fashion on a surface using scanning probe microscopy (SPM) techniques. ${ }^{3}$ However, just as in chemical synthesis, for most practical applications the utility of a nanocrystal molecule will hinge on the ability to synthesize a large number of assemblies in parallel. Second is the need to control the 'bonding' - the connections between the nanocrystals as part of a parallel assembly process. This is important both in the sense that bond length may influence the extent to which the nanocrystals interact, and in that the bond may or may not be susceptible to further reactions after linking the nanocrystals, just as single and double bonds between carbon atoms exhibit different reactivities. The third requirement is modular synthesis, the ability to construct a number of different nanocrystal molecules with different properties via similar synthetic approaches. The final requirement is the ability to establish and control chirality, which in a device context 
is relevant to creating functionally distinct inputs and outputs, and in a biological sensor might relate to the chirality of the biological substrate molecule.

\section{Parallel Self-Assembly Using Biomolecules}

Self-assembling biological systems offer a number of excellent means by which to address these challenges in nanocrystal molecule synthesis. Organisms have evolved based on their ability to perform parallel self-assembly of components at the nanoscale with exquisite precision and selectivity. ${ }^{9}$ Thus many researchers have investigated the possibility of integrating proteins, DNA, and other self-assembling biomaterials as agents to direct the formation of discrete nanocrystal molecules or more extensive nanocrystal networks. ${ }^{10,11}$

\section{Modularity in Biomolecular Assembly}

A key prerequisite for this research is the ability for a biomolecule to bind to the surface of an inorganic nanocrystal. Typically inorganic nanocrystals are passivated with molecules containing functional groups such as phosphonic acids, carboxylic acids, amines, or thiols, which bind to the nanocrystal surface. ${ }^{1}$ Fortuitously, amines, thiols, and carboxylic acids occur naturally in proteins, ${ }^{9}$ and commercially available DNA oligonucleotides are widely available with a thiol modification. Since biotin-tagging has been widely developed for use in biological experiments, a large number of nanocrystal assembly experiments have also been performed in which a nanocrystal surface is passivated with a layer of streptavidin protein, and biotin-streptavidin attachment is used for subsequent assembly. ${ }^{11}$ Thus a biomolecular approach to nanocrystal molecule synthesis can be considered to be modular in terms of attachment chemistry. 
Although both proteins and DNA offer distinct advantages in terms of selfassembly, one key benefit to using DNA is the ability to program self-assembly in a very modular manner, using Watson-Crick base pairing. Pairs of DNA strands hybridize to form double helices based on sequence complementarity between the two strands, and the number of distinct sequences available increases with the number of bases $n$ in each strand, as $4^{n}$. Thus in principle it is possible to create an extremely large number of mutually exclusive complementary sequence pairs as a basis for self-assembly. In practice DNA can also hybridize to nearly-complementary sequences, so the number of 'distinct' sequence pairs is less than $4^{n}$. However, since hybrids in self-assembly experiments are typically at least 10 bases in length (and often as many as 100), nominally resulting in at least $1 \times 10^{6}$ sequence pairs, this restriction is not prohibitive.

An additional degree of modularity which can be engineered into DNAnanoparticle building blocks for nanocrystal assembly is that of control over the number of DNA strands used to functionalize the particle surface, which can have major implications for the physical properties of the nanocrystal molecules produced. As an example, initial demonstrations of DNA-directed assembly were presented in 1996 in back-to-back publications by Mirkin ${ }^{12}$ and Alivisatos. ${ }^{8}$ Both related experiments in which DNA was modified with a thiol functional group on one end, which was used to covalently link DNA strands to the surface of gold nanoparticles.

Mirkin and coworkers reported that by conjugating large numbers of DNA strands to the surface of each nanoparticle, it was possible to engineer systems in which reversible aggregation of the nanoparticles was observed in response to addition of a complementary DNA strand. ${ }^{12}$ Aggregation was accompanied by a large shift in the 
plasmon resonance, visible as a striking color change from red to blue in the nanoparticle solution. Thus the system was capable of acting as a 'colorimetric' biosensor for the presence of the linker strand.

In complementary experiments, Alivisatos and coworkers showed that by instead forming discrete monoconjugates, in which each nanoparticle was attached to a single DNA strand, it was then possible to use the nanoparticle conjugates to form small groupings with precise control over the placement of each nanoparticle. ${ }^{8}$ These experiments represented the first demonstration of the assembly of nanocrystal-DNA molecules with well-defined composition and connectivity. This type of precise assembly would be essential in creating nanoscale device components, as well as for singlemolecule characterization in biosensing experiments.

Later experiments by Zanchet et al. ${ }^{13}$ demonstrated that it is possible not only to distinguish between building blocks comprising one or many DNA strands, but also to isolate gold nanoparticles discretely functionalized with zero, one, two, three, or more strands of DNA using agarose gel electrophoresis. In this technique, gold nanoparticles are first combined with thiolated DNA to give a statistical mixture of conjugates bearing zero, one, two, or more strands of DNA. The mixture is loaded into a porous gel and subjected to an electric field, which causes components of the mixture to separate based upon both their size and their charge. Discrete bands form for structures comprising different numbers of DNA strands. The bands may then be extracted to yield purified starting materials with a controlled number of functional DNA linkers for constructing nanocrystal molecules. 


\section{Control Over Bond Properties in Biomolecular Assembly}

One straightforward means of control over bonding in DNA-directed nanocrystal assembly is that of DNA sequence length, which can be used to determine interparticle distance, in analogy to bond length. Double-helical DNA in its standard form has a width of approximately $2 \mathrm{~nm}$, and its length scales with the number of DNA bases $n$, as $0.34 \mathrm{~nm}$ $\mathrm{x} n .{ }^{9}$ With helices ranging from 10-100 bases, the resulting interparticle distances should then be tunable from approximately 3 - $33 \mathrm{~nm}$, spanning a useful range for observing interparticle interactions such as FRET or plasmonic coupling. In practice, the precision of the interparticle distance is typically limited by a number of factors. In solution, the finite persistence length of double-helical $\mathrm{DNA}^{14}$ as well as the flexible thiolated linker typically used result in a distribution of interparticle distances, which have recently been investigated using small angle X-ray scattering (SAXS) techniques. When DNA-linked nanocrystal molecules are deposited on surfaces for characterization by transmission electron microscopy (TEM) or atomic force microscopy (AFM), capillary forces exerted on the structure during drying can cause more extreme distributions of interparticle distances and even larger-scale nonspecific aggregation.

Control over interparticle distance in nanocrystal molecules, both in solution and on surfaces, is a key issue in determining whether and how the nanocrystal properties may couple. The concept of distance dependence in energetic coupling is familiar in the context of FRET between donor and acceptor organic fluorophores, ${ }^{15}$ in which a photon is absorbed by the donor chromophore and reemitted at a longer wavelength, which may then be absorbed by the acceptor chromophore. The efficiency of energy transfer depends upon the distance $r$ between the two chromophores as $1 / r^{6}$. Similar coupling may be 
observed substituting an inorganic semiconductor nanoparticle for one organic chromophore. $^{5}$

One compelling motivation for the study and control of distance-dependent properties in gold nanocrystal assemblies, both for device and biosensing applications, is the strong surface plasmon resonance associated with noble metal nanoparticles. ${ }^{4}$ Plasmons in single particles arise from a collective oscillation of conduction band electrons in response to irradiation by light at characteristic wavelengths. ${ }^{16}$ The plasmon resonance wavelength for a nanoparticle depends upon the polarizability of the metal, the size of the particle, and the dielectric constant of the surrounding medium. Importantly, the resonance is also sensitive to the proximity of other resonating nanoparticles. This can be understood by considering each particle as an oscillating dipole. Coupling between dipoles can lead to either a red shift or a blue shift in the plasmon absorption maximum wavelength, depending on whether the coupling is favorable or unfavorable. Such coupling is strongly dependent upon the distance between particles. These effects are typically observable for pairs of nanoparticles at least $20 \mathrm{~nm}$ in diameter with a center-tocenter distance no more than two times the particle diameter. It should be noted that plasmon coupling is much stronger in aggregates composed of many particles; thus in the colorimetric experiments performed by Mirkin, a strong shift resulting in a color change from red to blue can be observed in DNA-linked networks of 13-nm particles.

The strong distance-dependence of plasmon shifts in coupled DNA-linked noble metal nanoparticles can be used as a single-molecule plasmonic ruler to measure conformational changes in the DNA linker. ${ }^{7}$ This technique is complementary to distance-dependent FRET measurements ${ }^{15}$, which can typically be applied only for 
distances less than $10 \mathrm{~nm}$ and on relatively short timescales, up to several minutes. Plasmon shift and scattering intensity measurements have been applied on length scales of tens of nanometers. Measurements may also be taken on much longer timescales (up to days), since the nanoparticle probes, unlike organic fluorophores, do not blink or bleach. However, significant challenges exist in purifying discrete nanoparticle-biomolecule substrates for such experiments, since the inorganic nanocrystals are typically extremely large (on the order of $40 \mathrm{~nm}$ ) relative to the biomolecules (generally from 2-30 nm). Many chromatographic purification techniques discriminate at least in part based on size, thus it is often difficult to differentiate between nanoparticles conjugated to zero, one, or more biomolecules. In Chapter 4 we discuss the development of protocol allowing purification of large nanocrystals conjugated to discrete numbers of very short DNA strands, which may be used for single-molecule plasmon ruler experiments.

In addition to the 'bond length' considerations described above, it is also useful to consider the means by which a DNA linker may be further manipulated or 'reacted' to influence the behavior of the assembly. In the plasmon ruler example above, addition of the enzyme ecoRV can cause bending and then cleavage of the DNA helix, first intensifying plasmon coupling and then removing coupling. The use of other DNA-active enzymes such as polymerases and ligases has also been investigated. More generally, we expect that this will be a productive avenue for investigation, since there are a wide variety of commercially available enzymes which act on DNA to influence its length, hybridization, and conformation. Many of these have specific requirements for activity, including sequence-selectivity, a requirement for a chemical modification such as phosphorylation, or a chemical additive such as adenosine triphosphate (ATP) or 
nicotinamide adenine dinucleotide (NAD). ${ }^{9}$ In a materials context, these can be considered an orthogonal set of internal and external signals which may be used to direct the behavior of a nanocrystal molecule. In Chapter 5, we discuss the use of enzymes to create assemblies in which multiple nanocrystals are linked by single-stranded DNA (ssDNA). For these assemblies, the ability of the ssDNA linker to hybridize in a sequence specific manner after linkage of the nanocrystals represents an additional type of reactivity.

\section{Controlling Chirality in Biomolecular Assembly}

Establishing and controlling chirality has become an important problem in molecular synthesis, ${ }^{17}$ as chirality can control optical and pharmaceutical as well as materials properties. Chirality is equally vital to biological function ${ }^{9}$, and thus it may be anticipated that in creating nanocrystal molecules via biomolecular linkers it will ultimately be possible to reflect biological chirality in designed materials. The asymmetrically branched DNA scaffolds discussed in Chapter 3 demonstrate one solution for symmetry-breaking in nanocrystal molecules; true chirality may soon be achieved using more extensive and rigid DNA scaffolds incorporating crossovers ${ }^{18,19}$ or other motifs. $^{20}$

\section{References}

(1) Murray, C. B.; Kagan, C. R.; Bawendi, M. G. Annual Review of Materials Science 2000, 30, 545-610.

(2) Nirmal, M.; Brus, L. Accounts of Chemical Research 1999, 32, 407-414. 
(3) Maier, S. A.; Kik, P. G.; Atwater, H. A.; Meltzer, S.; Harel, E.; Koel, B. E.; Requicha, A. A. G. Nature Materials 2003, 2, 229-232.

(4) Daniel, M. C.; Astruc, D. Chemical Reviews 2004, 104, 293-346.

(5) Medintz, I. L.; Clapp, A. R.; Mattoussi, H.; Goldman, E. R.; Fisher, B.; Mauro, J. M. Nature Materials 2003, 2, 630-638.

(6) Sonnichsen, C.; Reinhard, B. M.; Liphard, J.; Alivisatos, A. P. Nature Biotechnology 2005, 23, 741-745.

(7) Reinhard, B. M.; Sheikholeslami, S.; Mastroianni, A.; Alivisatos, A. P.; Liphardt, J. Proceedings of the National Academy of Sciences of the United States of America 2007, 104, 2667-2672.

(8) Alivisatos, A. P.; Johnsson, K. P.; Peng, X. G.; Wilson, T. E.; Loweth, C. J.; Bruchez, M. P.; Schultz, P. G. Nature 1996, 382, 609-611.

(9) Voet, D.; Voet, J. G. Biochemistry; 2 ed.; John Wiley and Sons, Inc.: New York, 1995.

(10) Niemeyer, C. M. Angewandte Chemie-International Edition 2001, 40, 4128-4158.

(11) Katz, E.; Willner, I. Angewandte Chemie-International Edition 2004, 43, 6042-6108.

(12) Mirkin, C. A.; Letsinger, R. L.; Mucic, R. C.; Storhoff, J. J. Nature 1996, $382,607-609$.

(13) Zanchet, D.; Micheel, C. M.; Parak, W. J.; Gerion, D.; Alivisatos, A. P. Nano Letters 2001, 1, 32-35.

(14) Bustamante, C.; Bryant, Z.; Smith, S. B. Nature 2003, 421, 423-427. 
(15) Jares-Erijman, E. A.; Jovin, T. M. Nature Biotechnology 2003, 21, 13871395.

(16) Kreibig, U. V., M. Optical Properties of Metal Clusters; Springer: Berlin, 1995.

(17) Corey, E. J.; Guzman-Perez, A. Angewandte Chemie-International Edition 1998, 37, 388-401.

(18) Seeman, N. C. Journal of Biomolecular Structure \& Dynamics 1990, 8, 573-581.

(19) Zheng, J. W.; Constantinou, P. E.; Micheel, C.; Alivisatos, A. P.; Kiehl, R. A.; Seeman, N. C. Nano Letters 2006, 6, 1502-1504.

(20) Rothemund, P. W. K. Nature 2006, 440, 297-302. 


\title{
Chapter 3 - Directed Assembly of Discrete Gold Nanoparticle Groupings Using Branched DNA Scaffolds
}

\begin{abstract}
The concept of self-assembled dendrimers is explored for the creation of discrete nanoparticle assemblies. Hybridization of branched DNA trimers and nanoparticle-DNA conjugates results in the synthesis of nanoparticle trimer and tetramer complexes. Multiple tetramer architectures are investigated, utilizing Au-DNA conjugates with varying secondary structural motifs. Hybridization products are analyzed by gel electrophoresis, and discrete bands are observed corresponding to structures with increasing numbers of hybridization events. Samples extracted from each band are analyzed by transmission electron microscopy, and statistics compiled from micrographs are used to compare assembly characteristics for each architecture. Asymmetric structures are also produced in which both 5 and $10 \mathrm{~nm}$ Au particles are assembled on branched scaffolds. This chapter has been reproduced with permission from Chem.
\end{abstract} Mater. 2005, 17, 1628-1635. 


\section{Introduction}

Current investigations in nanomaterials have identified the need for greater control over the patterning of nanoscale components. The ability to program nanoparticle assemblies may be crucial to characterizing and directing their function. ${ }^{1 ; 2}$ Considerable effort has been directed towards investigating the effect of gold nanoparticle placement on the resulting plasmon resonance, since the physical properties of nanoparticles can be strongly influenced by surrounding nanoparticles. ${ }^{3-6}$ Neighboring nanoparticles can affect the resonance frequency in a distance-dependent manner, allowing electromagnetic energy to propagate along linear arrays. In this fashion, controlled arrangements of nanoparticles can be used to direct the propagation of light on a length scale smaller than the wavelength of the light itself. ${ }^{7}$

Although many synthetic routes to nanoparticles of controlled morphology and composition have been established, the programmed spatial arrangement of nanoparticles remains a challenge. Arrays can be fabricated via AFM manipulation or e-beam lithography, ${ }^{8}$ however self-assembly provides an attractive alternative if methods can be developed that allow sufficient control over feature size and geometry. Many avenues to self-assembly are currently under investigation, several of which take advantage of macromolecular elements from biological systems. ${ }^{9-12}$

A number of approaches employ the DNA-based assembly of nanoparticles. DNA functionalized with a thiol or amino moiety can undergo facile ligand exchange with citrate or phosphine coated gold nanoparticles to give DNA-Au conjugates. ${ }^{13}$ Hybridization to a complementary single stranded oligonucleotide template can then be used to align nanoparticles at defined distances along a single DNA helix. ${ }^{13-18}$ Radial assemblies have also been generated by combining two types of nanoparticle conjugates, 
each bearing multiple copies of complementary single-stranded DNA. ${ }^{19 ; 20}$ Larger threedimensional arrays of programmed DNA have been prepared by Seeman ${ }^{21}$ and Mao and co-workers, ${ }^{22}$ and their use as scaffolds are currently under investigation. ${ }^{23}$ More complex scaffolds can also be accessed using branched DNA, in which multiple sequences are attached in a nonlinear arrangement. Branched DNA has recently been synthesized using solution phase coupling ${ }^{24}$ as well as variations in solid phase techniques that incorporate the branching unit directly on the support ${ }^{25 ; 26}$ or within the DNA sequence. Preliminary studies using statistical conjugates indicate that phosphoramidite branched DNA will be an appropriate scaffold for nanoparticle assemblies. ${ }^{27}$

Controlled conjugation is of primary importance in the formation of discrete DNAbased nanoparticle arrays. Several means to controlled conjugation have been investigated, including electrophoresis, ${ }^{28}$ solid-phase methods, ${ }^{29}$ and solution-phase extraction based on product solubility. ${ }^{30}$ In the electrophoretic protocol used here, conjugation initially results in a statistical mixture of non-, mono-, and poly-conjugated Au particles based on the DNA:Au ratio used. Agarose gel electrophoresis of the mixture results in discrete bands corresponding to successive orders of conjugation, if the length of the conjugating DNA is great enough. Previously single-stranded 50-base oligonucleotides have been shown to give discrete bands when conjugated to 5 and $10 \mathrm{~nm}$ $\mathrm{Au}^{28}{ }^{28}$ Bands can then be isolated from the gel, yielding purified conjugates of the desired order.

Here, the DNA-based self-assembly of discrete nanoparticle structures is explored, extending the scope and characterization of this approach with an investigation into the synthesis of gold nanoparticle trimer and tetramer arrangements, illustrated in Figure 3.1. Since the DNA length required for conjugate purification is greater than the maximum 
arm length feasible for the synthesis of branched DNA on an automated synthesizer, two hybridization strategies are pursued, as shown in Figure 3.2. In the first design, the excess bases on the 50 base conjugate form a hairpin loop near the branch point, decreasing the maximum distance between nanoparticles in a single structure. In the second strategy, excess conjugate bases are moved to the exterior of the structure. This eliminates the possible steric issues caused by multiple tails at the branch point and allows formation of extended structures, which can potentially act as the basis of a switchable system if scaffold and conjugates are crosslinked covalently. Hybridized structures are separated by gel electrophoresis, resulting in discrete bands that are extracted and analyzed by transmission electron microscopy (TEM). Band identities are suggested based on the number of hybridization events, and statistics and images from TEM analysis are provided to support the validity of the proposed structure. Such self-assembled arrangements represent a first step toward accessing complex arrays of nanoparticles with multiple branch points and nanoparticle sizes.

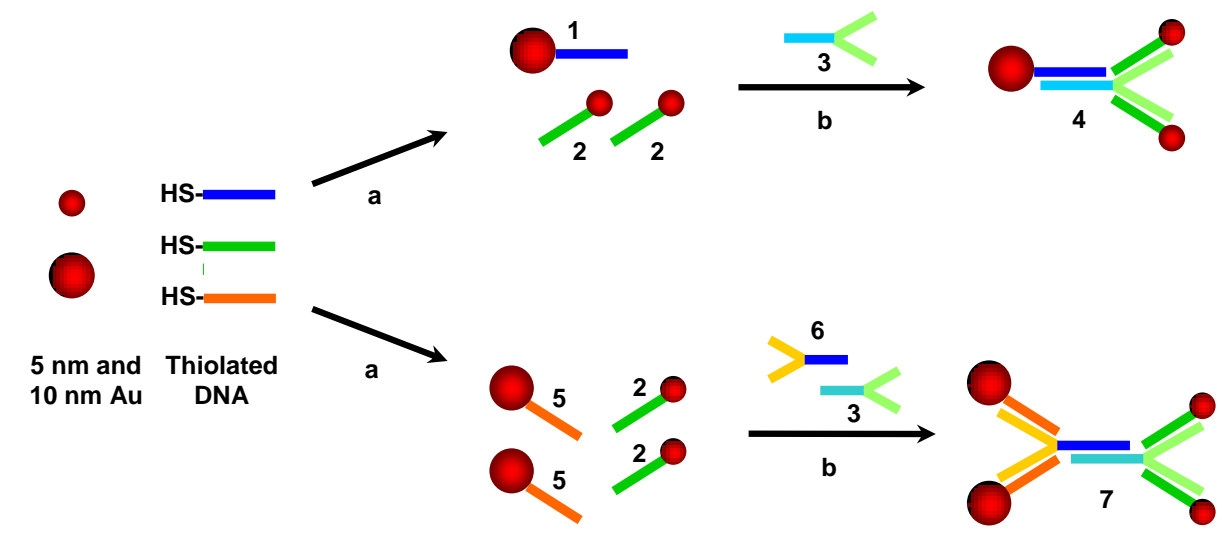

Figure 3.1. Nanoparticle assemblies using branched DNA scaffolds. (a) Conjugation and purification of single conjugates $\mathbf{1}, \mathbf{2}$, and $\mathbf{5}$. (b) Hybridization with branched scaffolds $\mathbf{3}$ and $\mathbf{6}$ to produce asymmetric trimer $\mathbf{4}$ and tetramer $\mathbf{7 .}$ 
a)

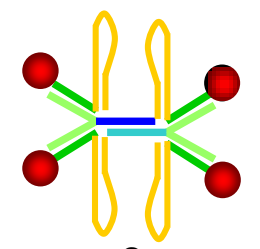

8 b)

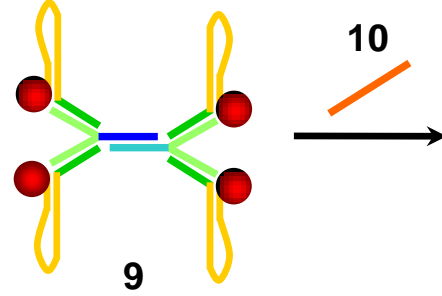

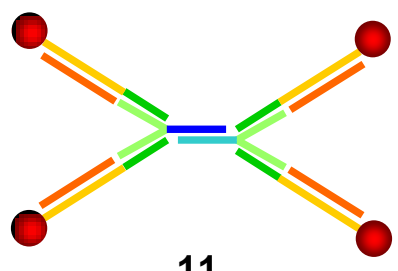

11

Figure 3.2. Symmetric tetramer assemblies using branched DNA scaffolds. (a) Tetramer structure 8 with interior hairpin loops. (b) Tetramer structure 9 with exterior hairpin loops hybridizing to complementary linear DNA sequence $\mathbf{1 0}$ to form extended tetramer 11.

\section{Results and Discussion}

Design of Self-Assembled Au-DNA Complexes. Gold nanoparticles were arranged on a DNA scaffold to generate both symmetric and asymmetric trimers and tetramers as illustrated in Figure 3.1. The branched DNA was synthesized on solid phase in the 3' to $5^{\prime}$ direction to produce a three armed dendritic structure comprised of one unique and two duplicate sequences. To generate well-defined assemblies, gold nanoparticles functionalized with a single complementary DNA sequence were utilized. Previous studies in the Alivisatos and Schultz groups have shown that mixing 5 or $10 \mathrm{~nm} \mathrm{Au}$ particles with thiolated DNA produces a statistical mixture of mono- and poly-conjugates, but that monoconjugated gold can be purified by agarose gel electrophoresis if a sufficiently long DNA sequence is used for conjugation. ${ }^{13 ; 15 ; 28 ; 31 ; 36}$ Use of 50 base single stranded oligonucleotides allows for adequate separation of conjugates of both 5 and 10 $\mathrm{nm} \mathrm{Au}$ particles. Due to the directionality inherent in the synthesis of the DNA trimer, Au-DNA conjugates were synthesized with either a $3^{\prime}$ or $5^{\prime}$ thiol attachment, as necessary. 
DNA sequences were designed to minimize competitive binding events between strands. The arm length of the dendritic DNA was chosen so as to give a melting temperature above room temperature for stable duplex formation $\left(\mathrm{T}_{\mathrm{m}} \sim 60{ }^{\circ} \mathrm{C}\right)$ while accommodating the pore size of the solid support. In the following discussions, sequences are labeled as $\mathbf{A}, \mathbf{B}$, etc. with the sequences given in Table $1 . \mathbf{A B}_{2}$ refers to a branched DNA trimer having one $\mathbf{A}$ and two $\mathbf{B}$ arms. $\mathbf{A}^{\prime}$ denotes a sequence complementary to $\mathbf{A}$. The portion of the conjugate sequence not hybridizing to the scaffold, labeled $\mathbf{H}$, formed a hairpin loop with either 8 or 9 hybridizing bases on each end, and a $T_{m}$ of approximately $50{ }^{\circ} \mathrm{C}$. While hairpin formation slightly decreases the band separation observed in the conjugate purification, the separation is still more than adequate for monoconjugate isolation.

Internal hairpin structures were formed from conjugates in which the hairpin sequence was positioned near the branch point of the scaffold; for external hairpin and extended structures, the hairpin sequence was proximal to the nanoparticle, placing it at the exterior edge of the scaffold. In the extended architecture, linear unthiolated sequence $\mathbf{H}^{\prime}$ was also added to prevent hairpin formation. For asymmetric structures, a non-hybridizing tail of sequence $\mathbf{N}$ was used. 
Table 3.1. DNA sequences for the synthesis of nanoparticle assemblies.

\begin{tabular}{|c|c|}
\hline Strand & DNA Sequence $\left(3^{\prime}-5^{\prime}\right){ }^{a, b, c}$ \\
\hline $\mathbf{H A}^{\prime}$ & $\begin{array}{c}C C C G A G \text { TTC TGA TGT TTA CGC TTA } A C T T G G G C \underline{C} \\
\text { AGT GTA TCG CAA TGA CG-SH }\end{array}$ \\
\hline HB' $^{\prime}$ & $\begin{array}{c}\text { HS-CCC GAG TTC TGA TGT TTA CGC TTA } A C T T G G \\
G C \underline{\text { TAC AGG TCC AAA GCA CG }}\end{array}$ \\
\hline $\mathbf{B}^{\prime} \mathbf{H}$ & $\frac{\mathrm{HS}-\mathrm{TGA} \text { CAG GTC CAA AGC ACG } C C C G A G T T C}{\text { TGA TGT TTA CGC TT } A C T T G G G C}$ \\
\hline $\mathbf{C}^{\prime} \mathbf{N}$ & 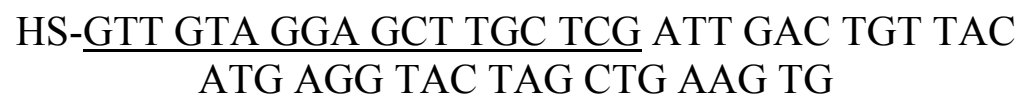 \\
\hline $\mathbf{H}^{\prime}$ & $\begin{array}{l}\text { GCC CAA GTT AAG CGT AAA CAT CAG AAC TCG } \\
\text { GG }\end{array}$ \\
\hline $\mathbf{A B}_{2}$ & $\begin{array}{c}\text { CGT CAT TGC GAT ACA CTG-X-(CGT GCT TTG GAC } \\
\text { CTG TCA })_{2}\end{array}$ \\
\hline $\mathbf{A}^{\prime} \mathbf{B}_{2}$ & $\begin{array}{l}\text { CAG TGT ATC GCA ATG ACG-X-(CGT GCT TTG GAC } \\
\text { CTG TCA })_{2}\end{array}$ \\
\hline $\mathrm{AC}_{2}$ & $\begin{array}{l}\text { CGT CAT TGC GAT ACA CTG-X-(CGA GCA AGC TCC } \\
\text { TAC AAC })_{2}\end{array}$ \\
\hline
\end{tabular}

Synthesis and Characterization of a Symmetric $10 \mathrm{~nm}$ Au-DNA Trimer.

Characterization of nanoparticle trimers provides a simple model of the behavior of nanoparticle assemblies on branched scaffolds. Gold nanoparticle trimers with conjugate hairpins near the branch point were prepared using the $\mathbf{A B}_{2}$ DNA trimer and $\mathbf{H A}^{\prime}$ and B'H monoconjugated $10 \mathrm{~nm}$ Au particles. The reaction mixture was analyzed using gel electrophoresis as shown in Figure 3.3a. In the gel, free gold colloid and monoconjugated $10 \mathrm{~nm}$ gold were run as standards in lanes 1 and 2, respectively. Varying volumes of trimer reaction mixture were loaded in different lanes, corresponding to gold nanoparticle 
loadings from 2 pmol to 8 pmol, to allow for simultaneous visualization of bands with differing intensities. For example, band 5 only becomes clearly visible with high loading in lane 5, while bands 2 and 3 blur together at this loading and are only visible as distinct bands at lower loadings as in lane 3 .

Although DNA hybridization is inherently both specific and stable, a mixture of hybridization products is found, as seen in lanes $3-5$. Since bands are detected visually based on the presence of the highly colored gold colloid, there is no band corresponding to unhybridized branched DNA. The five remaining possibilities for statistical hybridization are pictured to the right of the gel in Figure 3.3a. The free gold and monoconjugate standards provide positive identification of bands 1 and 2. Structures with increasing numbers of nanoparticles and amounts of DNA are expected to exhibit reduced mobilities since their larger size slows progress through the pores of the gel. Thus bands 3-5 are assigned to structures corresponding to one, two, and three hybridization events respectively. The relative retention of each band is calculated as a ratio of the band migration to that of free $10 \mathrm{~nm}$ gold. Based on the band-structure correlations above, a fully formed trimer was found to have a retention of 0.44 .

Sample isolated from each band was analyzed via TEM. Representative micrographs from bands 2-5 are shown in Figure 3.3b. According to the suggested band assignments, structures isolated from bands 2 and 3 should each contain a single nanoparticle, while those from bands 4 and 5 should contain dimers and trimers, respectively. Visual inspection of the nanoparticle groupings in the micrographs supports these assignments, and compiled statistics demonstrate that band 5 contains the highest percentage of particles participating in trimer groupings. 
(a)

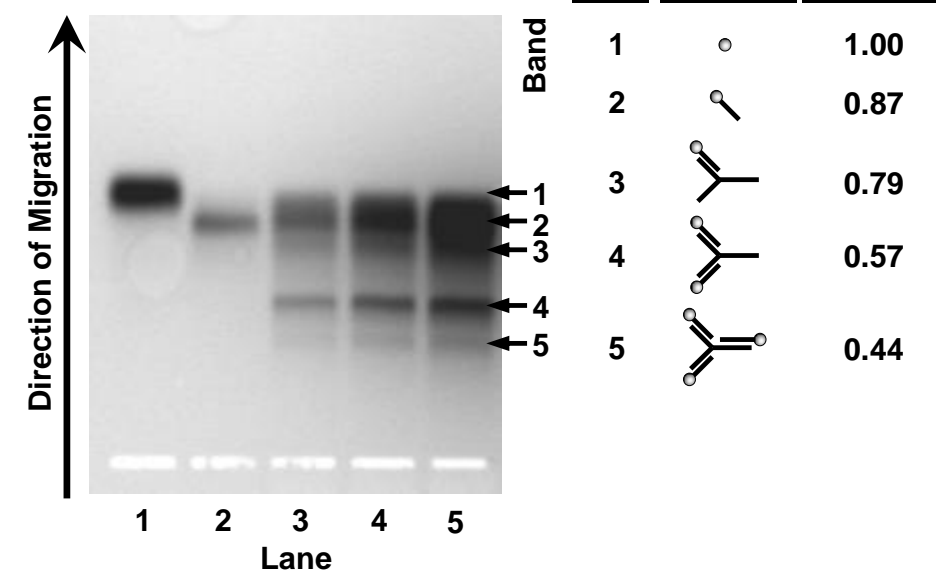

(b)
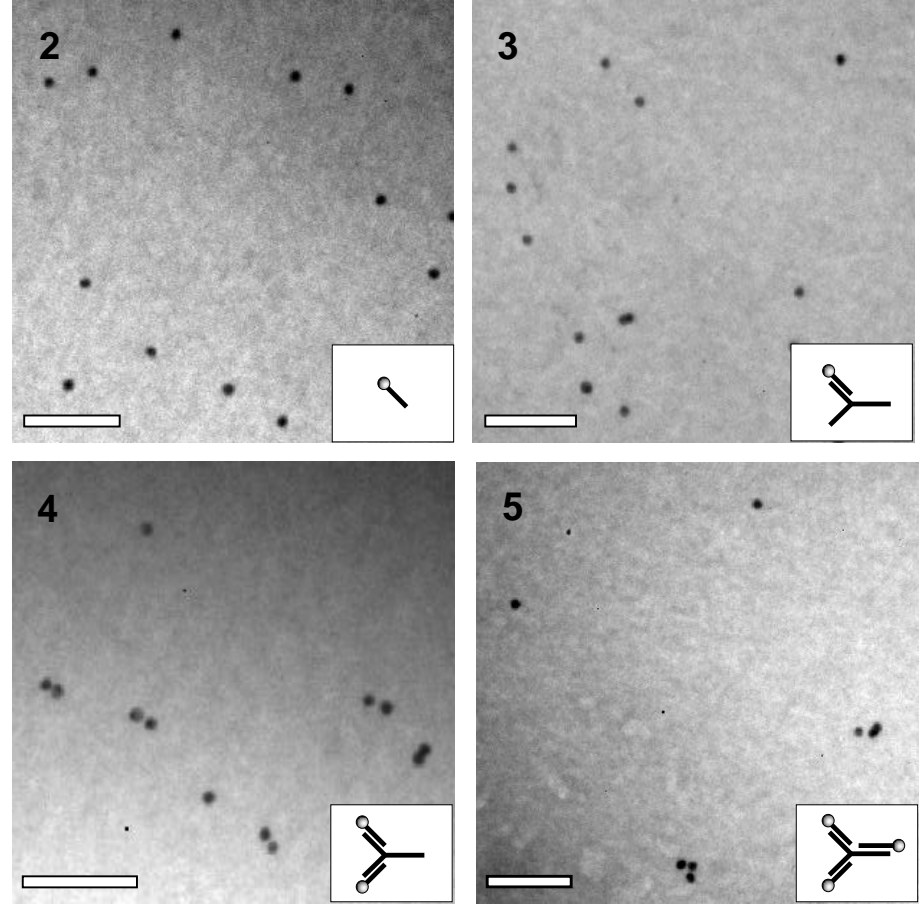

Figure 3.3. Analysis of internal hairpin trimer hybridization products by (a) agarose gel electrophoresis and (b) transmission electron microscopy. (a) Lane 1: $10 \mathrm{~nm}$ gold. Lane 2: $10 \mathrm{~nm}-\mathbf{H B}^{\prime}$ conjugate. Lanes 3-5: $10 \mathrm{~nm}$ trimer mixture, loaded by conjugate content, with 2, 4, and 8 pmol of Au-DNA per lane. (b) Transmission electron micrographs, labeled by band number and suggested structure. Scale bar $=100 \mathrm{~nm}$. 
Synthesis and Characterization of Three Symmetric $10 \mathrm{~nm}$ Au-DNA Tetramers. Having successfully synthesized and purified gold nanoparticle trimers using a branched DNA scaffold, this approach was elaborated using two complementary branched DNA trimers to provide a more complex scaffold. Three versions of the tetramer architecture were explored. Two branched scaffolds $\mathbf{A B}_{2}$ and $\mathbf{A}^{\prime} \mathbf{B}_{2}$ were prepared and hybridized with appropriate conjugates to form the three structures shown in Figure 3.2: Au-B'H to generate the internal hairpin tetramer 8, Au-HB' for the external hairpin 9, and both Au$\mathbf{H B}^{\prime}$ and $\mathbf{H}^{\prime}$ for the extended structure 11. Each design has a different potential benefit: internal hairpins guarantee a small distance between nanoparticles in a single structure; external hairpins likely provide similar particle spacing, but without the potential steric issues caused by hairpins near the branch point; addition of complementary DNA to linearize the hairpin is expected to increase interparticle distances, but may facilitate conjugate hybridization since the hybridizing sequence will not be folded back toward the nanoparticle surface. In addition, the external hairpin and extended structures could be developed as a bistable or 'switchable' system in which the interparticle distance could be varied with temperature or with the addition of the $\mathbf{H}^{\prime}$ extending sequence. This functionality would rely on the covalent crosslinking of scaffold to scaffold and scaffold to conjugate, since the melting temperatures of the 18-base scaffold arms and the hairpin sequence are similar.

Hybridization products were analyzed by agarose gel electrophoresis (Figure 3.4), and band retentions for the internal hairpin tetramer architecture were compared with those for the internal hairpin trimer. Electrophoretic analysis of the tetramer hybridization yielded more bands than trimer hybridization, which was expected since tetramer hybridization affords a larger number of possible structures. Visible bands are believed 
to correspond to the eight structures shown in Figure 3.4a, with the identities of bands 1 and 2 again confirmed by the migration of the free gold and conjugate standards. Retention values for each band were calculated relative to the free gold standard. Retention values of bands 3 and 5 in the tetramer gel ( 0.80 and 0.60 , respectively) are comparable with those of bands 3 and 4 of the trimer hybridization gel ( 0.79 and 0.57$)$, as would be expected for identical single-scaffold monomer and dimer structures. The retention of tetramer band 6 ( 0.57 for the internal hairpin structure) is also comparable to that of trimer band 4, so an additional experiment was performed to show that tetramer bands 5 and 6 indeed correspond to the single- and double-scaffold dimers, respectively (see Supporting Information). Retentions for tetramer band 7 (0.43) and trimer band 5 (0.44), both assigned as structures containing three nanoparticles, were quite similar despite the extra DNA scaffold in the structure from the tetramer hybridization. This implies that the number of nanoparticles is more important than the quantity of DNA present in a structure, in determining the rate of migration through the gel. An analogous case is bands 5 (single-scaffold dimer), 6 (double-scaffold dimer), and 7 (trimer) in the tetramer gel: structures in bands 5 and 6 differ by a branched scaffold and have almost identical retentions $(\Delta=0.03)$, whereas bands 5 and 7 differ by addition of a nanoparticle conjugate and have a more substantial difference in retention $(\Delta=0.17)$.

Comparison of retention values across the three tetramer architectures shows that bands are similarly retained even with differences in structure organization. One likely explanation is that structures migrate through the gel in a partially collapsed form, in agreement with previous findings for the behavior of Au-DNA conjugates. ${ }^{31}$ Thus, little difference is expected when comparing the migrations of internal hairpin structures to those of external hairpin structures. 
Visual analysis of band optical densities reveals that in both outside-hairpin and extended structures, the desired tetramer structure (band 8) is formed in significantly higher yield than for the inside-hairpin structure. While band 8 is extremely faint in the inside-hairpin gel even at high sample loadings (8 pmol Au-DNA conjugate), it is clearly visible in both external hairpin and extended gels at much lower loading (2.5 pmol). Further, the increased percentage of conjugate hybridization (reduced band 2 intensity) in the extended structure gel implies that straightening of the hairpin facilitates scaffoldconjugate hybridization. In both outside-hairpin and extended hybridizations, singlescaffold dimers appear to be the primary product, suggesting that the central arm of the tetramer is the weak link in both the external hairpin and extended structures. Ongoing experiments involve exploration of methods for increasing the extent and stability of central arm hybridization; realizing this goal should greatly increase tetramer yields, which are currently very low.

Transmission electron micrographs were used to evaluate nanoparticle organization in tetramer hybridization samples before and after electrophoretic purification. Statistical analysis of TEM micrographs from an unpurified external hairpin hybridization sample shows nanoparticles participate in groupings in ratios that appear to correlate with the optical densities of the bands observed in the gel: $38 \%$ monomer, $33 \%$ dimer, $20 \%$ trimer, and 9\% tetramer (excluding 11\% higher-order aggregates). Micrographs of samples extracted from hybridization gels again support the assertion that bands with decreasing mobility correlate to increasing numbers of hybridization events (Figure 3.5). Statistics compiled from the full set of micrographs of each sample (see Supporting Information) show that for external hairpin and extended structures, approximately 60$75 \%$ of the particles participate in their predicted grouping. For internal hairpin samples, 
statistics were less conclusive, suggesting that the steric factors introduced by the hairpin near the branch point decrease structure stability. Since a small number of monomers and high-order aggregates were observed in micrographs from most grids, it is believed that some amount of structural reorganization is induced by the extraction and grid preparation processes, however the extent of reorganization is far greater in the internal hairpin samples. Importantly, the large majority of particles participating in a single structure type per band in both external hairpin and extended structures seems to indicate that each discrete band initially contains structures of a single type, and that optimization of the extraction procedure will yield samples of pure dimers, trimers, and tetramers.

Diameters were determined for all tetramers extracted from band 8 of the extended and external hairpin hybridization gels, with the diameter taken to be the maximum distance between centers of two particles in a single grouping. Theoretical maximum diameters were calculated to be 55 and $32 \mathrm{~nm}$, respectively, for the extended and external hairpin structures, assuming that hairpins remained intact and flexible points adopt their most extended configurations. Observed mean diameters were found to be 44 and $35 \mathrm{~nm}$, with a significant number of diameters within $1 \mathrm{~nm}$ of each calculated maximum. Although the mean diameter of the extended structure is greater than that of the external hairpin as expected, it is also well below the theoretical maximum. This result is not unreasonable given that a nick near the midpoint of each arm allows considerable rotation, which can only decrease the interparticle distances. For the external hairpin structure, $46 \%$ the diameters were within $1 \mathrm{~nm}$ of the calculated maximum for a structure with intact hairpins. However, $30 \%$ of the diameters were also between the calculated maxima for the intact external hairpin and the extended structures, suggesting that one or more of the 


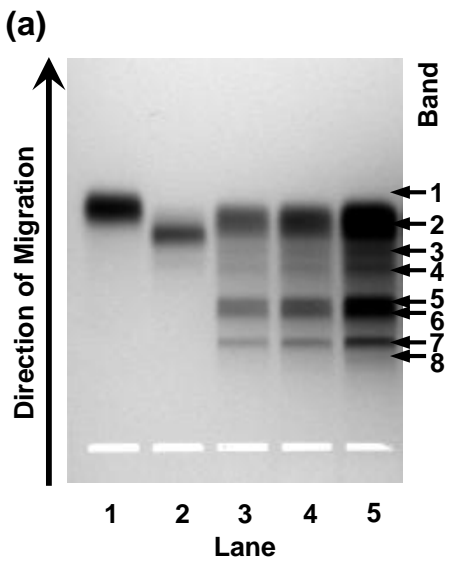

Band Structure Retention

(b)
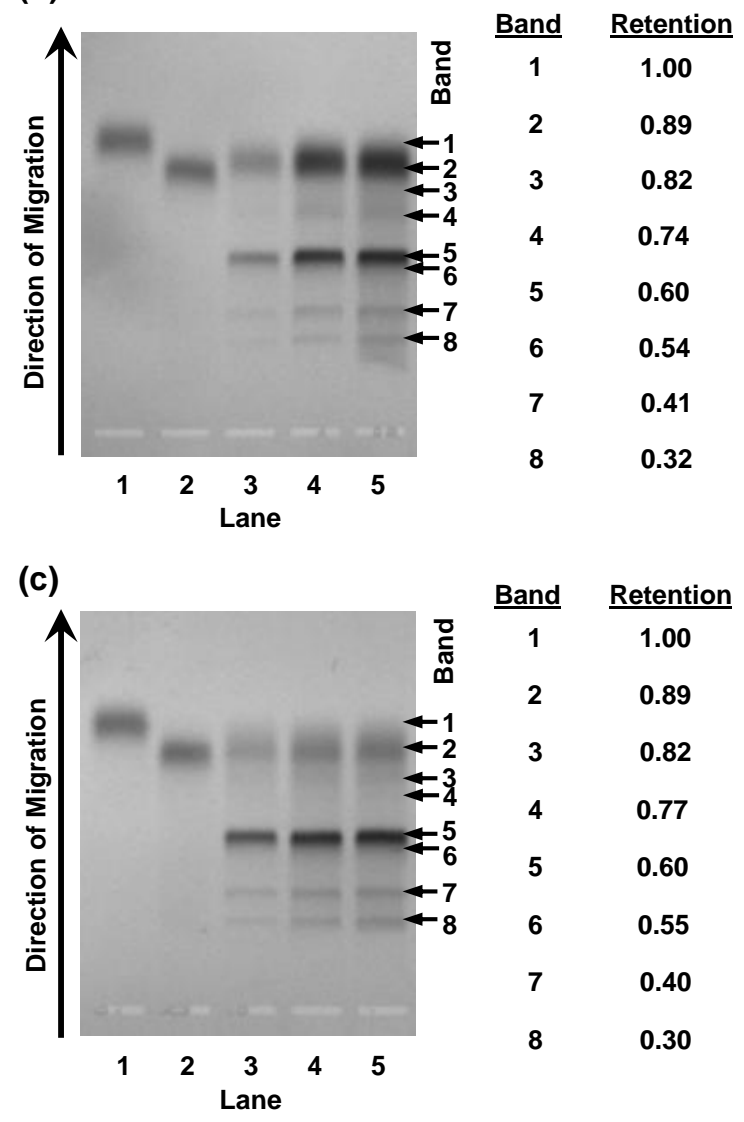

Figure 3.4. Electrophoretic analysis of tetramer hybridization products for (a) internalhairpin (b) external-hairpin, and (c) extended structures. Lane 1: $10 \mathrm{~nm}$ gold. Lane 2: 10 nm-B'H conjugate. Lanes 3-5: $10 \mathrm{~nm}$ tetramer mixture, loaded by conjugate content, with 2, 4, and 8 pmol of Au-DNA per lane in (a), and 1.5, 2.5, and 5 pmol of Au-DNA per lane in (b) and (c). 

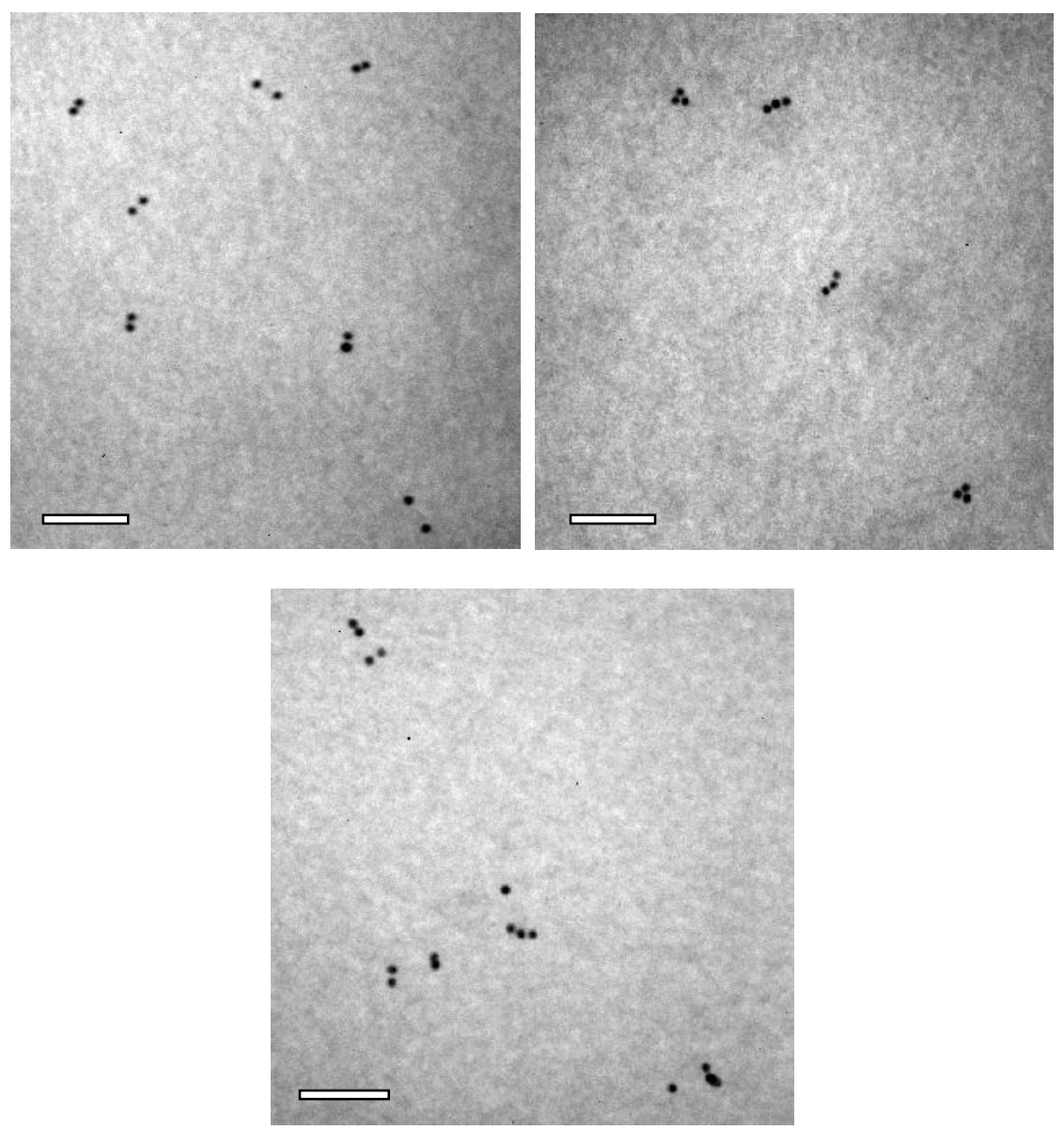

Figure 3.5. Representative transmission electron micrographs of sample extracted from dimer, trimer, and tetramer bands in the external hairpin tetramer gel shown in Figure 3.4b. Scale bar $=100 \mathrm{~nm}$.

four hairpins may partially unwind, allowing the conjugated gold particle to move farther from the others in the structure.

Expanding the Synthetic Capabilities: Asymmetric Assemblies.

The asymmetric nature of the branched DNA scaffold was further exploited for the synthesis of self-assembled asymmetric trimer and tetramer structures containing both 5 
$\mathrm{nm}$ and $10 \mathrm{~nm}$ gold particles, as shown in Figure 3.6. Trimers were prepared using $5 \mathrm{~nm}$ Au-B' $\mathbf{H}$ and $10 \mathrm{~nm}$ Au-HA' $\mathbf{A}^{\prime}$ conjugates and an $\mathbf{A B}_{2}$ scaffold. Tetramers were prepared

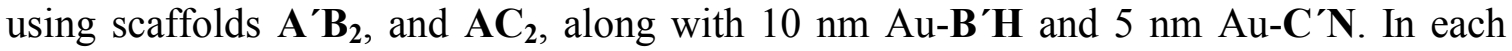
asymmetric structure sample, the highest band was extracted from the agarose gel and analyzed by TEM (Figure 3.6). The target assemblies were present in micrographs for both the trimer and tetramer structures, in addition to lower-order structures and aggregates. Future experiments will utilize asymmetric assemblies to further probe the conformations adopted at flexible points in the structure.
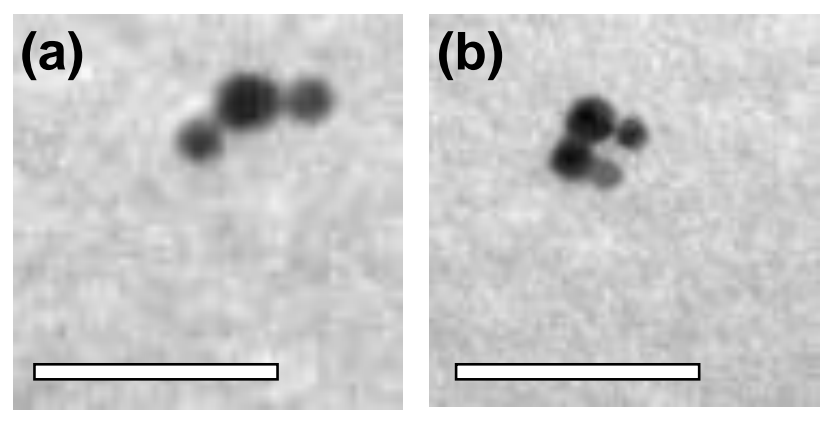

Figure 3.6. Transmission electron micrographs of (a) asymmetric 5 and $10 \mathrm{~nm}$ trimer, and (b) asymmetric 5 and $10 \mathrm{~nm}$ tetramer. Scale bar $=50 \mathrm{~nm}$.

\section{Conclusion}

Branched DNA scaffolds and gold nanoparticles conjugated to single strands of thiolated linear DNA have been hybridized to give discrete nanoparticle trimers and tetramers of controlled composition, as evidenced by gel electrophoresis and TEM. Three tetramer architectures were investigated, and though the extended architecture resulted in the highest degree of conjugate hybridization, both external hairpin and extended 
conformations produced tetramer assemblies in similar yields as measured by gel band intensities. Micrographs from extracted gel bands show that a large majority of particles from each band participate in a single type of grouping (tetramers, trimers, dimers, etc.), suggesting that each discrete band in the gel corresponds to a specific structure type, and indicating that development of an optimized band extraction procedure will make gel electrophoresis purification appropriate for isolation of a variety of nanoparticle assemblies.

Ongoing experiments focus on increasing tetramer yield and forming a bistable DNAAu structure through covalent crosslinking of scaffolds and conjugates. Crosslinking of exterior hairpins may also provide a means to achieve accurate close placement of even larger nanoparticles, which currently require long conjugate sequences ( $>100$ bases) for monoconjugate purification. Additionally, use of a more rigid branching moiety in the scaffold will reduce conformational flexibility, resulting in more predictable structure geometry. Optical experiments will be performed on assemblies in solution, using darkfield microscopy to probe the plasmon coupling behavior of trimer and tetramer structures.

\section{Materials and Methods}

General Procedures. Citrate coated 5 and $10 \mathrm{~nm}$ gold particles with $<10 \%$ deviation in diameter were purchased from Ted Pella (Redding, CA). In these solutions, nanoparticle concentrations were approximately $80 \mathrm{nM}$ for the $5 \mathrm{~nm}$ particles, and $10 \mathrm{nM}$ for $10 \mathrm{~nm}$ particles. The bis-( $p$-sulfonatophenyl $)$ phenylphosphine dihydrate dipotassium ligand used to stabilize the nanoparticles in aqueous solutions was obtained from Strem Chemicals (Newburyport, MA). DNA purified by polyacrylamide gel electrophoresis 
(PAGE), thiolated and non-thiolated $\mathbf{H A}^{\prime}, \mathbf{A}^{\prime} \mathbf{H}, \mathbf{B}^{\prime} \mathbf{H}, \mathbf{C}^{\prime} \mathbf{N}$, and $\mathbf{H}^{\prime}$, was purchased from Integrated DNA Technologies (Coralville, IA). Nanoparticle sample purification and concentration were carried out in a Fisher Marathon $8 \mathrm{~K}$ bench top centrifuge. UV-Vis absorption measurements were taken using a Perkin-Elmer Lambda 35 spectrometer.

Transmission electron microscopy was performed using the Phillips Tecnai 12 instrument at the Electron Microscopy Laboratory at the University of California, Berkeley, CA, with samples visualized at a magnification of $87 \mathrm{k}$. Carbon-coated copper TEM grids (Ted Pella) were prepared according to modified literature procedure ${ }^{31}$ described briefly here: $5 \mu 1$ of dilute aqueous sample was spotted onto a grid and left for 90 seconds before lightly touching one edge of the grid to filter paper to wick off moisture. Grids were then allowed to air dry prior to analysis.

Electrophoresis of Au-DNA Conjugates and Nanoparticle Assemblies. Gels were prepared with $3 \%$ agarose by weight in $0.5 \mathrm{X}$ Tris-Borate-EDTA (TBE) buffer. Samples were diluted with 3X loading buffer containing 15\% Ficoll 400 (Fluka, Milwaukee, WI) and then loaded into the appropriate well. Gels were run at $5 \mathrm{~V} / \mathrm{cm}$ for $90 \mathrm{~min}$ and then visualized under white light using an Eagle Eye ${ }^{\circledR}$ II CCD and EagleSight ${ }^{\circledR} 2.2$ software from Stratagene (La Jolla, CA) or a GelDoc gel imaging system from UVP (Upland, CA).

Synthesis of Branched DNA. Branched DNA was synthesized in the 3' to $5^{\prime}$ direction on solid phase on a $1 \mu \mathrm{mol}$ scale using an Expedite ${ }^{\mathrm{TM}} 8909$ DNA synthesizer (Applied Biosystems, Foster City, CA) with $\mathrm{A}^{\mathrm{Pac}}, \mathrm{G}^{\mathrm{iPr}-\mathrm{Pac}}, \mathrm{C}^{\mathrm{Ac}}$, and $\mathrm{T}$ (UltraMILD) phosphoramidites from Glen Research Corporation (Sterling, VA). A symmetric doubler phosphoramidite available from Glen Research was used to introduce the branch point; the standard synthesizer protocol was modified to allow a 15 minute coupling time for the doubler phosphoramidite. DNA was purified by $10 \%$ denaturing polyacrylamide gel 
electrophoresis. ${ }^{32}$ The identity of the trimers was confirmed with matrix assisted laser desorption ionization time-of-flight (MALDI-TOF) mass spectrometry using a PerSeptive Biosystems Voyager-DE instrument in negative ion mode, with samples crystallized in a matrix of 0.35 M 3-hydroxypicolinic acid (HPA) ${ }^{33}$ and $0.1 \mathrm{M}$ ammonium citrate in a 2:1 mixture of $\mathrm{CH}_{3} \mathrm{CN}$ and $\mathrm{H}_{2} \mathrm{O}$. MALDI-TOF MS: $(\mathrm{m} / \mathrm{z}) \mathbf{A B}_{2}$ Calc.: $16962(\mathrm{M}-\mathrm{H})$. Found: 16897. A'B'B $\mathbf{B}_{2}$ Calc.: $16972(\mathrm{M}-\mathrm{H})$. Found: 16964. $\mathbf{A C}_{2}$ Calc.: 16892 (M-H). Found: 16874.

Synthesis of Gold-DNA Conjugates. Gold samples were prepared following literature procedure ${ }^{13}$ To $100 \mathrm{~mL}$ of citrate coated gold nanoparticle solution, $60 \mathrm{mg}$ of bis-( $p$ sulfonatophenyl)phenylphosphine dihydrate dipotassium salt was added, and the mixture was stirred at room temperature in order to allow phosphine ligands to replace the citrate ligands. Following overnight incubation, $\mathrm{NaCl}$ was added to the stirring mixture until a color change from red to cloudy purple was observed. The solution was transferred to 50 $\mathrm{mL}$ centrifuge tubes and centrifuged at room temperature for $15 \mathrm{~min}$ at $3000 \mathrm{rpm}$ to collect the precipitated gold. The supernatant was removed, and the pellet re-suspended in approximately $1 \mathrm{~mL}$ of phosphine buffer $\quad\left(\begin{array}{llll}1 & \mathrm{mg} & \text { of } & \text { bis- }(p-\end{array}\right.$ sulfonatophenyl)phenylphosphine in $1 \mathrm{~mL}$ of de-ionized water). Samples were then concentrated at room temperature using 50k MWCO Centricon ${ }^{\circledR}$ centrifugal concentrators (Millipore, Billerica, MA) for 5-15 minutes at $3000 \mathrm{rpm}$, to a final nanoparticle concentration of $5.0-10.0 \mu \mathrm{M}$ for $5 \mathrm{~nm}$ Au particles and 1.0-1.5 $\mu \mathrm{M}$ for $10 \mathrm{~nm}$ particles. Nanoparticles and Au-DNA conjugates were quantified by measuring the absorbance at $\lambda$ $=520 \mathrm{~nm}$ and calculating the concentration using Beer's law based on their extinction coefficients: $\varepsilon_{520}(5 \mathrm{~nm})=9.3 \times 10^{6} \mathrm{M}^{-1} \mathrm{~cm}^{-1}$ and $\varepsilon_{520}(10 \mathrm{~nm})=8.1 \times 10^{7} \mathrm{M}^{-1} \mathrm{~cm}^{-1}$. 
To prepare Au-DNA conjugates, $3^{\prime}$ - or 5'-thiolated DNA was mixed with concentrated gold colloid in a molar ratio chosen to maximize the monoconjugate yield, typically $0.5-$ 2.0 DNA:Au. A final concentration of $50 \mathrm{mM} \mathrm{NaCl}$ was achieved using a solution of 250 $\mathrm{mM} \mathrm{NaCl}$, and the mixture was incubated at room temperature for 1 hour before adding one-fifth volume 15\% Ficoll loading buffer and loading into agarose gels.

For $5 \mathrm{~nm} \mathrm{Au}$ conjugates, sufficient sample was added to achieve a loading of $120 \mathrm{pmol}$ of Au per lane; for $10 \mathrm{~nm}$ conjugates, a loading of $20 \mathrm{pmol}$ of Au per lane was used. Following 90 minutes of electrophoresis, gels were cut downstream of the monoconjugate band, and glass fiber filter paper and 10k MWCO dialysis membrane were inserted. After a further 7-9 minutes of gel electrophoresis, the desired band entered the filter paper and was stopped by the dialysis membrane. The filter paper was removed and the sample eluted by centrifuging with a $0.22 \mu \mathrm{m}$ centrifugal filter. The sample was then further concentrated using 50k MWCO Centricon ${ }^{\circledR}$ centrifugal filters at room temperature for 510 minutes at $2500 \mathrm{rpm}$, to a final conjugate concentration of approximately $2.0 \mu \mathrm{M}$ for conjugates of $5 \mathrm{~nm} \mathrm{Au}$ particles and approximately $0.5 \mu \mathrm{M}$ for conjugates of $10 \mathrm{~nm}$ particles. Concentrated conjugate was collected from the top of the filter and quantified by measuring the absorption at $520 \mathrm{~nm}$.

Synthesis of Internal Hairpin Au-DNA Trimer. Au-DNA conjugates Au-HA' and Au-B' $\mathbf{H}$ bearing $10 \mathrm{~nm}$ gold particles were mixed with the branched trimer $\mathbf{A B}_{2}$ in 50 $\mathrm{mM} \mathrm{NaCl}$. The mixture was heated briefly to $75^{\circ} \mathrm{C}$ to ensure complete melting of the DNA strands and then allowed to cool slowly to room temperature overnight in order to form stable duplexes. Typically, a 1.5-fold molar excess of conjugates was used in order to maximize the number of hybridized structures. Following overnight incubation, the 
sample was analyzed by agarose gel electrophoresis. Bands were isolated using the filter paper and dialysis membrane procedure described for the Au-DNA conjugates.

Synthesis of Internal Hairpin Au-DNA Tetramer (8). To prepare the symmetric tetramer, the DNA trimers $\mathbf{A B}_{\mathbf{2}}$ and $\mathbf{A}^{\prime} \mathbf{B}_{\mathbf{2}}$ were hybridized with 6 equivalents of $10 \mathrm{~nm}$ Au-B'H conjugate in $50 \mathrm{mM} \mathrm{NaCl}$ using the hybridization protocol described for the trimer synthesis. Gel electrophoresis was also performed as described previously, and the sample was extracted using a crush and soak procedure in which each band was cut out, finely chopped, and gently agitated in $50 \mu \mathrm{L} 0.5 \mathrm{X}$ TBE for 5 minutes prior to preparation of TEM grids.

\section{Synthesis of External Hairpin (9) and Extended Au-DNA Tetramers (11).} Symmetric external hairpin and extended Au-DNA tetramers were prepared and extracted as described for the internal hairpin tetramer. In this case trimers $\mathbf{A B}_{2}$ and $\mathbf{A}^{\prime} \mathbf{B}_{2}$ were hybridized with 6 equivalents of $10 \mathrm{~nm}$ Au-HB' conjugate and 0 or 12 equivalents of $\mathbf{H}^{\prime}$ for external hairpin and extended structures, respectively.

Synthesis of Asymmetric Au-DNA Structures. Branched scaffold $\mathbf{A B}_{2}, 10 \mathrm{~nm} \mathrm{Au-}$ $\mathbf{H A}^{\prime}$ conjugate, and $5 \mathrm{~nm}$ Au-B' $\mathbf{H}$ conjugate were hybridized to generate the asymmetric trimer, using approximately a 1.5 fold molar excess of conjugate per binding site. Asymmetric tetramers were prepared by incubating $\mathbf{A C}_{\mathbf{2}}, \mathbf{A}^{\prime} \mathbf{B}_{2}, 10 \mathrm{~nm} \mathrm{Au}-\mathbf{C}^{\prime} \mathbf{N}$, and $5 \mathrm{~nm}$ Au-B'H in a 1:1:4:4 molar ratio. Incubation, electrophoretic analysis, and TEM were performed as described above.

Statistics. Statistical analysis was performed on micrographs from each grid using either literature procedure ${ }^{31}$ or visual inspection to determine the percentage of particles participating in tetramer, trimer, dimer, and other groupings. Micrographs were first evaluated by Image Pro Plus graphics analysis software (Media Cybernetics, Inc.) to 
maximize the contrast between the particles and background. The number and distance between particles were counted, and the resulting data analyzed using a Labview (National Instruments) program. A particle was considered to be part of a tetramer if three and only three other particles were within an appropriate distance for connection via the DNA scaffold, approximately $30 \mathrm{~nm}$ for internal hairpin tetramers and $55 \mathrm{~nm}$ for external hairpin and extended tetramers. This distance is calculated to be the sum of the lengths of the three scaffold arms, the length of the branch points, twice the length of the six-carbon thiolating linker, and twice the radius of the gold particles. For internal hairpin trimers, the same criteria were applied to groups of three particles; distance calculations assuming a single scaffold give a diameter of approximately $20 \mathrm{~nm}$. It should be noted that although each 18 base hybridizing arm is shorter than the persistence length of helical DNA, ${ }^{34: 35}$ the conformational flexibility at the branch points of the scaffold and at the thiol attachment points make it possible for all particles in a hybridized structure to lie in contact with one another. Tetramer diameters were also evaluated using Image Pro Plus software, taking the diameter of a structure to be the maximum distance between particle centers.

\section{References}

(1) Xia, Y. N.; Yang, P. D.; Sun, Y. G.; Wu, Y. Y.; Mayers, B.; Gates, B.; Yin, Y. D.; Kim, F.; Yan, Y. Q. Adv.Mater. 2003, 15, 353-389.

(2) Zhang, Z. L.; Horsch, M. A.; Lamm, M. H.; Glotzer, S. C. Nano Lett. 2003, 3, 1341-1346. 
(3) Kottmann, J. P.; Martin, O. J. F. Opt.Lett. 2001, 26, 1096-1098.

(4) Sonnichsen, C.; Franzl, T.; Wilk, T.; von Plessen, G.; Feldmann, J. New J.Phys. 2002, 4, 93.

(5) Storhoff, J. J.; Lazarides, A. A.; Mucic, R. C.; Mirkin, C. A.; Letsinger, R. L.; Schatz, G. C. J.Am.Chem.Soc. 2000, 122, 4640-4650.

(6) Su, K. H.; Wei, Q. H.; Zhang, X.; Mock, J. J.; Smith, D. R.; Schultz, S. Nano Lett. 2003, 3, 1087-1090.

(7) Maier, S. A.; Brongersma, M. L.; Kik, P. G.; Meltzer, S.; Requicha, A. A. G.; Atwater, H. A. Adv.Mater. 2001, 13, 1501-1505.

(8) Maier, S. A.; Brongersma, M. L.; Kik, P. G.; Meltzer, S.; Requicha, A. A. G.; Atwater, H. A. Adv.Mater. 2001, 13, 1501-1505.

(9) Niemeyer, C. M. Appl.Phys.A: Mater.Sci.Process. 1999, 68, 119-124.

(10) Niemeyer, C. M. Angew.Chem.Int.Ed. 2001, 40, 4128-4158.

(11) Storhoff, J. J.; Mirkin, C. A. Chem.Rev. 1999, 99, 1849-1862.

(12) Hooker, J. M.; Kovacs, E. W.; Francis, M. B. J.Am.Chem.Soc. 2004, 126, 37183719.

(13) Loweth, C. J.; Caldwell, W. B.; Peng, X. G.; Alivisatos, A. P.; Schultz, P. G. Angew.Chem.Int.Ed. 1999, 38, 1808-1812.

(14) Niemeyer, C. M.; Ceyhan, B.; Blohm, D. Bioconjugate Chem. 1999, 10, 708-719. 
(15) Alivisatos, A. P.; Johnsson, K. P.; Peng, X. G.; Wilson, T. E.; Loweth, C. J.; Bruchez, M. P.; Schultz, P. G. Nature 1996, 382, 609-611.

(16) Niemeyer, C. M.; Burger, W.; Peplies, J. Angew.Chem.Int.Ed. 1998, 37, 22652268.

(17) Taton, T. A.; Mucic, R. C.; Mirkin, C. A.; Letsinger, R. L. J.Am.Chem.Soc. 2000, 122, 6305-6306.

(18) Letsinger, R. L.; Mirkin, C. A.; Elghanian, R.; Mucic, R. C.; Storhoff, J. J. Phosphorus Sulfur and Silicon and the Related Elements 1999, 146, 359-362.

(19) Niemeyer, C. M.; Ceyhan, B. Angew.Chem.Int.Ed. 2001, 40, 3685-3688.

(20) Mucic, R. C.; Storhoff, J. J.; Mirkin, C. A.; Letsinger, R. L. J.Am.Chem.Soc. 1998, $120,12674-12675$.

(21) Seeman, N. C. Angew.Chem.Int.Ed. 1998, 37, 3220-3238.

(22) Liu, D.; Wang, M. S.; Deng, Z. X.; Walulu, R.; Mao, C. D. J.Am.Chem.Soc. 2004, $126,2324-2325$.

(23) Xiao, S. J.; Liu, F. R.; Rosen, A. E.; Hainfeld, J. F.; Seeman, N. C.; MusierForsyth, K.; Kiehl, R. A. J.Nanoparticle Res. 2002, 4, 313-317.

(24) Eckardt, L. H.; Naumann, K.; Pankau, W. M.; Rein, M.; Schweitzer, M.; Windhab, N.; von Kiedrowski, G. Nature 2002, 420, 286. 
(25) Scheffler, M.; Dorenbeck, A.; Jordan, S.; Wustefeld, M.; von Kiedrowski, G. Angew.Chem.Int.Ed. 1999, 38, 3312-3315.

(26) Shi, J. F.; Bergstrom, D. E. Angew.Chem.Int.Ed. 1997, 36, 111-113.

(27) Grimau, M. G.; Iacopino, D.; Avino, A.; de la Torre, B. G.; Ongaro, A.;

Fitzmaurice, D.; Wessels, J.; Eritja, R. Helv.Chim.Acta 2003, 86, 2814-2826.

(28) Zanchet, D.; Micheel, C. M.; Parak, W. J.; Gerion, D.; Alivisatos, A. P. Nano Lett. 2001, 1, 32-35.

(29) Sung, K. M.; Mosley, D. W.; Peelle, B. R.; Zhang, S. G.; Jacobson, J. M. J.Am.Chem.Soc. 2004, 126, 5064-5065.

(30) Jhaveri, S. D.; Foos, E. E.; Lowy, D. A.; Chang, E. L.; Snow, A. W.; Ancona, M. G. Nano Lett. 2004, 4, 737-740.

(31) Zanchet, D.; Micheel, C. M.; Parak, W. J.; Gerion, D.; Williams, S. C.; Alivisatos, A. P. Journal of Physical Chemistry B 2002, 106, 11758-11763.

(32) Sambrook, J.; Fritsch, E. F.; Maniatis, T. Gel Electrophoresis of DNA; In Molecular Cloning: A Laboratory Manual; Nolan, C., Ferguson, M., eds. Cold Spring Harbor Laboratory Press: Plainview, 1989; p 6.1-6.62.

(33) Wu, K. J.; Steding, A.; Becker, C. H. Rapid Commun.Mass Spectrom. 1993, 7 , $142-146$.

(34) Bloomfield, V. A.; Crothers, D. M.; Tinoco, Jr. I. Physical Chemistry of Nucleic Acids; Harper \& Row: New York, 1974. 
(35) Viovy, J. L. Rev.Mod.Phys. 2000, 72, 813-872.

(36) Parak, W. J.; Pellegrino, T.; Micheel, C. M.; Gerion, D.; Williams, S. C.; Alivisatos, A. P. Nano Lett. 2003, 3, 33-36. 


\title{
Chapter 4 - Isolation of Discrete Nanoparticle-DNA Conjugates for Plasmonic Applications
}

\begin{abstract}
Discrete DNA-gold nanoparticle conjugates with DNA lengths as short as 15 bases for both $5 \mathrm{~nm}$ and $20 \mathrm{~nm}$ gold particles have been purified by anion-exchange HPLC. Conjugates comprising short DNA ( $<40$ bases) and large gold particles ( $\geq 20 \mathrm{~nm})$ are difficult to purify by other means, and are potential substrates for plasmon coupling experiments. Conjugate purity is demonstrated by hybridizing complementary conjugates to form discrete structures, which are visualized by TEM. This chapter has been reproduced with permission from Nano Lett. 2008, 8, 1202-1206.
\end{abstract}




\section{Introduction}

DNA-nanocrystal conjugates have proven to be an important addition to the arsenal for addressing many emerging challenges of nanoscience. ${ }^{1-3}$ Gold and quantum $\operatorname{dot}^{4}$ conjugates have been used extensively as biomolecular markers. Additionally, DNA base pairing has directed the self-assembly of discrete groupings and arrays of inorganic nanocrystals, ${ }^{5,6}$ which may ultimately provide a route to self-assembled nanoscale electronic devices and memory components. Recently, plasmon coupling between gold nanoparticles conjugated to DNA has also been developed as a molecular ruler capable of detecting sub-nanometer distance changes over length and time scales inaccessible via fluorescence resonance energy transfer (FRET) measurements. ${ }^{7,8}$

For many of these applications, it is desirable to obtain nanocrystals functionalized with discrete numbers of DNA strands. For instance, hybridization of a mixture of two complementary DNA-gold monoconjugates will result in the formation of DNA-gold dimers, ${ }^{9}$ whereas hybridizing polyconjugates results in formation of a network solid. ${ }^{10}$ Thus, control over DNA-mediated assembly of complex inorganic nanostructures depends crucially upon the ability to isolate discrete DNA-gold building blocks in which the number of DNA strands is controlled.

Plasmon coupling experiments place substantial additional constraints on the conjugates. ${ }^{7,8}$ In such experiments, the scattering intensity of a pair of nanoparticles depends on both the particle radius $(R)$ as $R^{6}$, and the interparticle distance $\left(R_{P}\right)$ as $1 / \mathrm{R}_{\mathrm{P}}{ }^{6}{ }^{11}$ For good plasmon coupling efficiency, noble metal nanoparticles at least $20 \mathrm{~nm}$ in diameter are required, with an interparticle distance less than or equal to the diameter of the particles. Consequently, it is desirable to use a DNA spacer that is short relative to the diameter of the nanoparticle, resulting in a small interparticle distance. 
Although DNA-gold monoconjugates are routinely used by a variety of researchers, isolating nanocrystals functionalized with discrete numbers of short $(<40$ base) DNA strands has proven difficult. Separations are often carried out by agarose gel electrophoresis, in which both the size of the nanoparticle and the length of the attached DNA are important, meaning that even longer DNA strands must be utilized to achieve adequate resolution for larger particles. ${ }^{9}, 12$ Other separation methods have been successfully used to purify nanoparticles bound to short DNA, ${ }^{13-15}$ but to date these have been restricted to very small particles $(\leq 10 \mathrm{~nm})$, which have limited utility for plasmonic applications.

High-performance liquid chromatography (HPLC) and size-exclusion chromatography (SEC) are techniques that offer high resolving power and have been successfully used by other researchers to measure size distributions in samples of unconjugated nanoparticles, ${ }^{16-20}$ and to purify nanoparticle-protein polyconjugates from unconjugated protein. $^{21}$ Here we investigate the use of anion exchange HPLC, a technique popular for purification of short, single-stranded DNA, in order to isolate nanocrystals functionalized with discrete numbers of short DNA strands.

Anion exchange is a form of HPLC in which the stationary phase is functionalized with cationic (usually quaternary ammonium) functional groups. The cationic surface strongly binds anions, in particular polyanionic molecules such as DNA. Analytes are eluted by increasing the salt concentration of the mobile phase until equilibrium favors release of the analyte from the stationary phase. AE-HPLC has been particularly successful in separations of short, single-stranded DNA, giving single-base resolution up to approximately sixty bases. ${ }^{22}$ 


\section{Results and Discussion}

Agarose gel electrophoresis has been widely used to purify gold nanocrystals conjugated to controlled numbers of DNA strands. When DNA-gold conjugate structures are analyzed by agarose gel electrophoresis, they give discrete bands corresponding to structures with increasing numbers of DNA strands. ${ }^{12}$ For a given gel percentage, greater separation is observed for long DNA strands than for short strands. Figure 4.1 demonstrates this effect. When thiolated poly(T) DNA was conjugated to $5 \mathrm{~nm}$ gold particles and analyzed in a 3\% agarose gel, bands were visible (although not wellresolved) for DNA as short as 40 bases. However, when the same DNA was conjugated to $20 \mathrm{~nm}$ AuNP, bands were only clearly visible for DNA at least 70 bases in length.

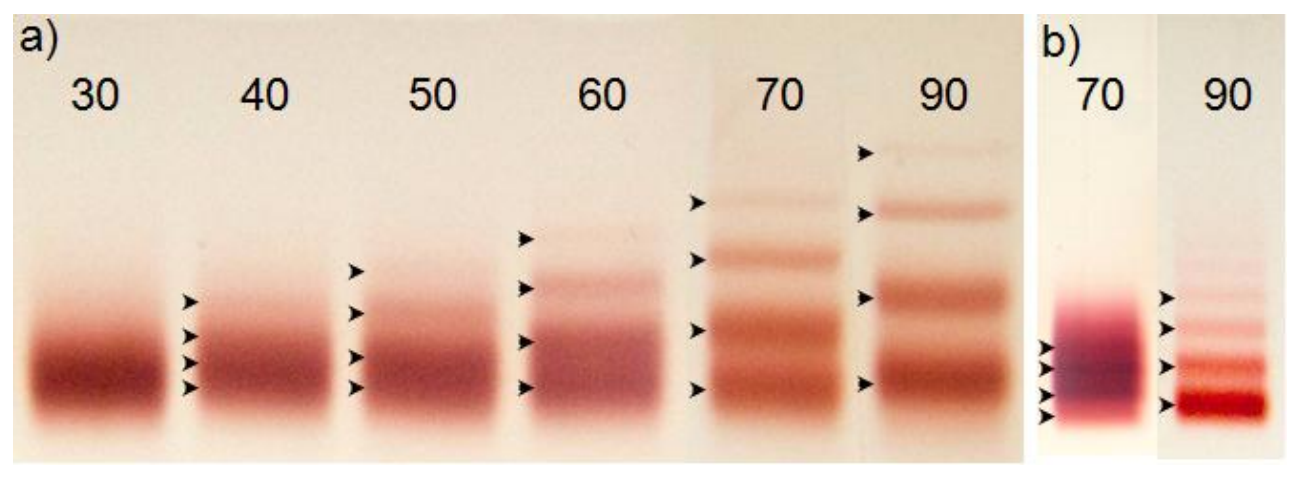

Figure 4.1. Electrophoretic analysis of gold conjugated to thiolated DNA of varying lengths. (a) $5 \mathrm{~nm}$ gold particles are conjugated to polyT DNA 30-90 bases in length. Black arrowheads indicate visible bands as a guide to the eye. (b) $20 \mathrm{~nm}$ gold particles conjugated to 70- and 90-base polyT DNA.

Aliquots of $5 \mathrm{~nm}$ and $20 \mathrm{~nm}$ conjugates were then analyzed by AE-HPLC. In a typical analysis, $100 \mu \mathrm{l}$ of nanoparticle conjugate solution (about $300 \mathrm{pmol}$ of $5 \mathrm{~nm}$ 
particles or 3 pmol of $20 \mathrm{~nm}$ particles) was injected with an aqueous mobile phase incorporating $40 \mathrm{mM} \mathrm{NaCl}$ to encourage strong binding of polyanions (such as DNA) to the stationary phase. After 3 minutes at the low salt concentration, the $\mathrm{NaCl}$ concentration was raised from $40 \mathrm{mM}$ to $900 \mathrm{mM}$ over 20 minutes. Gold elution was observed by monitoring the UV-Vis absorbance at the gold plasmon peak of $520 \mathrm{~nm} v s$ a reference wavelength of $850 \mathrm{~nm}$, at which gold colloid has very low absorbance, and visually confirmed by the presence of the characteristic red color of the colloid in collected fractions. A representative set of HPLC traces are shown in Figure 4.2. As expected, each sample exhibits a broad peak eluting at a low ionic strength, corresponding to unconjugated gold. Small variations in these peaks were sometimes observed, due to slight differences in the completeness of the neutral poly(ethylene glycol) (PEG) ligand shell passivating the particles (see Supporting Information). The traces in Figure 4.2 are normalized to the position of the unconjugated gold peak in order to observe the effect of increasing DNA length.

The second peak eluted at an ionic strength dependent upon the length of DNA oligomer conjugated to the gold particle. As in the electrophoretic purification, the separation between unconjugated (first peak) and monoconjugated (second peak) gold increased with increasing DNA length. Diconjugate (third peak) was also separated from monoconjugate, although the separation was not as pronounced as that between unconjugated gold and monoconjugate. Near-baseline resolution was achieved for 15base conjugates in the HPLC, while for DNA shorter than 15 bases, peaks were not well resolved. It should be noted that DNA retention in AE-HPLC is known to be slightly sequence-dependent; ${ }^{23}$ in these experiments the use of polyT sequences ensures that differences in retention can be attributed solely to DNA length. 


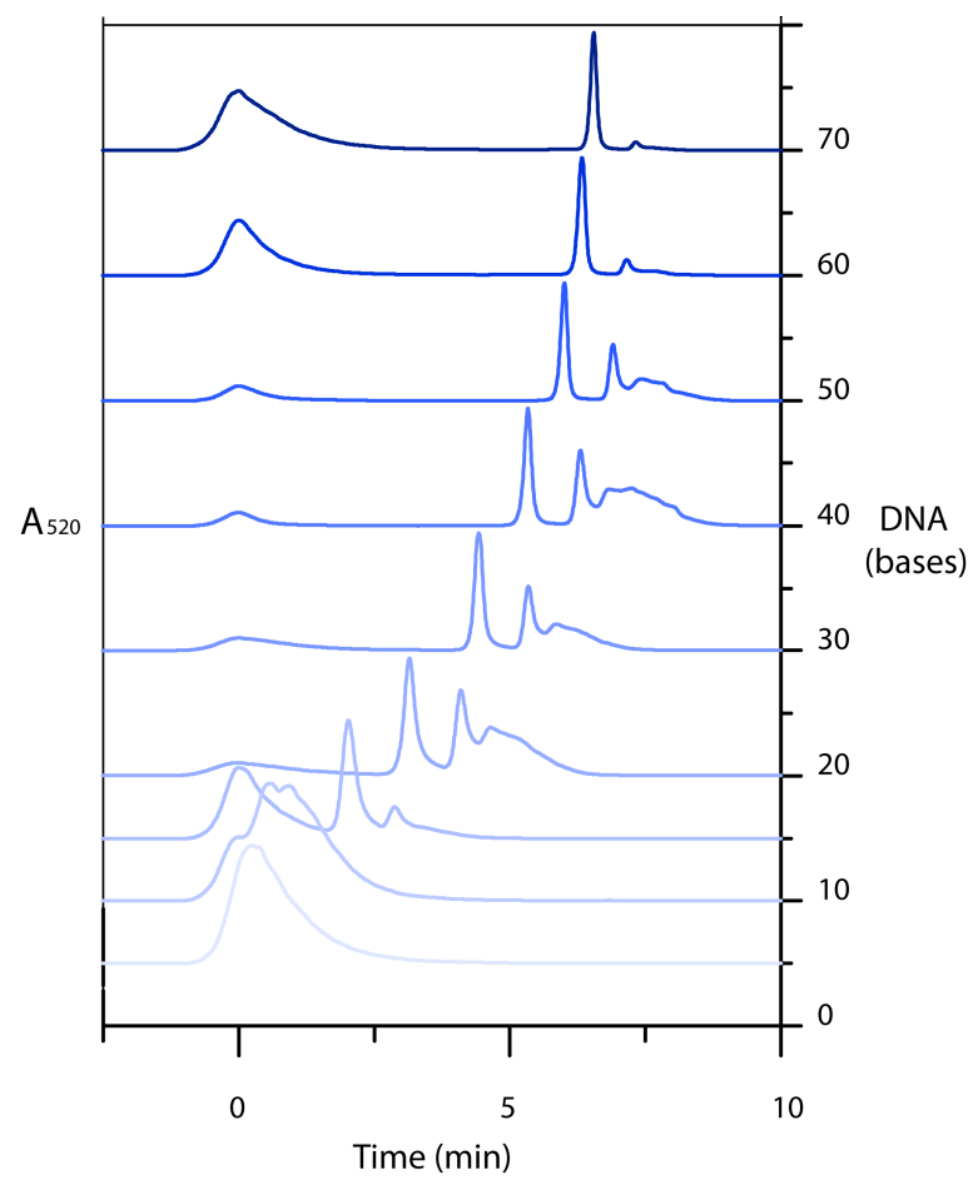

Figure 4.2. Elution profiles of varying lengths of polyT DNA conjugated to $20 \mathrm{~nm}$ AuNP. Leftmost peak is unconjugated gold. Monoconjugate peak migrates to longer retention times as DNA length is increased, with near-baseline separation achieved for monoconjugates of 15-base DNA.

It should also be noted that AE-HPLC is often superior to gel electrophoresis as a DNA-gold conjugate purification method, even for cases in which discrete bands are clearly visible in a gel. A direct comparison of the two methods is shown in Figure 4.3, for $5 \mathrm{~nm}$ AuNP conjugated to 70-base DNA. Although bands in the gel appear wellseparated, optical density analysis (Figure 4.3a, lower frame) demonstrates that the 
monoconjugate band has significant overlap with both the unconjugated gold and the diconjugate. HPLC purification of the same type of conjugates is shown in Figure $4.3 \mathrm{~b}-$ here, baseline resolution is achieved for the first three peaks, indicating that high-purity monoconjugates can be recovered. Typical monoconjugate yields from a $100-\mathrm{uL}$ injection were $30-50$ pmol for $5 \mathrm{~nm}$ particles and 0.3-0.5 pmol for $20 \mathrm{~nm}$ particles, similar to quantities extracted from an 8-well agarose gel, making AE-HPLC a viable preparative technique for DNA-Au conjugate self-assembly experiments.
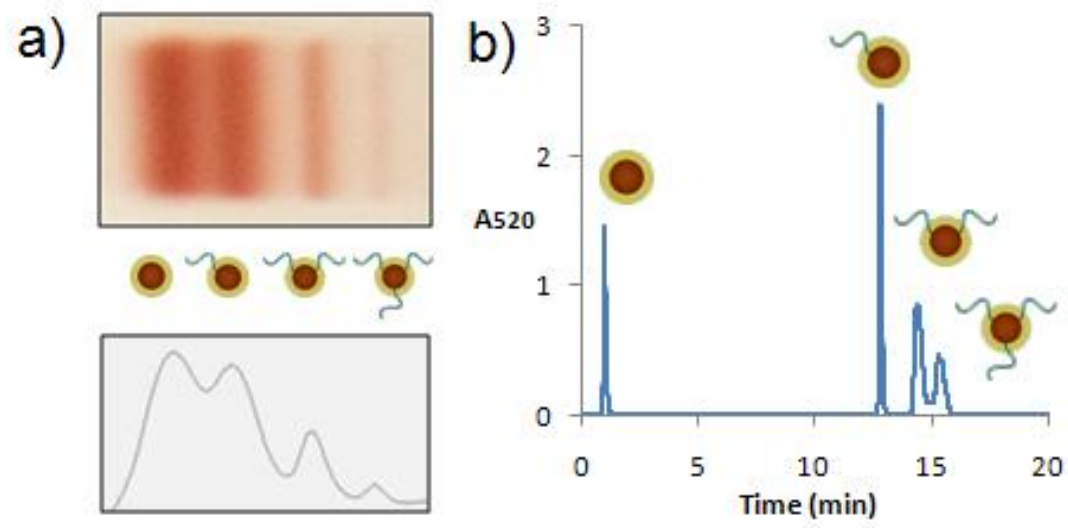

Figure 4.3. Comparison of agarose gel and AE-HPLC purification of 70-base polyT DNA conjugated to $5 \mathrm{~nm}$ AuNP. (a) Gel purification of conjugates. Although four distinct bands are visible, a lane trace produced by optical density analysis shows monoconjugate overlaps with both unconjugated gold and diconjugate. (b) When the same structures are purified by AE-HPLC, baseline resolution is observed for the first three peaks.

Although monoconjugates can clearly be separated from unconjugated gold and diconjugate using AE-HPLC, the conjugates should also be separated from any excess 
unconjugated DNA in order to ensure that no further conjugation can take place after purification.

To quantify DNA retention, free thiolated poly(T) DNA was analyzed using the same gradient applied to the conjugates. Elution was observed by monitoring the UVVis absorption at the DNA absorption peak of $260 \mathrm{~nm} v s$ a reference wavelength of 360 nm at which DNA does not absorb strongly. In general, a single large peak was observed, although occasionally a very small secondary peak (area $<5 \%$ of primary peak area) was also observed at slightly lower ionic strength, suggestive of a small amount of DNA degradation. The position of the primary peak was used in plotting DNA retention (Figure $4.4 a)$.

Interestingly, both mono- and di-conjugates elute at lower ionic strength (shorter times) than the free thiolated DNA of the same length. Attaching the DNA to a gold nanoparticle coated with neutral ligands is expected to decrease retention of the DNA, since the ligand shell around the gold nanoparticle will interfere with binding of the DNA bases proximal to the nanoparticle. It is also not surprising that addition of a second DNA strand does not impact retention as much as the first, since the effect of additional DNA bases binding the column decreases sharply after the first 30 bases (see DNA curve in Figure 4.4a). Finally, it is expected that the DNA strands are distributed on the surface of the nanoparticle, which may prevent the second strand from binding as completely as the first.

Surface passivation of the nanoparticle is also key in determining the retention behavior of conjugate structures (Figure 4.4b). Passivation with neutral thiolated PEG results in unconjugated gold eluting at very low ionic strengths, whereas use of carboxy-terminated (anionic) PEG results in much stronger retention of unconjugated gold, since the ligands 
on the surface of the gold can also bind the column. Differences can be seen in the gold and monoconjugate elution for passivation with short neutral vs long neutral PEG molecules, presumably because the thicker ligand shell created by longer PEG molecules slightly reduces the number of DNA bases free to bind the column. Since the Debye screening length in the mobile phase ranges from $1.24 \mathrm{~nm}$ at the beginning of the run to $0.34 \mathrm{~nm}$ at the end of the run, it is also possible that charges on the gold surface under the PEG ligands could play a small role in retention behavior. These charges could arise either from the gold particle synthesis procedure or from a small number of residual anionic phosphine ligands left after the PEG ligands are exchanged onto the particles.

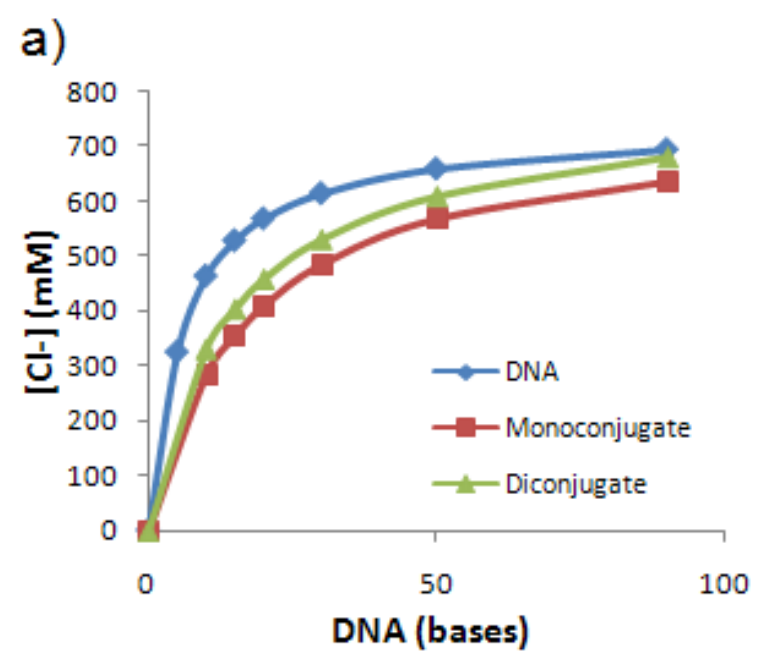

b)

\section{PEG ligand}

long neutral

short neutral

anionic
Retention (min)

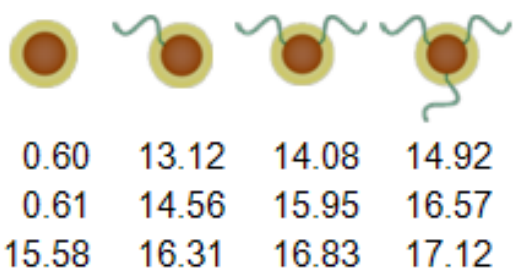


Figure 4.4. (a) AE-HPLC retention of free DNA compared with DNA conjugated to 5 $\mathrm{nm}$ AuNP. At all DNA lengths, free DNA is retained more strongly than $5 \mathrm{~nm}$ AuNP conjugated to one or two strands of the same DNA. Peak width at half the maximum value is approximately $4 \mathrm{mM}$ for DNA and $20 \mathrm{mM}$ for mono- and di-conjugate. (b) Ligand used to passivate gold surface plays an important role in conjugate retention, although in each case, increasing numbers of DNA strands correlate with increased retention.

To demonstrate that HPLC-purified conjugates are good substrates for selfassembly, $20 \mathrm{~nm}$ gold particles discretely functionalized with one, two, or three strands of DNA were isolated and hybridized with complementary conjugates of $5 \mathrm{~nm}$ gold. Hybrid structures were visualized by TEM.

Typically when TEM images are used to characterize DNA-templated selfassembly of nanoparticles, interparticle distance can be used to infer the length of the DNA linker, which is not itself visible under the electron beam. However, the increased forces acting on larger nanoparticles as the sample dries on the TEM grid can be sufficient to bend the DNA linker (Figure 4.6), so structures were also assembled in which a central, discretely functionalized $20 \mathrm{~nm}$ particle bearing one (Figure 4.5a), two (Figure 4.5b), or three (Figure 4.5c) 60-base DNA strands was hybridized to the appropriate number of monofunctional $5 \mathrm{~nm}$ particles. Although some drying-induced DNA bending was observed in these structures as well (Figure 4.5b inset), enough hybrids adopt an extended conformation to make a convincing argument for DNAmediated assembly rather than nonspecific aggregation. These experiments demonstrate 
that not only mono- but also di- and tri- conjugates can be isolated in sufficient purity for use as self-assembly substrates.

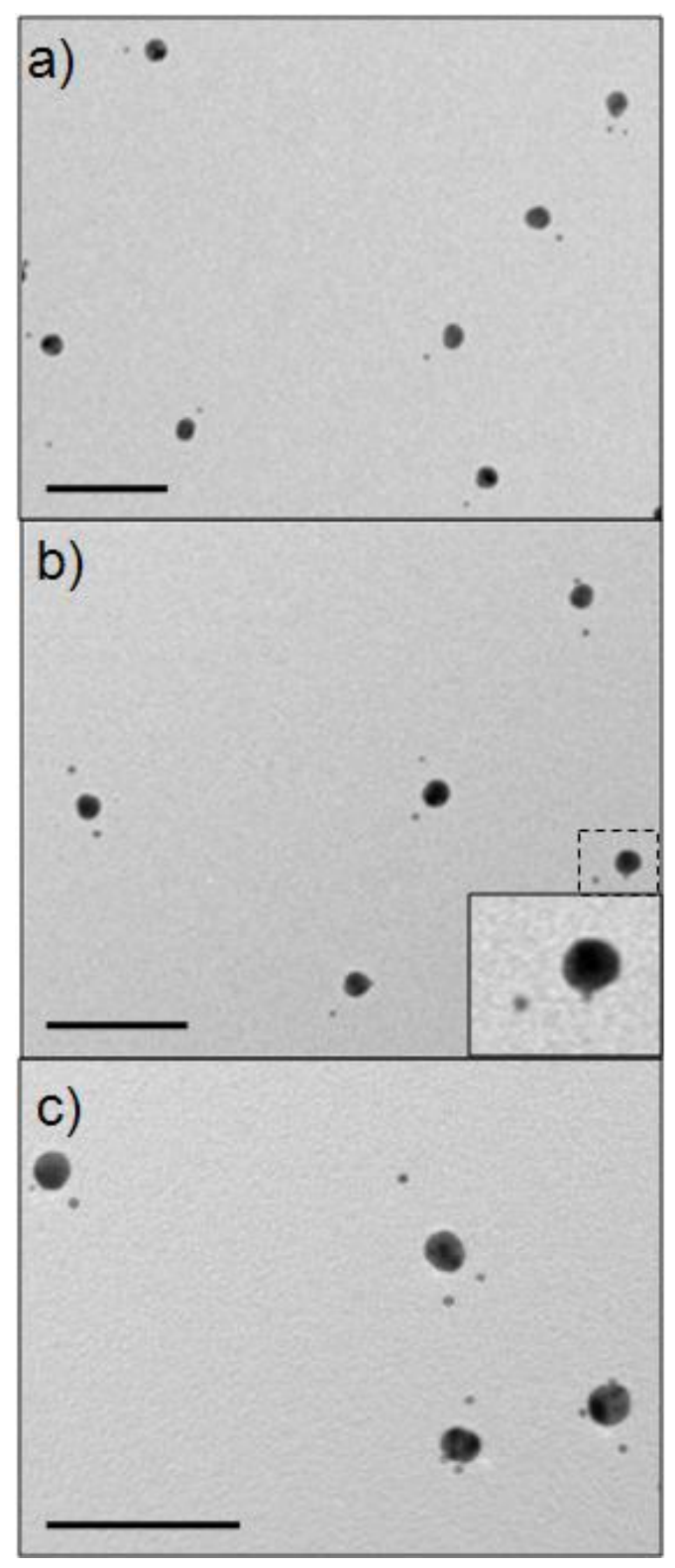

Figure 4.5. TEM characterization of hybridized $20 \mathrm{~nm} / 5 \mathrm{~nm}$ conjugate structures: (a) 20 $\mathrm{nm}$ monoconjugates hybridized with complementary $5 \mathrm{~nm}$ monoconjugates, (b) $20 \mathrm{~nm}$ diconjugates hybridized with $5 \mathrm{~nm}$ monoconjugates, and (c) 20nm triconjugates hybridized with $5 \mathrm{~nm}$ monoconjugates. Inset in (b) shows that structures may collapse 
during drying on the TEM grid, pulling one or more of the $5 \mathrm{~nm}$ particles close to the 20 $\mathrm{nm}$ particle. Scale bar $=100 \mathrm{~nm}$.

Radial assemblies were also formed in which $5 \mathrm{~nm}$ polyconjugates were hybridized to $20 \mathrm{~nm}$ monoconjugates. In a large percentage of structures, the $20 \mathrm{~nm}$ particles are pulled into contact with each other during drying (Figure 4.6a). This can obscure the $5 \mathrm{~nm}$ polyconjugated hub, however the $5 \mathrm{~nm}$ particle is usually visible when the structure is viewed more closely (Figure 4.6b). Drying conditions are believed to play an important role in the morphology of $20 \mathrm{~nm}$ multiparticle assemblies. For instance, Figures 4.6a and 4.6c are assembled using conjugates prepared from the same DNA. Importantly, this suggests that the $20 \mathrm{~nm}$ particles are not aggregated in solution, a key prerequisite for utilizing the assemblies in plasmonic experiments.

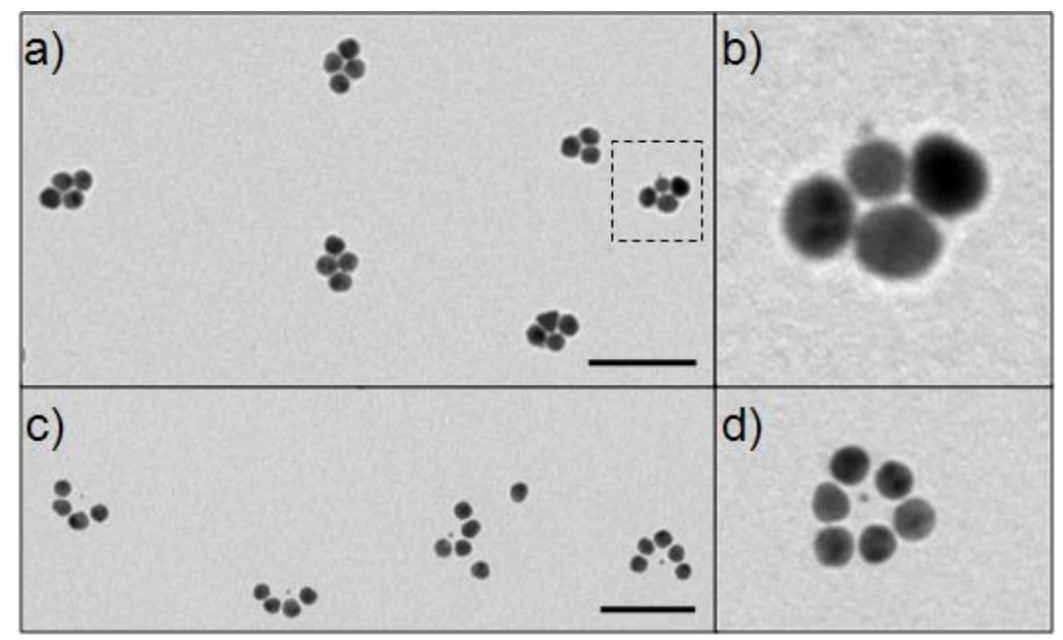

Figure 4.6. TEM characterization of hybridized $20 \mathrm{~nm} / 5 \mathrm{~nm}$ conjugate structures: (a) 20 $\mathrm{nm}$ monoconjugates hybridized with complementary $5 \mathrm{~nm}$ tetraconjugates, (b) closeup of boxed structure from (a), showing that a single $5 \mathrm{~nm}$ particle is part of the assembly as 
expected. (c) $20 \mathrm{~nm} / 5 \mathrm{~nm}$ assemblies demonstrating local differences in dried assembly morphology. (d) Higher-order $20 \mathrm{~nm} / 5 \mathrm{~nm}$ assembly with ringlike morphology. Scale bar $=100 \mathrm{~nm}$.

\section{Conclusions}

In conclusion, we have successfully isolated discrete DNA-gold conjugates suitable for plasmonic applications, comprised of a large gold nanoparticle attached to controlled numbers of short DNA strands. The anion-exchange purification method used in isolating these conjugates is also an improvement on the existing gel electrophoresis purification method for other DNA gold conjugates (e.g. small nanoparticle attached to longer DNA) routinely used for nanoscale self-assembly experiments.

Ongoing experiments seek to determine the size limits of this new method. The large size of the column packing material (approximately $13 \mu \mathrm{m}$ spheres) results in interstitial spaces quite large in comparison to the conjugates, thus it is expected that similar methodology may be applied to much larger particles. However, the increased sensitivity of larger nanoparticles to high salt concentrations will require careful optimization of the nanoparticle surface passivation conditions. We also plan to leverage the new range of discrete nanoparticle conjugates described here to develop an expanded set of plasmon ruler measurements.

\section{Materials and Methods}


General Procedures. Citrate coated 5 and $20 \mathrm{~nm}$ gold particles with $<10 \%$ deviation in diameter were purchased from Ted Pella (Redding, CA). The bis-( $p$ sulfonatophenyl)phenylphosphine dihydrate dipotassium ligand used to stabilize the nanoparticles in aqueous solutions was obtained from Strem Chemicals (Newburyport, MA). Thiolated poly(ethylene glycol) (PEG), MW=356.5 was purchased from PolyPure (Oslo, Norway); alkyl thiolated PEG was purchased from ProSigma (Sopot, Poland). Thiolated DNA purified by polyacrylamide gel electrophoresis (PAGE, was purchased from Integrated DNA Technologies (Coralville, IA); trithiolated PAGE-purified DNA was obtained from Fidelity Sytems (Gaithersburg, MD). DNA was resuspended in deionized water to a final concentration of $50-100 \mu \mathrm{M}$. Nanoparticle sample purification and concentration were carried out in a Fisher Centrific 228 or IEC MicroCL 218 bench top centrifuge. UV-Vis absorption measurements were taken using a Perkin-Elmer Lambda 35 spectrometer.

Transmission electron microscopy was performed using a Phillips Tecnai $G^{2} 20$ instrument. Carbon-coated copper TEM grids (Ted Pella) were ionized for $30 \mathrm{~s}$ in a Harrick Plasma PDC-32G oxygen plasma cleaner to increase surface hydrophilicity, then $0.5 \mu \mathrm{L}$ of dilute aqueous sample was spotted on the surface. The sample was left on the grid for 3 minutes to allow particles to adsorb to the surface before adding $10 \mu \mathrm{L}$ of $0.5 \mathrm{X}$ Tris-Borate-EDTA (TBE) buffer and touching the edge of the grid with a filter paper to wick off excess moisture and salts. Buffer addition and wicking were repeated two more times. Grids were then allowed to air dry prior to analysis.

DNA Sequences. For experiments in which purifications of DNA sequences of different lengths were compared, thiolated polyT DNA of the appropriate length was utilized as described in the manuscript. For self-assembly experiments, the following 
complementary trithiolated sequences A and Ac were used, incorporating the trithiol modifier originally described by Letsinger et $a^{l}$ :

A: 5'- (trithiol) - GCA GTA ACG CTA TGT GAC CGA GAT ATC GGA GCA TTT GTA GTC TTG CAG ATG GGA ACA GCA -3'

Ac: 5'- (trithiol) - TGC TGT TCC CAT CTG CAA GAC TAC AAA TGC TCC GAT ATC TCG GTC ACA TAG CGT TAC TGC -3'

Synthesis of Gold-DNA Conjugates. Gold samples were prepared following a literature procedure, described briefly here. ${ }^{2}$ To $100 \mathrm{~mL}$ of citrate coated gold nanoparticle solution, $60 \mathrm{mg}$ of bis-( $p$-sulfonatophenyl)phenylphosphine dihydrate dipotassium salt was added, and the mixture was stirred at room temperature in order to allow phosphine ligands to replace the citrate ligands. Following overnight incubation, $\mathrm{NaCl}$ was added to the stirring mixture until a color change from red to cloudy purple was observed. The solution was transferred to $50 \mathrm{~mL}$ centrifuge tubes and centrifuged at room temperature for $10 \mathrm{~min}$ at $3500 \mathrm{rpm}$ to collect the precipitated gold. The supernatant was removed, and the pellet re-suspended in phosphine buffer (1 $\mathrm{mg}$ of bis( $p$-sulfonatophenyl)phenylphosphine (BSPP) in $1 \mathrm{~mL}$ of de-ionized water), to a final nanoparticle concentration of approximately $3 \mu \mathrm{M}$ for $5 \mathrm{~nm} \mathrm{Au}$ particles and approximately $0.2 \mu \mathrm{M}$ for $20 \mathrm{~nm}$ particles. Nanoparticles and Au-DNA conjugates were quantified by measuring the absorbance at $\lambda=520 \mathrm{~nm}$ and calculating the concentration using Beer's law based on their extinction coefficients: $\varepsilon_{520}(5 \mathrm{~nm})=9.3 \times 10^{6} \mathrm{M}^{-1} \mathrm{~cm}^{-1}$ and $\varepsilon_{520}(20 \mathrm{~nm})=6.4 \times 10^{8} \mathrm{M}^{-1} \mathrm{~cm}^{-1}$.

To prepare Au-DNA conjugates, 5'-thiolated DNA was mixed with concentrated gold

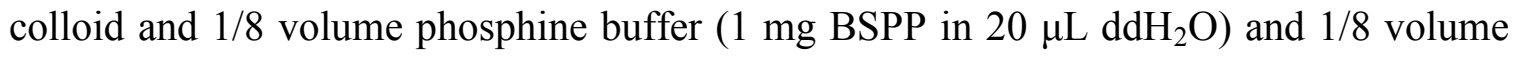
$20 \mathrm{mM}$ phosphate buffered saline (PBS), $\mathrm{pH}$ 7.4. In a typical experiment, $80 \mu \mathrm{L}$ of gold 
colloid was mixed with $10 \mu \mathrm{L}$ of phosphine buffer and $10 \mu \mathrm{L}$ of PBS and the appropriate volume of DNA (usually about $5 \mu \mathrm{L}$ ). The mixture was incubated with gentle agitation at room temperature for $4-24 \mathrm{~h}$, then $1 / 5$ volume PEG solution $(1 \mu \mathrm{L}$ thiolated PEG in 50 $\mu \mathrm{L} \mathrm{ddH}_{2} \mathrm{O}$ ) was added and the solution was incubated with gentle agitation for a further 2 h.

Electrophoresis of Au-DNA Conjugates. Gels were prepared with 3\% (for $5 \mathrm{~nm}$ particles) or $2 \%$ (for $20 \mathrm{~nm}$ particles) agarose by weight in $0.5 \mathrm{X}$ TBE buffer. Samples were diluted with 3X loading buffer containing 15\% Ficoll 400 (Fluka, Milwaukee, WI) and then loaded into the appropriate well. Gels were run at $10 \mathrm{~V} / \mathrm{cm}$ for $45 \mathrm{~min}$ and then visualized over white light using a Nikon D1x digital SLR camera.

AE-HPLC of DNA-Au Conjugates. Conjugates were separated using a Dionex DNAPac PA100 anion exchange column (Sunnyvale, CA) on an Agilent 1100 series HPLC with in-line degasser, autosampler, multi-wavelength UV-Vis detector, and fluorescence detector. Fractions were collected using an Agilent 1200 series automatic fraction collector. In a typical separation, $100 \mu 1$ of conjugate prepared as described above was injected using an autosampler and an initial mobile phase composed of $25 \mathrm{mM}$ Tris $(\mathrm{pH}$ 8) and $40 \mathrm{mM} \mathrm{NaCl}$ in deionized water. The low ionic strength in the mobile phase was maintained for 3 minutes to encourage strong binding of the sample to the column. Subsequently the $\mathrm{NaCl}$ concentration was increased from $40 \mathrm{mM}$ to $900 \mathrm{mM}$ over a period of 20 minutes. Sample elution was detected by monitoring UV-Vis absorption at the gold plasmon maximum of $520 \mathrm{~nm}$ against a reference of $850 \mathrm{~nm}$, at which the gold colloid does not absorb. Automatic fraction collection was also triggered by monitoring these wavelengths. Collected fractions were concentrated either in Centricon 50k MWCO centrifugal filters, or pelleted by high-speed centrifugation (15 min at $4000 \mathrm{rpm}$ for $20 \mathrm{~nm}$ 
conjugates, or $60 \mathrm{~min}$ at $14800 \mathrm{rpm}$ for $5 \mathrm{~nm}$ conjugates) prior to use in hybridization experiments. Typical final concentrations for collected conjugates were $0.2-1.5 \mu \mathrm{M}$ for $5 \mathrm{~nm}$ conjugates and $0.02-0.1 \mu \mathrm{M}$ for $20 \mathrm{~nm}$ conjugates.

Preparation of 5 nm Au-DNA Polyconjugates. Polyconjugates were synthesized using a method similar to that described above for monoconjugates. $5 \mathrm{~nm}$ Au NP were mixed with approximately a 5-fold excess of thiolated DNA, 1/8 volume phosphine

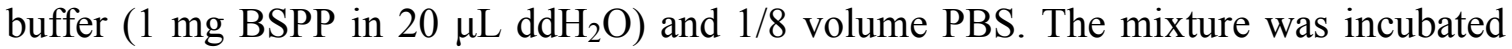
overnight with gentle agitation. Conjugates were purified in a $3 \%$ agarose gel and extracted using published techniques ${ }^{3}$ or pelleted by high-speed centrifugation $(60 \mathrm{~min}$ at $14800 \mathrm{rpm}$ ) to remove unconjugated DNA.

Hybridization of DNA-Au Conjugates. Concentrated conjugates as described above were hybridized with equimolar quantities of complementary conjugates to create gold nanoparticle dimers and higher-order structures. In a typical experiment, 0.2 pmol each of $5 \mathrm{~nm}$ monoconjugate and complementary $20 \mathrm{~nm}$ monoconjugates were vortexed briefly, inserted in a heat block at $45 \mathrm{C}$, and left to cool slowly to room temperature for at least 2 hours or as long as overnight. For trimers, 0.4 pmol of $5 \mathrm{~nm}$ monoconjugates was mixed with $0.2 \mathrm{pmol}$ of $20 \mathrm{~nm}$ diconjugate, and for tetramers, $0.6 \mathrm{pmol}$ of $5 \mathrm{~nm}$ monoconjugates was mixed with $0.2 \mathrm{pmol}$ of $20 \mathrm{~nm}$ triconjugate. Structures were also prepared in which $0.05 \mathrm{pmol} 5 \mathrm{~nm}$ tetraconjugates were hybridized with $0.2 \mathrm{pmol} 20 \mathrm{~nm}$ monoconjugates.

\section{References}

1. Katz, E.; Willner, I. Angewandte Chemie-International Edition 2004, 43, (45), 6042-6108. 
2. Niemeyer, C. M. Angewandte Chemie-International Edition 2001, 40, (22), 41284158.

3. Alivisatos, A. P.; Johnsson, K. P.; Peng, X. G.; Wilson, T. E.; Loweth, C. J.; Bruchez, M. P.; Schultz, P. G. Nature 1996, 382, (6592), 609-611.

4. Fu, A. H.; Gu, W. W.; Larabell, C.; Alivisatos, A. P. Current Opinion in Neurobiology 2005, 15, (5), 568-575.

5. Zheng, J. W.; Constantinou, P. E.; Micheel, C.; Alivisatos, A. P.; Kiehl, R. A.; Seeman, N. C. Nano Letters 2006, 6, (7), 1502-1504.

6. Claridge, S. A.; Goh, S. L.; Frechet, J. M. J.; Williams, S. C.; Micheel, C. M.; Alivisatos, A. P. Chemistry of Materials 2005, 17, (7), 1628-1635.

7. Sonnichsen, C.; Reinhard, B. M.; Liphardt, J.; Alivisatos, A. P. Nature Biotechnology 2005, 23, (6), 741-745.

8. Reinhard, B. M.; Sheikholeslami, S.; Mastroianni, A.; Alivisatos, A. P.; Liphardt, J. Proceedings of the National Academy of Sciences of the United States of America 2007, 104, (8), 2667-2672.

9. Zanchet, D.; Micheel, C. M.; Parak, W. J.; Gerion, D.; Williams, S. C.; Alivisatos, A. P. Journal of Physical Chemistry B 2002, 106, (45), 11758-11763.

10. Elghanian, R.; Storhoff, J. J.; Mucic, R. C.; Letsinger, R. L.; Mirkin, C. A. Science 1997, 277, (5329), 1078-1081.

11. Kreibig, U. V., M., Optical Properties of Metal Clusters. Springer: Berlin, 1995.

12. Zanchet, D.; Micheel, C. M.; Parak, W. J.; Gerion, D.; Alivisatos, A. P. Nano Letters 2001, 1, (1), 32-35.

13. Ackerson, C. J.; Sykes, M. T.; Kornberg, R. D. Proceedings of the National Academy of Sciences of the United States of America 2005, 102, (38), 13383-13385. 
14. Qin, W. J.; Yung, L. Y. L. Langmuir 2005, 21, (24), 11330-11334.

15. Jhaveri, S. D.; Foos, E. E.; Lowy, D. A.; Chang, E. L.; Snow, A. W.; Ancona, M. G. Nano Letters 2004, 4, (4), 737-740.

16. Al-Somali, A. M.; Krueger, K. M.; Falkner, J. C.; Colvin, V. L. Analytical Chemistry 2004, 76, (19), 5903-5910.

17. Krueger, K. M.; Al-Somali, A. M.; Falkner, J. C.; Colvin, V. L. Analytical Chemistry 2005, 77, (11), 3511-3515.

18. Wilcoxon, J. P.; Provencio, P. P. Journal of Physical Chemistry B 2005, 109, (28), 13461-13471.

19. Wilcoxon, J. P.; Martin, J. E.; Provencio, P. Langmuir 2000, 16, (25), 9912-9920.

20. Choi, M. M. F.; Douglas, A. D.; Murray, R. W. Analytical Chemistry 2006, 78, (8), 2779-2785.

21. Wang, S. P.; Mamedova, N.; Kotov, N. A.; Chen, W.; Studer, J. Nano Letters 2002, 2, (8), 817-822.

22. Weiss, J., Handbook of Ion Chromatography. Wiley: Darmstadt, 2004; Vol. 1.

23. Yamamoto, S.; Nakamura, M.; Tarmann, C.; Jungbauer, A. Journal of Chromatography A 2007, 1144, (1), 155-160. 


\title{
Chapter 5 - Enzymatic Ligation Creates Discrete Multi-Nanoparticle Building Blocks for Self-Assembly
}

\begin{abstract}
Enzymatic ligation of discrete nanoparticle-DNA conjugates creates nanoparticle dimer and trimer structures in which the nanoparticles are linked by single-stranded DNA, rather than double-stranded DNA as in previous experiments. Ligation is verified by agarose gel and small-angle X-ray scattering. This capability is utilized in two ways: first to create a new class of multiparticle building blocks for nanoscale self-assembly; second to create a nanoparticle analog of the polymerase chain reaction.
\end{abstract}




\section{Introduction}

Recent research in nanoassembly has demonstrated that DNA may be used to control

the self-assembly of inorganic nanoparticles into designed functional materials, ${ }^{1-3}$ by exploiting the sequence-specific base pairing that governs its native assembly. In living systems, DNA serves as genetic information, a function so vital that nature has developed a multitude of enzymes to control its replication, correct errors in DNA sequences, and even destroy foreign DNA that enters a cell. ${ }^{4}$ Certain DNA-manipulating enzymes, such as restriction enzymes ${ }^{5}$ and polymerases ${ }^{6}$, have also proven to be active on DNAnanoparticle conjugates, suggesting that it may ultimately be possible to leverage the library of DNA-active enzymes to create more complex self-assembled nanomaterials and perhaps even to enable such functions as self-replication and error correction in a materials context. Nature's enzymatic toolkit is an important and underutilized asset in DNA-mediated self-assembly of functional materials.

Here, we show that DNA ligases, which seal single-stranded nicks in double-stranded DNA (dsDNA), can also operate on DNA-gold monoconjugates, structures in which a single strand of thiolated DNA is bound to a gold nanocrystal. Previous work has demonstrated that large networks may be formed through ligation of nanoparticles whose surfaces are conjugated with large numbers of DNA strands. ${ }^{7,8}$ In this work, ligation causes formation of a covalent bond between discrete nanoparticle-DNA conjugates, creating a new type of building block for self-assembly.

These new nanoassembly components offer a number of advantages. In these building blocks, multiple gold nanoparticles are linked by single-stranded DNA (ssDNA) (Scheme 1), and thus retain the sequence-specific targeting ability of the ssDNA linker. This contrasts with previous experiments, in which DNA-gold dimers have been formed by 
hybridization of two DNA-gold monoconjugates ${ }^{9}$ and thus are intrinsically linked by double-stranded DNA (dsDNA). Additionally, since particles within these new ligated building blocks are covalently linked the particles will remain connected under conditions such as high temperature or low salt concentrations which would cause disassembly in structures formed by base pairing. The ability to pre-form multiparticle components for later assembly is also a powerful asset in that it allows preformed components to be purified individually, which may ultimately facilitate assembly into complex structures such as nanoscale devices.

Scheme 5.1. Overview of ligation process. Nanoparticle-DNA monoconjugates are hybridized to a ssDNA template and enzymatically ligated to create gold nanoparticle dimers. Template strand is then removed, leaving two nanoparticles connected by ssDNA.

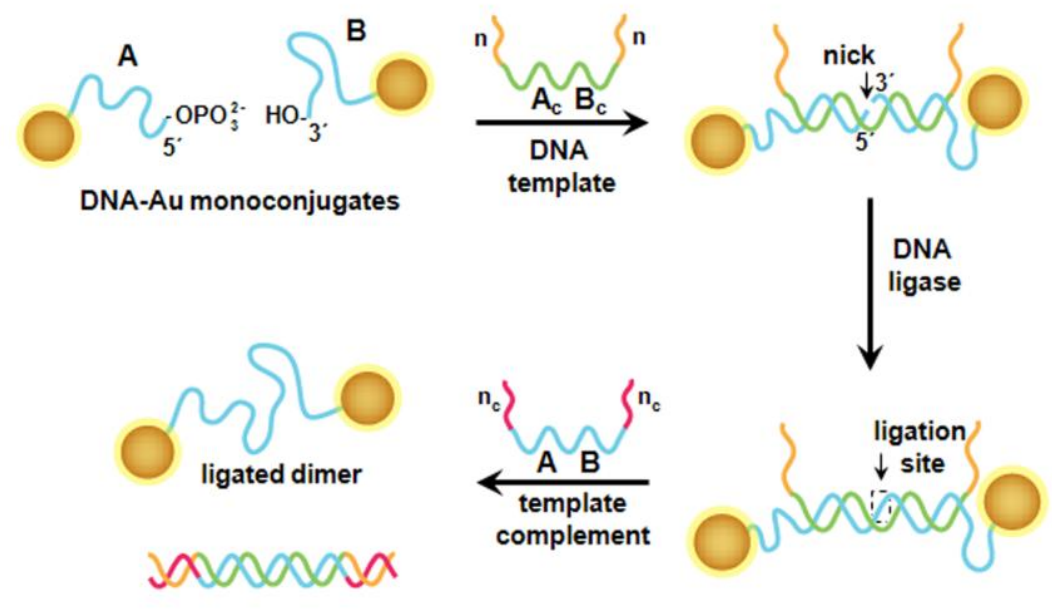

The capability to utilize DNA-active enzymes on discrete DNA-nanocrystal conjugates also opens the door to the use of enzymatic chain reaction technology, such as the polymerase chain reaction $(\mathrm{PCR})^{10}$, in nanomaterial construction. Similar to the manner 
in which PCR can be used to amplify tiny amounts of DNA, we use a ligase chain reaction $(\mathrm{LCR})^{11}$ to amplify the quantity of ligated DNA-gold dimer structures starting from small amounts of template.

Ligation of discrete gold nanoparticle monoconjugates bearing a single strand of DNA offers substantial rewards in terms of control over self-assembly, but levies additional requirements on the substrates involved. DNA used for conjugation must be highly purified, as the ligation process depends critically upon the matching of $3^{\prime}$ and $5^{\prime}$ ends of DNA at the ligation site. The nanoparticle surface must be thoroughly passivated (in this case, by thiolated poly(ethylene glycol) ligands) in order to prevent aggregation in enzymatic buffers containing divalent cations. Further, monoconjugates purified via gel electrophoresis ${ }^{12}$ are not ideal substrates as the samples may contain agarose impurities which are potent inhibitors of ligases. ${ }^{13}$ We have used conjugates purified by anion exchange high performance liquid chromatography (AE-HPLC). ${ }^{14}$

\section{Results and Discussion}

We first demonstrate successful hybridization and ligation as shown in Scheme 1 by analyzing reaction products in an agarose gel. Template removal is confirmed by smallangle X-ray scattering experiments. Multi-nanoparticle ssDNA building blocks are then self-assembled into complex nanoscale structures which are visualized by transmission electron microscopy. Finally, the ability to use an enzymatic exponential amplification method similar to the polymerase chain reaction is explored as a means to amplify nanoparticle-DNA building block products. 
Enzymatic Ligation Analyzed by Electrophoresis. Gold nanoparticles functionalized with a single strand of thiolated DNA were isolated using an AE-HPLC protocol previously described. ${ }^{15}$ Enzymatic ligation using the T4 and Taq DNA ligase enzymes requires nicked double-stranded DNA, with the $5^{\prime}$ side of the nick phosphorylated. ${ }^{11,16,17}$ For these experiments, gold nanoparticles were conjugated to 30-base sequences A and B, where A was purchased with a commercially available thiol modifier at its $3^{\prime}$ terminus and was 5'-phosphorylated, and B was 5'-thiolated (Scheme 1). Hybridization of conjugates $\mathrm{A}$ and $\mathrm{B}$ to the 54-base template strand $\mathrm{nAcBcn}$, in which the central 30 base $\mathrm{AcBc}$ sequence is complementary to conjugate sequences $\mathrm{A}$ and $\mathrm{B}$, and the 12 bases on each end labeled 'n' do not hybridize, leaving a toehold for later removal of the template. Hybridization of conjugates and template created a nicked double-stranded hybrid, in which the $5^{\prime}$ side of the nick was the phosphorylated end of conjugate A. Addition of T4 DNA ligase and incubation at $16^{\circ} \mathrm{C}$ for 30 min resulted in the formation of a covalent bond between the adjacent ends of conjugates $\mathrm{A}$ and $\mathrm{B}$, creating ligated dimer $5 \mathrm{~nm}-\mathrm{AB}-$ 5nm. Following ligation, the template strand was removed by addition of a DNA strand $\mathrm{n}_{\mathrm{c}} \mathrm{ABn}_{\mathrm{c}}$ complementary to the template.

When DNA-gold conjugate structures are analyzed by agarose gel electrophoresis, they give discrete bands corresponding to structures with increasing numbers of DNA strands and nanoparticles. ${ }^{18}$ We have used electrophoresis to confirm dimer hybridization and enzymatic ligation. In an agarose gel, constructs travel at a rate that depends upon both their size and their charge, with smaller structures passing more readily through the pores in the gel. Thus, in the electrophoretic analysis (Figure 5.1), monoconjugates (lane 1) such as A and B migrate more quickly than hybridized nicked dimers (lane 2). 


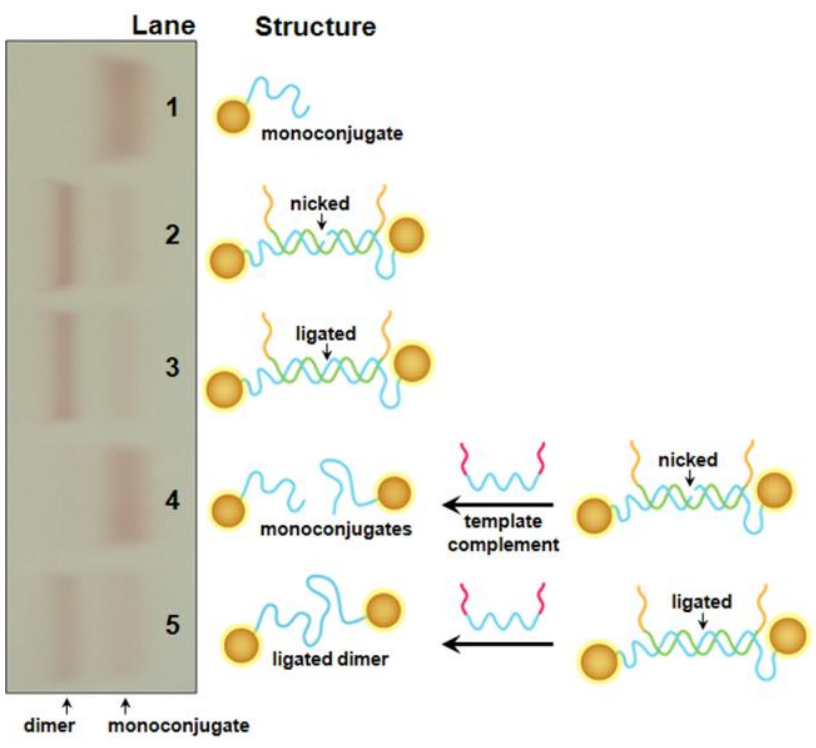

Figure 5.1. Electrophoretic analysis of monoconjugate ligation efficiency. Lane (1) monoconjugate $\mathrm{B},(2) \mathrm{A}$ and $\mathrm{B}$ plus ssDNA template, (3) A and B plus ssDNA template and T4 DNA ligase, (4) A and B plus ssDNA template and ssDNA complementary to template, (5) A, B, ssDNA template and ligase, with subsequent addition of ssDNA complementary to template.

Ligated dimers (lane 3) migrate at a similar rate to nicked dimers (lane 2), since the ligation process does not change the charge of the construct, and changes its size only insofar as the increased structural rigidity hinders progress through the porous gel. When unligated dimers such as those shown in lane 2 are mixed with the DNA strand complementary to the template strand, heated, and then slowly cooled, the template and its complement form a more stable hybrid than the template and the two conjugates. Thus, when the reaction products are analyzed in the gel (lane 4), the primary visible product is monoconjugate, rather than dimer. 
However, when ligated dimers are mixed with the template complement strand, heated, and then cooled, the majority of the particles ( $71 \%$ by optical density analysis) still migrate as dimers in the gel (lane 5). While it is not clear, based on gel analysis alone, whether or not the template strand has been removed by its complement, lane 5 demonstrates successful ligation.

\section{Analysis of Ligation and Template Removal by Small-Angle X-Ray Scattering}

(SAXS). In order to demonstrate that the template strand has indeed been removed through addition of its complement, leaving a ssDNA-nanoparticle dimer, the ligated dimers were analyzed by small-angle X-ray scattering. The relatively high electronic density of the gold nanoparticles and low electronic density of the DNA result in data which reflect the distribution of distances between the gold nanoparticles, without interference from the DNA between them. Previous studies ${ }^{19,20}$ have elucidated the distances between nanoparticles connected by dsDNA, demonstrating that the interparticle distance reflects the length of the double-helical DNA linker.

SAXS is used to observe the structural difference between ligated nanoparticle dimers bound to the template, and ligated dimers from which the template has been removed (Figure 5.2a, similar to Figure 5.1, lanes 3 and 5). In both structures, the nanoparticles are separated by a 60 -base DNA linker, but in the structure on the left, the central 30 bases of the linker are hybridized to the template, creating an approximately $10-\mathrm{nm}$ double helix flanked by 15-base lengths of flexible ssDNA. In the structure on the right, after the template strand has been removed by addition of the template complement, the nanoparticles are separated by 60 bases of ssDNA. Since the persistence length of ssDNA (about $2 \mathrm{~nm}$ ) is much shorter than that of dsDNA $(50 \mathrm{~nm})^{21}$, removal of the template is expected to lead to smaller interparticle distances. 


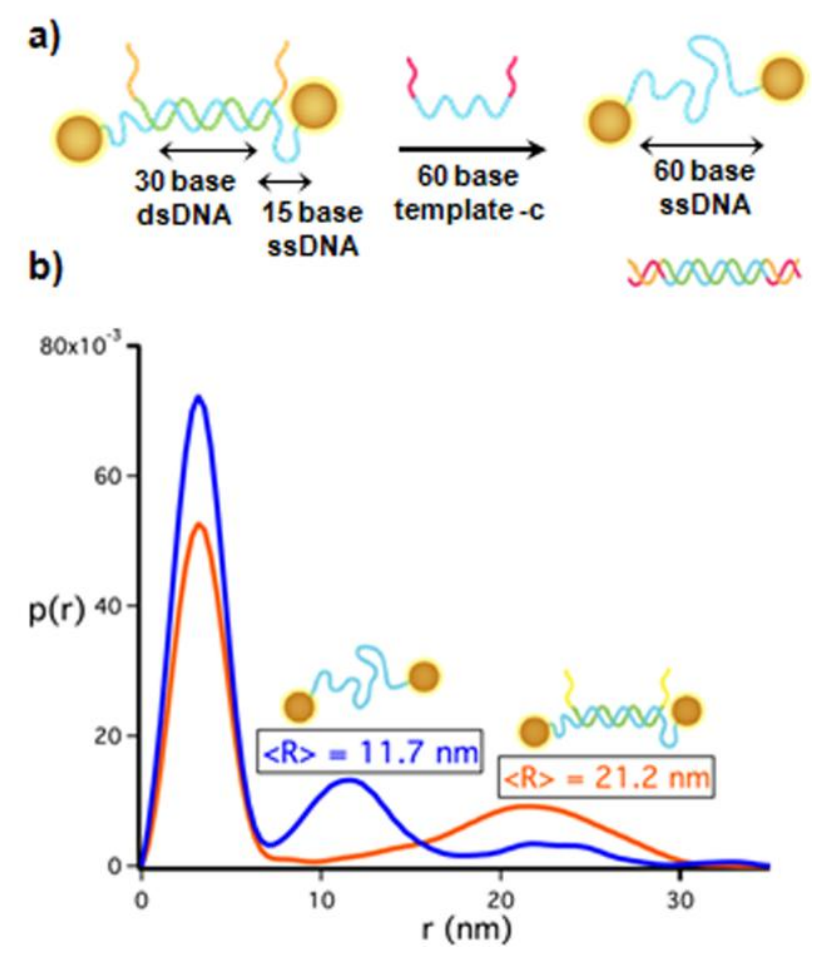

Figure 5.2. (a) Schematic of gold nanoparticle dimers connected by a single strand of ssDNA. (b) SAXS analysis shows a decrease in interparticle distance after removal of the template strand.

Figure $5.2 \mathrm{~b}$ shows the effect of adding the template complement strand. When no template complement has been added (red trace), the SAXS pair distribution function shows a peak at $21.2 \mathrm{~nm}$. When 2 equivalents of template complement are added and the sample is allowed to equilibrate for 24 hours (blue trace), a large peak appears at approximately $11.7 \mathrm{~nm}$. Since these two peaks are indicative of center-to-center distances between the nanoparticles, this would represent an end-to-end distance of approximately $16 \mathrm{~nm}$ for the DNA linker in the first case and $6 \mathrm{~nm}$ in the second case. Thus, although there is little difference in the migration of the two structures in an agarose gel, distinctive 
characteristics in the pair distribution functions allow them to be differentiated unambiguously.

Self-Assembly of Ligated Nanoparticle Dimer and Trimer Structures. As a demonstration that ligated ssDNA dimers and trimers retain the targeting ability of their DNA linker, ligated dimers and trimers were synthesized and assembled to form nanoparticle tetramers and hexamers (Scheme 2). Tetramers were formed by hybridization of two complementary ligated dimers. To synthesize hexameric structures, nanoparticle diconjugates were first specifically ligated to two monoconjugates to form a symmetric strand of three nanoparticles connected by ssDNA. Two such complementary strands were synthesized and subsequently hybridized to yield a hexameric nanoparticle structure comprising three pairs of nanoparticles.

Scheme 5.2. Overview of self-assembly process. Nanoparticle dimers and trimers are created by enzymatic ligation of mono- or diconjugates as shown. Hybridization of complementary dimers or trimers leads to nanoparticle tetramers or hexamers.

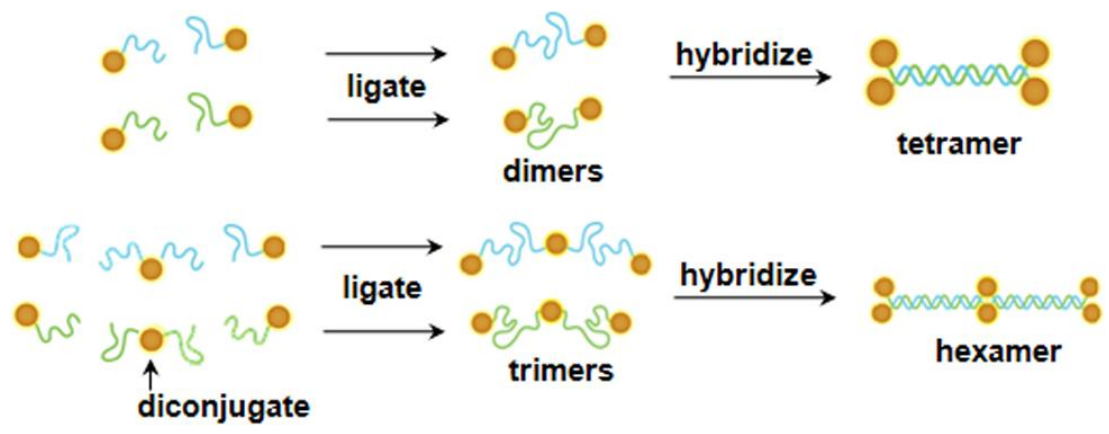


Figure 5.3a shows transmission electron micrographs of ligated nanoparticle dimers which have been incubated with template complement DNA to remove the ligation template strand. As a result, the two nanoparticles are attached to a length of ssDNA. Due to the decreased persistence length of ssDNA relative to dsDNA, the center-to-center interparticle distance varies widely, with an average of $20.9 \pm 14.0 \mathrm{~nm}$. It should be noted that the behavior of nanoparticle-DNA constructs dried on TEM grids differs markedly from their behavior in solution (Figure 5.2b), where the center-to-center distance of the same structures is $11.7 \pm 2.8 \mathrm{~nm}$. We presume that forces exerted on the sample while drying on the TEM grid override the entropic penalties associated with DNA stretching, resulting in larger interparticle distances as well as a larger distribution in the distances. 


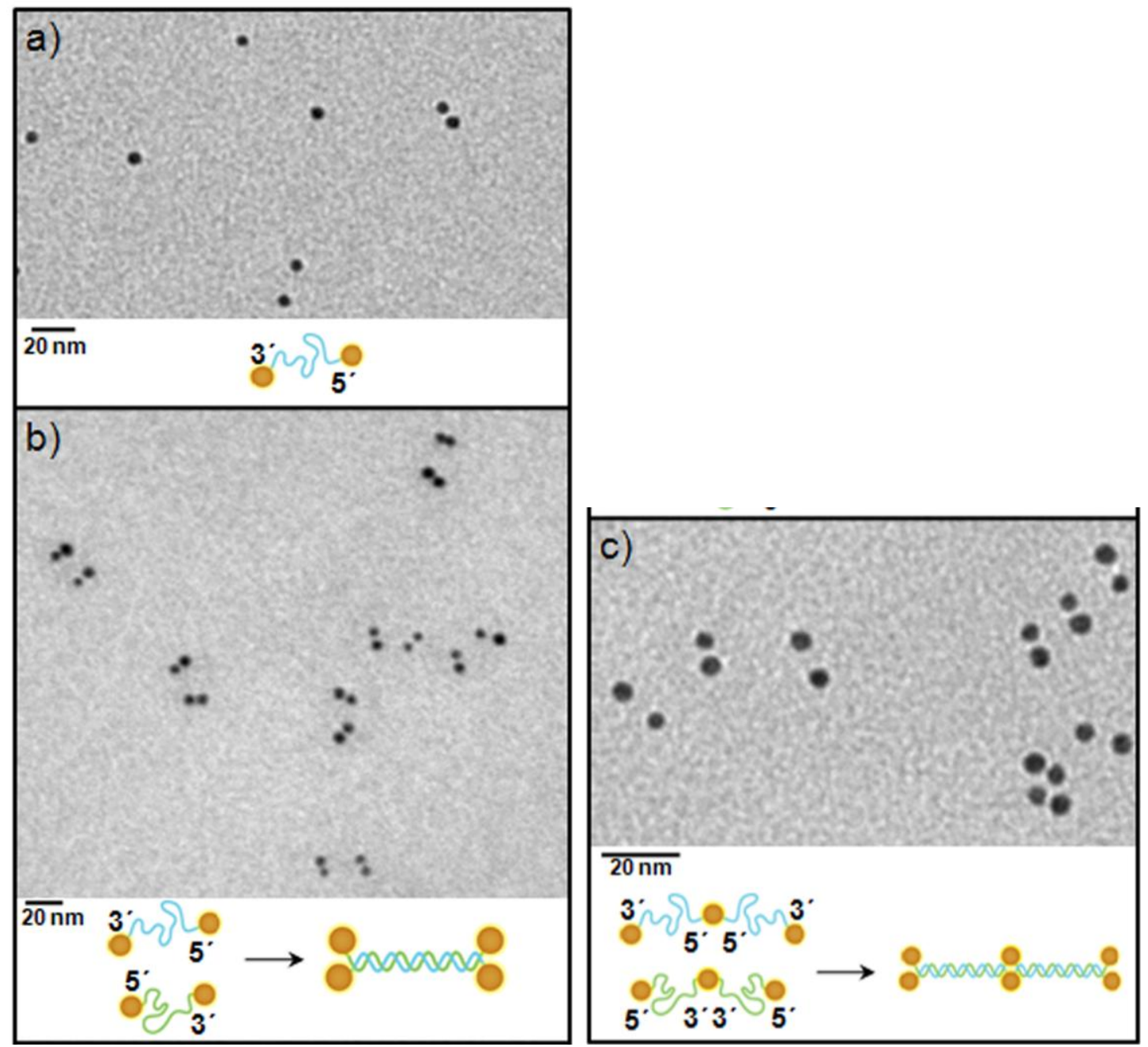

Figure 5.3. Transmission electron micrographs of ssDNA dimers and trimers hybridized to form larger multi-particle structures: a) ligated 60-base ssDNA dimers; b) complementary ligated dimers hybridized to form nanoparticle tetramers; c) complementary ligated trimers hybridized to form nanoparticle hexamers.

In Figure 5.3b, complementary ligated dimers have been hybridized to form nanoparticle tetramers, in which the increased structural rigidity provided by hybridization is evident. The majority of tetramers consist of two pairs of particles. If the long axis of the tetramer is taken to be the distance between the midpoints of the two 
pairs, the distribution is found to be $18.6 \pm 2.6 \mathrm{~nm}$, in agreement with the expected $20 \mathrm{~nm}$ length of a 60-base DNA double helix. The much smaller standard deviation reflects the increased rigidity of the structure.

The ligation strategy can also be extended to create more complex nanoscale building blocks. In Figure 5.3c, hybridization of two three-particle strands creates nanoparticle hexamers consisting of three pairs of particles. Due to the random distribution of the two DNA strands on the nanoparticle surface in the diconjugate, the observed hexamer structure morphology is not necessarily linear as depicted in the schematic representation.

Exponential Amplification of Ligated Nanoparticle Dimers. Polymerase chain reaction $(\mathrm{PCR})^{10}$ and ligase chain reaction $(\mathrm{LCR})^{11}$ have found wide use as a means of amplifying small amounts of DNA. We demonstrate the use of nanoparticle monoconjugates as substrates for a ligase chain reaction, amplifying the amount of DNAgold dimer product formed through repeated thermal cycling in the presence of Taq DNA ligase.

In this ligase chain reaction (Scheme 3), two strands of DNA are first hybridized to a complementary DNA template to form a nicked double helix. The reaction mixture is then incubated at a moderate temperature $\left(45^{\circ} \mathrm{C}\right)$ to allow the Taq DNA ligase enzyme to form a covalent bond at the nick site, and the reaction mixture is subsequently heated to $80{ }^{\circ} \mathrm{C}$ to melt the template from the ligated dimer. Since this exceeds the temperature range in which the thiol-gold bond is stable, ${ }^{22}$ trithiol terminated DNA is used in synthesizing conjugates to create more strongly bound structures. Following the hightemperature step, the temperature is lowered to $45{ }^{\circ} \mathrm{C}$, which allows the DNA to rehybridize. In the reaction mixture, conjugates and template halves are initially present in large excess. Thus, although it is possible for a ligated dimer to re-hybridize with a full 
template, it is statistically more likely that the template will hybridize with conjugate monomers and that the ligated dimer will hybridize with template halves. After the second ligation cycle, assuming $100 \%$ ligation efficiency, there will be twice as much ligated dimer. Repeated thermal cycling can then lead to exponential growth in the amount of ligated dimer product, as $2^{\mathrm{n}}$. The amount of dimer present can be monitored by gel electrophoresis (Figure 5.4a) and plotted against the number of thermal cycles (Figure 5.4b) to demonstrate exponential growth.

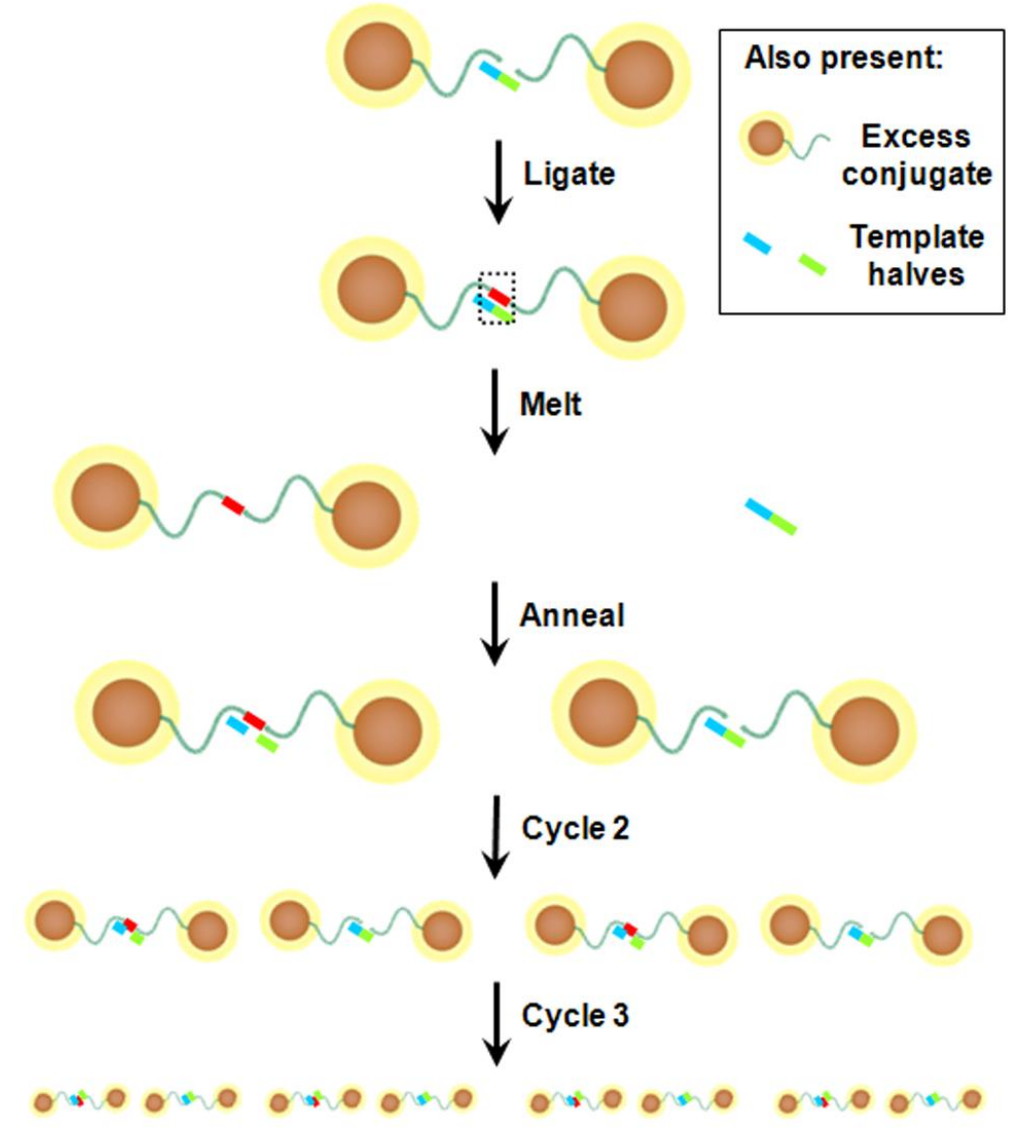

Scheme 5.3. Amplification of DNA-gold nanostructures via ligase chain reaction (LCR). 

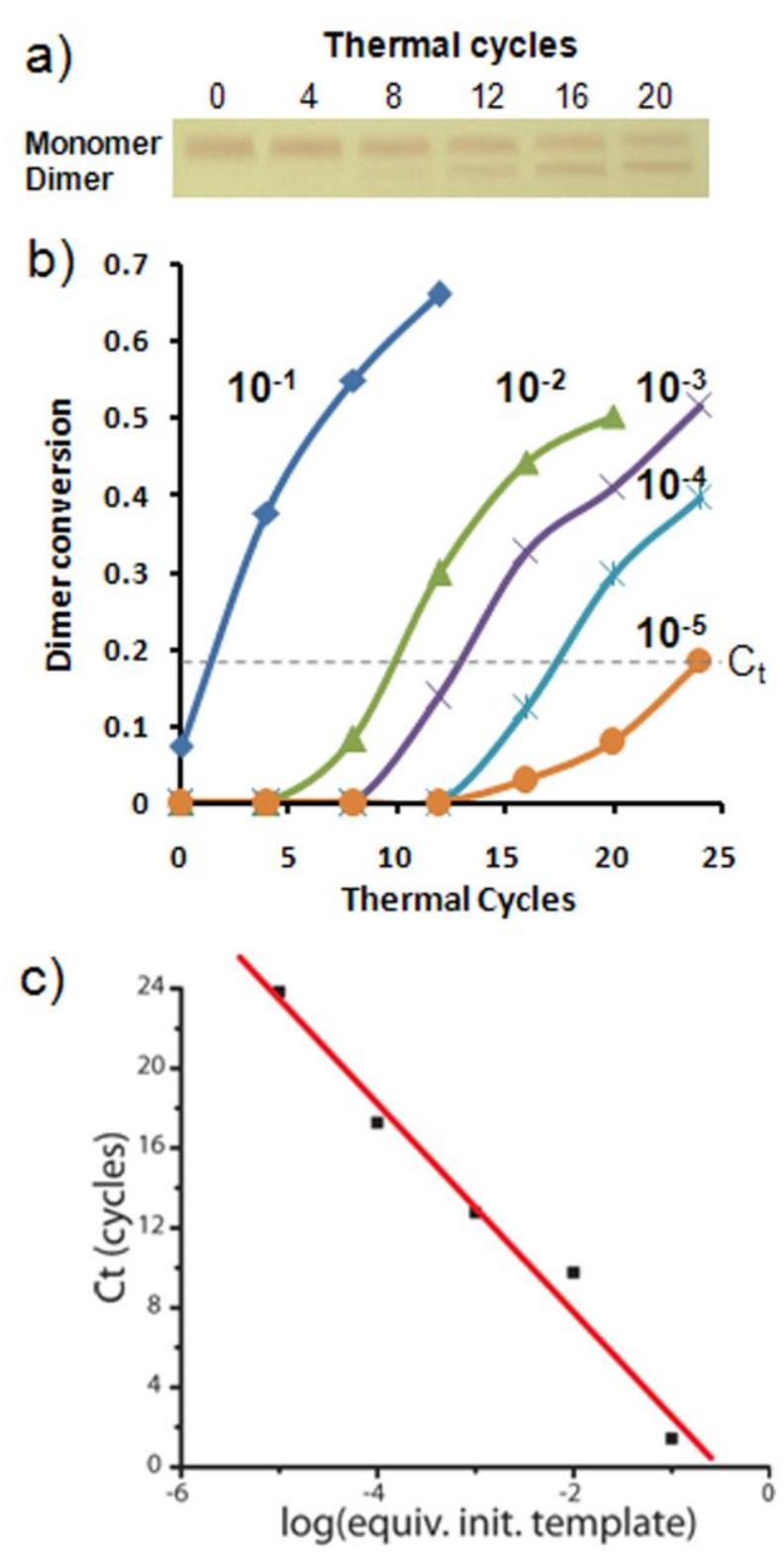

Figure 5.4. (a) Gel demonstrating exponential conversion of conjugate to dimer with increasing numbers of thermal cycles, starting with 0.01 equiv. template. (b) Graph of conversion to dimer for reactions with different starting equivalents of template strand (0.1 to 0.00001 equiv.) for increasing numbers of thermal cycles. (c) Plot of log initial template concentration vs number of cycles required to reach $20 \%$ conversion to dimer. 
In practice, ligation efficiency is less than $100 \%$, both in DNA-only experiments performed by others ${ }^{11}$ and in the nanoparticle conjugate experiments described here. The reaction efficiency can be calculated by plotting the $\log$ of the initial template concentration against the number of thermal cycles required to reach a certain percentage conversion. The conversion percentage used can be arbitrarily chosen within the range in which changes can be easily measured, but before the reaction reaches saturation. Here a conversion percentage of $18 \%$ was used. Plotting the data in this fashion (Figure 5.4c) results in a best-fit line with a slope $(m)$ of $-5.3 \pm 0.5$ cycles/ $\log ([$ template] $)$ which may then be used to calculate the reaction efficiency $(E)$ using the equation $E=10^{-1 / m}-1$, resulting in an efficiency of 55\%. While the gel assay used to measure conversion may result in some counting of unligated conjugates hybridized to a full template, this will not affect the calculated reaction efficiency, which depends upon the slope of the log plot (i.e., the number of thermal cycles separating the curves of the conversion graph in Figure 5.4c) and not upon the absolute conversion.

Sensitivity is limited by the rate of nonspecific ligation, as is the case for DNA-only LCR experiments. Small amounts of nonspecific ligation are observed after more than 20 thermal cycles, making amplification from less than $10^{-5}$ equivalents of template impractical. For applications in which sensitivity is critical, a gap-LCR protocoll ${ }^{23}$ could be adopted, in which conjugates and half-template sequences would be designed to form sticky ends in order to reduce blunt-end ligation.

These enzymatic amplification experiments demonstrate that it is possible to achieve exponential amplification of multi-particle products using a thermal cycling protocol. More broadly, this experiment can be considered as a nanoparticle analog of PCR, in which a two-nanoparticle 'sequence' is amplified through repeated thermal cycling. With 
optimization, such a protocol might provide a route to high-yield syntheses of complex multi-nanocrystal building blocks. Additionally, since the dimer is analytically different from the monoconjugates as measured by gel or other techniques, such a protocol could also potentially be utilized as a readout step in a DNA computing operation.

\section{Conclusion}

In these experiments, we have found DNA ligase enzymes to be effective agents for creating covalently linked multi-nanoparticle building blocks capable of self-assembly into complex nanoscale structures. Since the ligated dimers and trimers retain the sequence-specific targeting capability of the ssDNA linker, they can be hybridized in a controlled fashion to yield larger discrete assemblies. These structures are distinct from their dsDNA-linked counterparts when analyzed by SAXS, a feature that could be exploited to study the conformational dynamics of ssDNA in solution. The use of thermostable conjugates and ligase enzymes has also allowed the system to be developed as a nanoparticle analog of PCR. Further, since the double-labeled ligation product is analytically distinct from the single-labeled monoconjugate starting materials, DNA-gold conjugates can provide a visual metric for ligation efficiency and could be incorporated into the ligase chain reaction as a readout mechanism. Ongoing experiments seek to leverage these new multi-particle constructs as both self-assembly components and spectroscopic probes.

More broadly, the ability to use DNA-manipulating enzymes on discrete nanoparticle conjugates is potentially very powerful since there are a great number of these enzymes commercially available, each of which performs a very specific operation on its DNA 
substrate. Many also exhibit sequence specificity, a requirement for DNA modification such as phosphorylation, or a requirement for a chemical additive such as adenosine triphosphate (ATP) or nicotinamide adenine dinucleotide (NAD). In a materials context, these requirements represent an orthogonal set of internal and external signals which may be used for controlling the step-by-step construction of a functional material.

\section{Materials and Methods}

General Procedures. Citrate coated $5 \mathrm{~nm}$ gold particles with $<10 \%$ deviation in diameter were purchased from Ted Pella (Redding, CA). The bis-( $p$ sulfonatophenyl)phenylphosphine dihydrate dipotassium (BSPP) ligand used to stabilize the nanoparticles in aqueous solutions was obtained from Strem Chemicals (Newburyport, MA). Thiolated poly(ethylene glycol) (PEG), MW=356.5 was purchased from PolyPure (Oslo, Norway). Thiolated DNA purified by polyacrylamide gel electrophoresis (PAGE, was purchased from Integrated DNA Technologies (Coralville, IA); trithiolated PAGE-purified DNA was obtained from Fidelity Sytems (Gaithersburg, MD). DNA was resuspended in deionized water to a working concentration of 50-100 $\mu \mathrm{M} . \quad \mathrm{T} 4$ and Taq DNA ligases were purchased from New England Biolabs (Ipswich, MA). Nanoparticle sample purification and concentration were carried out in a Fisher Centrific 228 or IEC MicroCL 218 bench top centrifuge. UV-Vis absorption measurements were taken using a Perkin-Elmer Lambda 35 spectrometer. Thermal cycling was performed in a Bio-Rad (Hercules, CA) PTC-100 thermal cycler. SAXS data were collected using a Bruker (Madison, WI) Nanostar Small Angle Spectrometer with a 
Bruker HiStar two-dimensional gas filled detector, using samples sealed in $2 \mathrm{~mm}$ quartz capillaries purchased from Charles-Supper (Natick, MA).

Transmission electron microscopy was performed using a Phillips Tecnai $G^{2} 20$ instrument. Carbon-coated copper TEM grids (Ted Pella) were ionized for $30 \mathrm{~s}$ in a Harrick Plasma PDC-32G oxygen plasma cleaner to increase surface hydrophilicity, then $0.5 \mu \mathrm{L}$ of dilute aqueous sample was spotted on the surface. The sample was left on the grid for 3 minutes to allow particles to adsorb to the surface before adding $10 \mu \mathrm{L}$ of $0.5 \mathrm{X}$ Tris-Borate-EDTA (TBE) buffer and touching the edge of the grid with a filter paper to wick off excess moisture and salts. Buffer addition and wicking were repeated two more times. Grids were then allowed to air dry prior to analysis.

\section{DNA Sequences.}

A: $5^{\prime}-\mathrm{HS}-\left(\mathrm{CH}_{2}\right)_{6}-\mathrm{ATC}$ GAT GCG ATT AAA GGA TGC CTG AGA GCG - 3'

B: $5^{\prime}-\mathrm{H}_{2} \mathrm{PO}_{4}-\mathrm{CCG}$ AGG TGT CCA CAT AAA GGT GAG ATC CTG $-\left(\mathrm{CH}_{2}\right)_{3}-\mathrm{SH}$ $-3^{\prime}$

B $: 5^{\prime}-\mathrm{HS}-\left(\mathrm{CH}_{2}\right)_{6}-\mathrm{CAG}$ GAT CTC ACC TTT ATG TGG ACA CCT CGG - 3'

$\mathrm{A}_{\mathrm{c}}: 5^{\prime}-\mathrm{H}_{2} \mathrm{PO}_{4}-\mathrm{CGC}$ TCT CAG GCA TCC TTT AAT CGC ATC GAT $-\left(\mathrm{CH}_{2}\right)_{3}-\mathrm{SH}$ $-3^{\prime}$

$n A_{c} B_{c} n: 5 '-$ GGG AGT ACT ACG ATG TGG ACA CCT CGG CGC TCT CAG GCA TCC 
AGA ACT ATT CCG - 3'

$n_{\mathrm{c}} \mathrm{ABn}_{\mathrm{c}}: 5^{\prime}-$ CGG AAT AGT TCT GGA TGC CTG AGA GCG CCG AGG TGT CCA

CAT CGT AGT ACT CCC - 3'

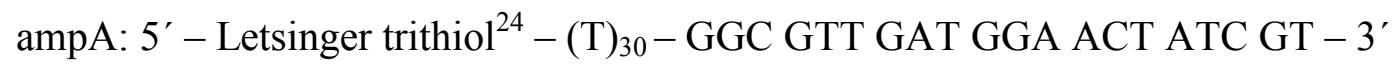

ampB: $5^{\prime}-\mathrm{H}_{2} \mathrm{PO}_{4}-$ GGT GTC TAC TCT GCC GGT AA $-(\mathrm{T})_{30}-$ dithiol dU $-\left(\mathrm{CH}_{2}\right)_{6}$ $-\mathrm{SH}-3^{\prime}$

C40: 5'- TTA GCG GCA GAG TAG ACA CCA CGA TAG TTC CAT CAA CGC C $3^{\prime}$

C40_1: 5'- $\mathrm{H}_{2} \mathrm{PO}_{4}-$ ACG ATA GTT CCA TCA ACG CC - 3'

C40_2: 5'-GGC GTT GAT GGA ACT ATC GT - 3'

Sequences ampA and ampB were purchased from Fidelity Systems with double polyacrylamide gel electrophoresis (PAGE) purification. All other sequences were purchased from IDT with either PAGE or high performance liquid chromatography (HPLC) purification.

Synthesis of Gold-DNA Conjugates. Gold samples were prepared following a literature procedure, described briefly here. ${ }^{9}$ To $100 \mathrm{~mL}$ of citrate coated $5 \mathrm{~nm}$ gold nanoparticle solution, $60 \mathrm{mg}$ of bis-( $p$-sulfonatophenyl)phenylphosphine dihydrate dipotassium salt was added, and the mixture was stirred at room temperature in order to allow phosphine ligands to replace the citrate ligands. Following overnight incubation, $\mathrm{NaCl}$ was added to the stirring mixture until a color change from red to cloudy purple was 
observed. The solution was transferred to $50 \mathrm{~mL}$ centrifuge tubes and centrifuged at room temperature for $10 \mathrm{~min}$ at $3500 \mathrm{rpm}$ to collect the precipitated gold. The supernatant was removed, and the pellet re-suspended in phosphine buffer (1 $\mathrm{mg}$ of BSPP in $1 \mathrm{~mL}$ of de-ionized water), to a final nanoparticle concentration of approximately 3 $\mu \mathrm{M}$. Nanoparticles and Au-DNA conjugates were quantified by measuring the absorbance at $\lambda=520 \mathrm{~nm}$ and calculating the concentration using Beer's law based on their extinction coefficients: $\varepsilon_{520}(5 \mathrm{~nm})=9.3 \times 10^{6} \mathrm{M}^{-1} \mathrm{~cm}^{-1}$.

To prepare $\mathrm{Au}$-DNA conjugates, 5'-thiolated DNA was mixed with concentrated gold colloid and $1 / 8$ volume phosphine buffer $\left(1 \mathrm{mg} \mathrm{BSPP}\right.$ in $\left.20 \mu \mathrm{L} \mathrm{ddH}_{2} \mathrm{O}\right)$ and $1 / 8$ volume $20 \mathrm{mM}$ phosphate buffered saline (PBS), $\mathrm{pH}$ 7.4. In a typical experiment, $80 \mu \mathrm{L}$ of gold colloid was mixed with $10 \mu \mathrm{L}$ of phosphine buffer and $10 \mu \mathrm{L}$ of PBS and the appropriate volume of DNA (usually about $5 \mu \mathrm{L}$ ). The mixture was incubated with gentle agitation at room temperature for $4-24 \mathrm{~h}$, then $1 / 5$ volume PEG solution $(1 \mu \mathrm{L}$ thiolated PEG in 50 $\mu \mathrm{L} \mathrm{ddH}_{2} \mathrm{O}$ ) was added and the solution was incubated with gentle agitation for a further 2 h.

AE-HPLC of DNA-Au Conjugates. Monoconjugates were purified using an anionexchange chromatography method published previously ${ }^{15}$ and described briefly here. Conjugates were separated using a Dionex DNA-Pac PA100 anion exchange column (Sunnyvale, CA) on an Agilent 1100 series HPLC with in-line degasser, autosampler, multi-wavelength UV-Vis detector, and fluorescence detector. Fractions were collected using an Agilent 1200 series automatic fraction collector. In a typical separation, $100 \mu 1$ of conjugate prepared as described above was injected using an autosampler and an initial mobile phase composed of $25 \mathrm{mM}$ Tris $(\mathrm{pH} 8)$ and $40 \mathrm{mM} \mathrm{NaCl}$ in deionized water. The 
low ionic strength in the mobile phase was maintained for 3 minutes to encourage strong binding of the sample to the column. Subsequently the $\mathrm{NaCl}$ concentration was increased from $40 \mathrm{mM}$ to $900 \mathrm{mM}$ over a period of 20 minutes. Sample elution was detected by monitoring UV-Vis absorption at the gold plasmon maximum of $520 \mathrm{~nm}$ against a reference of $850 \mathrm{~nm}$, at which the gold colloid does not absorb. Automatic fraction collection was also triggered by monitoring these wavelengths. In these experiments the monoconjugate (second peak, typically at or around 12 minutes) and diconjugate (third peak, at or around 13 minutes) were collected. It should be noted that the unconjugated gold peak sometimes spans the $40 \mathrm{mM}$ threshold; thus it is possible for the peak to split, resulting in one peak eluting immediately $(<1 \mathrm{~min})$, and one shortly after the sodium chloride concentration begins to increase (at or around 5 minutes). Collected fractions were concentrated either in Centricon 50k MWCO centrifugal filters, or pelleted by highspeed centrifugation (60 min at $14800 \mathrm{rpm}$ ) prior to use in hybridization experiments. Typical final concentrations for collected conjugates were $0.2-1.5 \mu \mathrm{M}$.

T4 DNA Ligation Buffer. Since standard T4 DNA ligase buffer contains dithiothreitol (DTT), which was found to precipitate gold nanoparticles, a modified buffer was prepared without DTT. $(5 \mathrm{mmol})$ Tris- $\mathrm{HCl}$ and $(1 \mathrm{mmol}) \mathrm{MgCl}_{2}$ were dissolved in deionized water to a volume of $9 \mathrm{~mL}$ and brought to $\mathrm{pH} 7.5$ by addition of a concentrated solution of $\mathrm{NaOH}$. The solution was stored frozen. Immediately prior to use in ligation experiments, buffer was thawed and 1/9 volume $100 \mathrm{mM}$ ATP (in deionized $\mathrm{H}_{2} \mathrm{O}$ at $\mathrm{pH}$ 7.5) was added to the volume of buffer to be used in the experiment.

Taq DNA Ligation Buffer. Since standard Taq DNA ligation buffer contains DTT and the detergent TritonX-100, which were found to precipitate gold nanoparticles, a 
modified buffer was prepared without these reagents. $(2 \mathrm{mmol})$ Tris- $\mathrm{HCl},(2.5 \mathrm{mmol})$ potassium acetate, and $(1 \mathrm{mmol})$ magnesium acetate were dissolved in deionized water to a final volume of $9 \mathrm{~mL}$ and brought to $\mathrm{pH} 7.6$ by addition of a concentrated solution of $\mathrm{NaOH}$. The solution was stored frozen. Immediately prior to use in thermal cycling experiments, buffer was thawed and $1 / 9$ volume $100 \mathrm{mM}$ nicotinamide adenine dinucleotide (NAD) (in deionized water at $\mathrm{pH}$ 7.6) was added to the volume of buffer to be used in the experiment.

Ligation of DNA-Au Conjugates. Concentrated conjugates as described above were hybridized with equimolar quantities of templates and partner conjugates to create gold nanoparticle dimers. In a typical experiment, 2 pmol each of $5 \mathrm{~nm}$ monoconjugates A and $\mathrm{B}$ and the template DNA strand $\mathrm{nA}_{c} \mathrm{~B}_{\mathrm{c}} \mathrm{n}$ were mixed, vortexed briefly, inserted in a heat block at $45{ }^{\circ} \mathrm{C}$, and left to cool slowly to room temperature for at least 2 hours or as long as overnight. Since conjugates purified by AE-HPLC are isolated in a high-salt buffer, no additional sodium chloride was added in the hybridization step. To the hybridized mixture, 1/9 volume T4 ligase buffer and 1/19 volume T4 DNA ligase were added. The mixture was vortexed briefly and incubated at $16{ }^{\circ} \mathrm{C}$ for 30 minutes.

Removal of Ligation Template. Following ligation, the template complement strand $\mathrm{n}_{\mathrm{c}} \mathrm{ABn}_{\mathrm{c}}$ was added. In a typical reaction, 1 pmol template complement was added per 1 pmol of template. The reaction was mixed thoroughly and placed in a heat block at $50{ }^{\circ} \mathrm{C}$ then allowed to cool slowly on the bench top to room temperature (at least 2 hours or as long as overnight).

Enzymatic Amplification of DNA-Au Conjugate Structures. Concentrated monoconjugates ampA and ampB as described above were mixed with varying 
substoichiometric amounts of template strand C40 and stoichiometric amounts of halftemplate strands C40_1 and C40_2, then subjected to thermal cycling in the presence of Taq DNA ligase to induce enzymatic amplification. In a typical experiment, 10 pmol each of $5 \mathrm{~nm}$ monoconjugates ampA and ampB were mixed with $0.01 \mathrm{pmol}$ template and 10 pmol each half-template with deionized water added to reach a volume of $85 \mu \mathrm{L}$. Addition of $5 \mu \mathrm{L}$ Taq DNA ligase and $10 \mu \mathrm{L}$ Taq ligase buffer (described above) brought the total reaction volume to $100 \mu \mathrm{L}$. The mixture was vortexed to ensure thorough mixing, then split into five $20-\mu \mathrm{L}$ aliquots, which were subjected to $4,8,12,16$, and 20 thermal cycles. Each thermal cycle comprised a 15 -min ligation period at $45^{\circ} \mathrm{C}$ followed by a 1-min melting period at $80^{\circ} \mathrm{C}$. Samples which were subjected to smaller numbers of thermal cycles were held at room temperature after cycling until all samples were finished. Following thermal cycling, reaction products were analyzed by gel electrophoresis.

Electrophoresis of Au-DNA Hybrid Structures. Gels were prepared with 3\% agarose by weight in $0.5 \mathrm{X}$ TBE buffer. Samples were diluted with $1 / 5$ volume $3 \mathrm{X}$ loading buffer containing 15\% Ficoll 400 (Fluka, Milwaukee, WI) and then loaded into the appropriate well. Gels were run at $10 \mathrm{~V} / \mathrm{cm}$ for $45 \mathrm{~min}$ and visualized over white light using a Nikon D1x digital SLR camera.

Small Angle X-ray Scattering Experiments. Nanoparticle dimer samples for SAXS were prepared with 15 pmol of DNA-gold conjugates hybridized with template to yield approximately $7.5 \mathrm{pmol}$ of dimers in a volume of $20 \mu \mathrm{L}$. Each sample was sealed in a quartz capillary with a diameter of $2 \mathrm{~mm}$. 
The X-ray source was a copper tube for which $\lambda=1.54 \AA$. The primary beam was collimated with pinholes to a $400 \mu \mathrm{m}$ diameter spot. Measurements were performed using a two-dimensional gas filled detector, with a diameter of $11.5 \mathrm{~cm}$ and a sample to detector distance of $105 \mathrm{~mm}$. Under these conditions the maximum scattered $2 \theta$ angle measurable was $3.0^{\circ}$. Scattered intensity was measured in terms of the scattering vector q. Given the presence of a $2.0 \mathrm{~mm}$ beam stop, and the finite size of the detector, the measured q range was from $0.013 \AA^{-1}$ to $0.213 \AA^{-1}$.

Each sample was probed for $18000 \mathrm{~s}$. The temperature in the experiment was estimated by sealing a thermocouple into a capillary containing a typical gold nanoparticle solution and measuring the temperature over the course of the scan. The average temperature was $20.1{ }^{\circ} \mathrm{C}$, and varied less than $0.5{ }^{\circ} \mathrm{C}$ over five hours of X-ray illumination.

The raw SAXS data, I(q) vs q, clearly show the presence of a structure factor indicative of proximal nanoparticles, however in reciprocal space it is difficult to observe the length scales present in the sample. Analytical expressions exist to transform the data between reciprocal space data, I(q), and real space pair distribution functions, $\mathrm{p}(\mathrm{r})$. However, the transformation from $\mathrm{I}(\mathrm{q})$ to $\mathrm{p}(\mathrm{r})$ is not generally possible as it requires integration over all $\mathrm{q}$, whereas here only a finite range is measured. Thus the q-space data were transformed into pair distribution functions via the Generalized Indirect Fourier Transformation (GIFT) method using the program GNOM. ${ }^{25}$ This algorithm defines the pair distribution function over $r$ as a set of spline functions with linear coefficients, then transforms their sum into $\mathrm{q}$ space data. This is possible because $\mathrm{p}(\mathrm{r})$ is bounded over a finite range. The transformed pair distribution function is compared to the experimental scattering data to solve for the coefficients of the spline functions. 
The pair distribution functions show two peaks. The first peak arises from scattering within a single nanoparticle, the second from scattering between the two particles in a

dimer. The positions of the peaks indicate, in our case, whether the dimer is joined by a relatively floppy or stiff linker.

\section{References}

(1) Alivisatos, A. P.; Johnsson, K. P.; Peng, X. G.; Wilson, T. E.; Loweth, C. J.; Bruchez, M. P.; Schultz, P. G. Nature 1996, 382, 609-611.

(2) Katz, E.; Willner, I. Angewandte Chemie-International Edition 2004, 43, 6042-6108.

(3) Niemeyer, C. M. Angewandte Chemie-International Edition 2001, 40, 4128-4158.

(4) Voet, D.; Voet, J. G. Biochemistry; 2 ed.; John Wiley and Sons, Inc.: New York, 1995.

(5) Kanaras, A. G.; Wang, Z. X.; Brust, M.; Cosstick, R.; Bates, A. D. Small 2007, 3, 590-594.

(6) Pena, S. R. N.; Raina, S.; Goodrich, G. P.; Fedoroff, N. V.; Keating, C. D. Journal of the American Chemical Society 2002, 124, 7314-7323.

(7) Kanaras, A. G.; Wang, Z. X.; Hussain, I.; Brust, M.; Cosstick, R.; Bates, A. D. Small 2007, 3, 67-70.

(8) Xu, X. Y.; Rosi, N. L.; Wang, Y. H.; Huo, F. W.; Mirkin, C. A. Journal of the American Chemical Society 2006, 128, 9286-9287. 
(9) Loweth, C. J.; Caldwell, W. B.; Peng, X. G.; Alivisatos, A. P.; Schultz, P. G. Angewandte Chemie-International Edition 1999, 38, 1808-1812.

(10) Saiki, R. K.; Gelfand, D. H.; Stoffel, S.; Scharf, S. J.; Higuchi, R.; Horn, G. T.; Mullis, K. B.; Erlich, H. A. Science 1988, 239, 487-491.

(11) Barany, F. Proceedings of the National Academy of Sciences of the United States of America 1991, 88, 189-193.

(12) Zanchet, D.; Micheel, C. M.; Parak, W. J.; Gerion, D.; Alivisatos, A. P. Nano Letters 2001, 1, 32-35.

(13) Sambrook, J.; Russell, D. W. In Molecular Cloning: A Laboratory Manual; 3 ed.; Argentine, J., Ed.; Cold Spring Harbor Laboratory Press: New York, 2001; Vol. 1.

(14) Weiss, J. Handbook of Ion Chromatography; Wiley: Darmstadt, 2004;

Vol. 1.

(15) Claridge, S. A.; Liang, H. W.; Basu, S. R.; Frechet, J. M. J.; Alivisatos, A. P. Nano Letters 2008, 8, 1202-1206.

(16) Takahashi, M.; Yamaguchi, E.; Uchida, T. Journal of Biological Chemistry 1984, 259, 41-47.

(17) Engler, M. J.; Richardson, C. C. The Enzymes; Academic Press: San Diego, 1982; Vol. 5.

(18) Zanchet, D.; Micheel, C. M.; Parak, W. J.; Gerion, D.; Williams, S. C.; Alivisatos, A. P. Journal of Physical Chemistry B 2002, 106, 11758-11763.

(19) Park, S. J.; Lazarides, A. A.; Storhoff, J. J.; Pesce, L.; Mirkin, C. A. Journal of Physical Chemistry B 2004, 108, 12375-12380. 
(20) Reinhard, B. M.; Sheikholeslami, S.; Mastroianni, A.; Alivisatos, A. P.; Liphardt, J. Proceedings of the National Academy of Sciences of the United States of America 2007, 104, 2667-2672.

(21) Bustamante, C.; Bryant, Z.; Smith, S. B. Nature 2003, 421, 423-427.

(22) Schessler, H. M.; Karpovich, D. S.; Blanchard, G. J. Journal of the American Chemical Society 1996, 118, 9645-9651.

(23) Abravaya, K.; Carrino, J. J.; Muldoon, S.; Lee, H. H. Nucleic Acids Research 1995, 23, 675-682.

(24) Li, Z.; Jin, R. C.; Mirkin, C. A.; Letsinger, R. L. Nucleic Acids Research 2002, 30, 1558-1562.

(25) Svergun, D. I. Journal of Applied Crystallography 1992, 25, 495-503. 


\section{Appendix A: Supporting Information for Chapter 3}

$10 \mathrm{~nm}$ Tetramer Band Analysis Experiment

Tetramer hybridization was explored by changing ratios of hybridization components and performing partial hybridizations in which one or more components were omitted (Figure S.A.1). Replacement of the $\mathbf{B}^{\prime} \mathbf{A}_{\mathbf{2}}$ scaffold with a $\mathbf{B}^{\prime} \mathbf{C}_{\mathbf{2}}$ scaffold in lanes 6 and 8 increased intensities of bands 4 and 6, corresponding to double-scaffold monomers and dimers, respectively. 


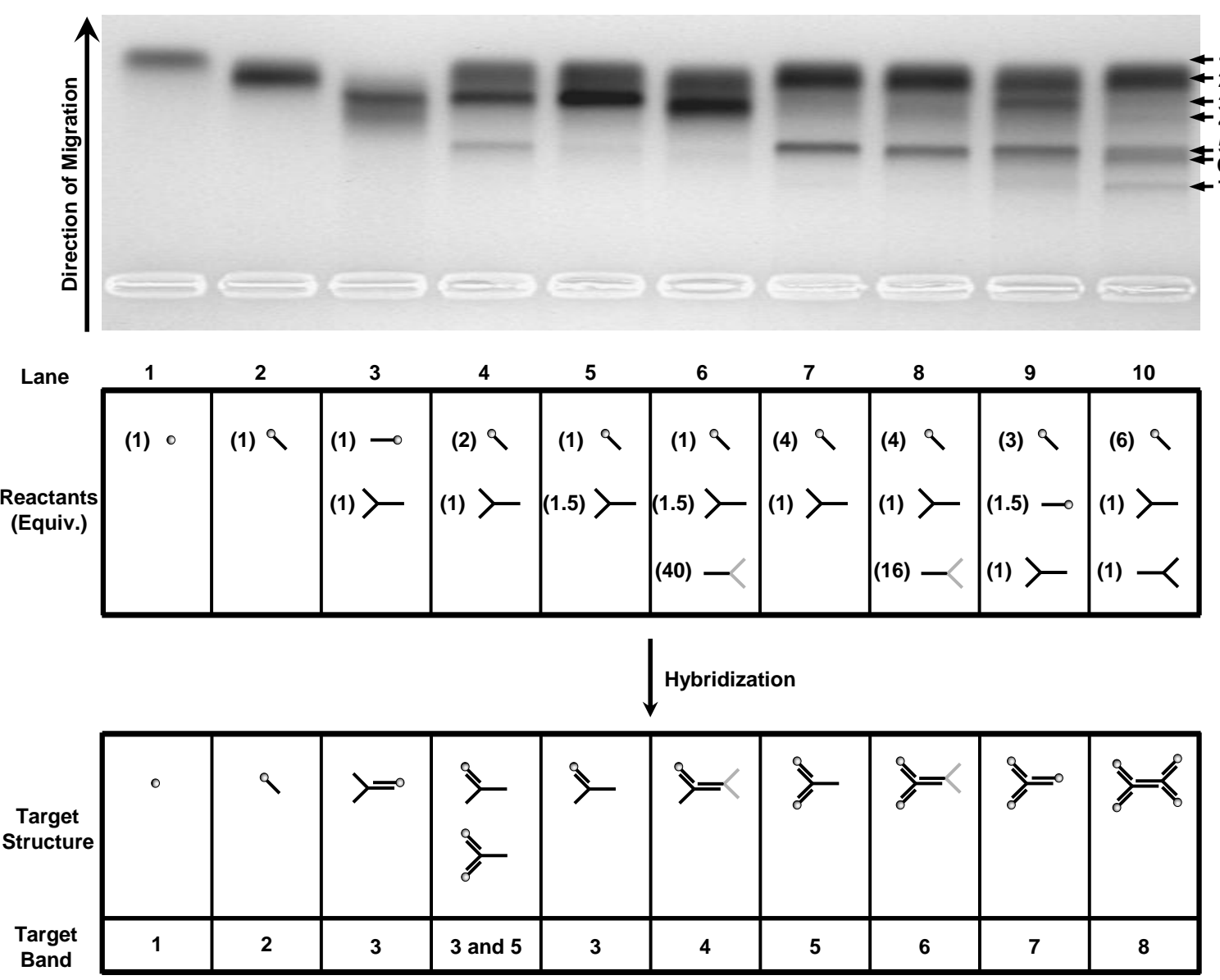

Figure S.A.1. Electrophoretic analysis of band identities in $10 \mathrm{~nm}$ tetramer hybridization. Lane 1: $10 \mathrm{~nm}$

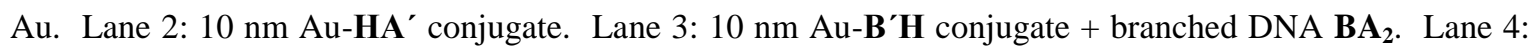
$10 \mathrm{~nm} \mathrm{Au-HA} \mathbf{A}^{\prime}+\mathbf{B} \mathbf{A}_{2}$. Lane 5: $10 \mathrm{~nm}$ Au-HA' + excess $\mathbf{B} \mathbf{A}_{2}$. Lane 6: $10 \mathrm{~nm}$ Au-HA' + excess $\mathbf{B} \mathbf{A}_{2}+$ excess $\mathbf{B}^{\prime} \mathbf{C}_{2}$. Lane 7: excess $10 \mathrm{~nm}$ Au-HA' $\mathbf{H}^{\prime}+\mathbf{B} \mathbf{A}_{2}$. Lane 8: excess $10 \mathrm{~nm}$ Au-HA' $+\mathbf{B A}_{\mathbf{2}}+$ excess $\mathbf{B}^{\prime} \mathbf{C}_{2}$. Lane 9: $10 \mathrm{~nm}$ trimer mixture. Lane 10: $10 \mathrm{~nm}$ tetramer mixture. Bands are indicated by arrows to the right of the gel. Samples are loaded by Au content, with 2.5 pmol of Au per sample lane and 1.5 pmol Au per standard lane. Samples were electrophoresed for 90 minutes at $7.5 \mathrm{~V} / \mathrm{cm}$ in $0.5 \mathrm{X}$ TBE prior to visualization under white light. 


\section{TEM Statistics from Extracted Tetramer Hybridization Bands}

Statistics were compiled from micrographs bands 6-8 of each tetramer hybridization, as well as a sample from the unpurified outside hairpin hybridization mixture (Figure S.A.2). Bands 6-8 are expected to contain dimers, trimers, and tetramers, respectively, and for each band the expected grouping is highlighted. Statistics are compiled for each sample both including and excluding higher-order aggregates. Since a few large nanoparticle groupings were found in virtually all samples, and should not have migrated through the gel at the same rate as other lower-order groupings, they are believed to be an artifact of the grid preparation procedure.

For both outside hairpin and extended architectures, target groupings for each band are observed in high yield (60-75\%), while for inside hairpin structures, statistics are not as conclusive. $\%$ Particles by grouping, including and excluding
higher-order aggregates

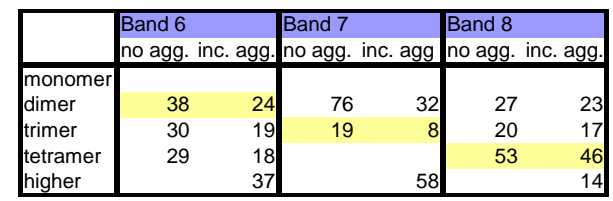

Outside Hairpin
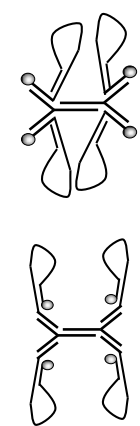

\begin{tabular}{|c|c|c|c|c|c|}
\hline & \multirow{2}{*}{\begin{tabular}{|l} 
Band 6 \\
no agg. inc. agg.
\end{tabular}} & Band 7 & Band 8 & \multicolumn{2}{|c|}{ Unpurified } \\
\hline & & no agg. inc. agg & no agg. inc. agg & no agg. & inc. agg. \\
\hline monomer & $11 \quad 11$ & 4 & $6 \quad 5$ & 38 & 33 \\
\hline dimer & 75 & 12 & 18 & 33 & 29 \\
\hline trimer & 4 & 74 & 3 & 20 & 18 \\
\hline $\begin{array}{l}\text { tetramer } \\
\text { higher }\end{array}$ & 11 & 10 & 73 & 10 & 9 \\
\hline
\end{tabular}

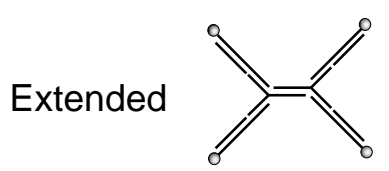

\begin{tabular}{|l|rr|rr|rr|}
\hline & Band 6 & \multicolumn{3}{|l|}{ Band 7 } & \multicolumn{3}{l|}{ Band 8 } \\
& no agg. inc. agg. & no agg. & inc. agg & no agg. inc. agg. \\
\hline monomer & 6 & 5 & 8 & 7 & 8 & 6 \\
dimer & 74 & 69 & 20 & 19 & 15 & 11 \\
trimer & 2 & 2 & 66 & 64 & 15 & 12 \\
tetramer & 18 & 17 & 6 & 6 & 61 & 46 \\
higher & & 6 & & 4 & & 33 \\
\hline
\end{tabular}

Figure S.A.2. TEM Statistics compiled from micrographs of samples from bands 6 (dimer), 7 (trimer) and $\mathbf{8}$ (tetramer) of each tetramer hybridization gel, given in figure 4, as well as unpurified sample from outside hairpin hybridization. 


\section{Tetramer Diameters for Outside Hairpin and Extended Structures}

Maximum diameters are expected to be different for outside hairpin and extended tetramer architectures. Theoretical maximum diameters were calculated for each structure as shown in Figure S.A.3, and this number was compared against the actual structure diameters observed in TEM micrographs. The mean diameter for the outside hairpin structure was found to be $34 \mathrm{~nm}$, smaller than the mean diameter of $44 \mathrm{~nm}$ observed for the extended structure. The mean diameter for the outside hairpin structure is actually larger than the calculated maximum, presumably due to one or more hairpins unwinding in some structure. The mean extended structure diameter was smaller than the calculated maximum, since rotation at any of the flexible points can only decrease the particle separation.
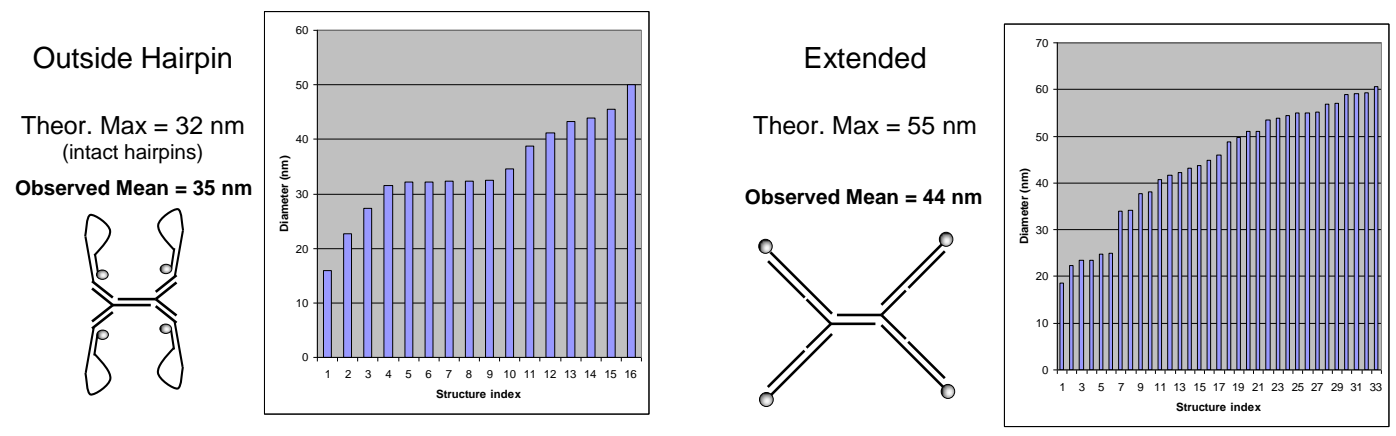

Figure S.A.3. Tetramer diameters for outside hairpin and extended structures, compared to calculated theoretical maximum for each. Diameter is taken to be maximum distance between particle centers in a single structure. Theoretical maximum is calculated to be the sum of the lengths of the scaffold arms, the length of the branch points, twice the length of the six-carbon thiolating linker, and twice the radius of the gold particles, for the outside hairpin structure. The calculation for the extended structure also includes twice the length of the 32 base linearizing sequence. 
TEM Data for Interior Hairpin Structures: Dimers
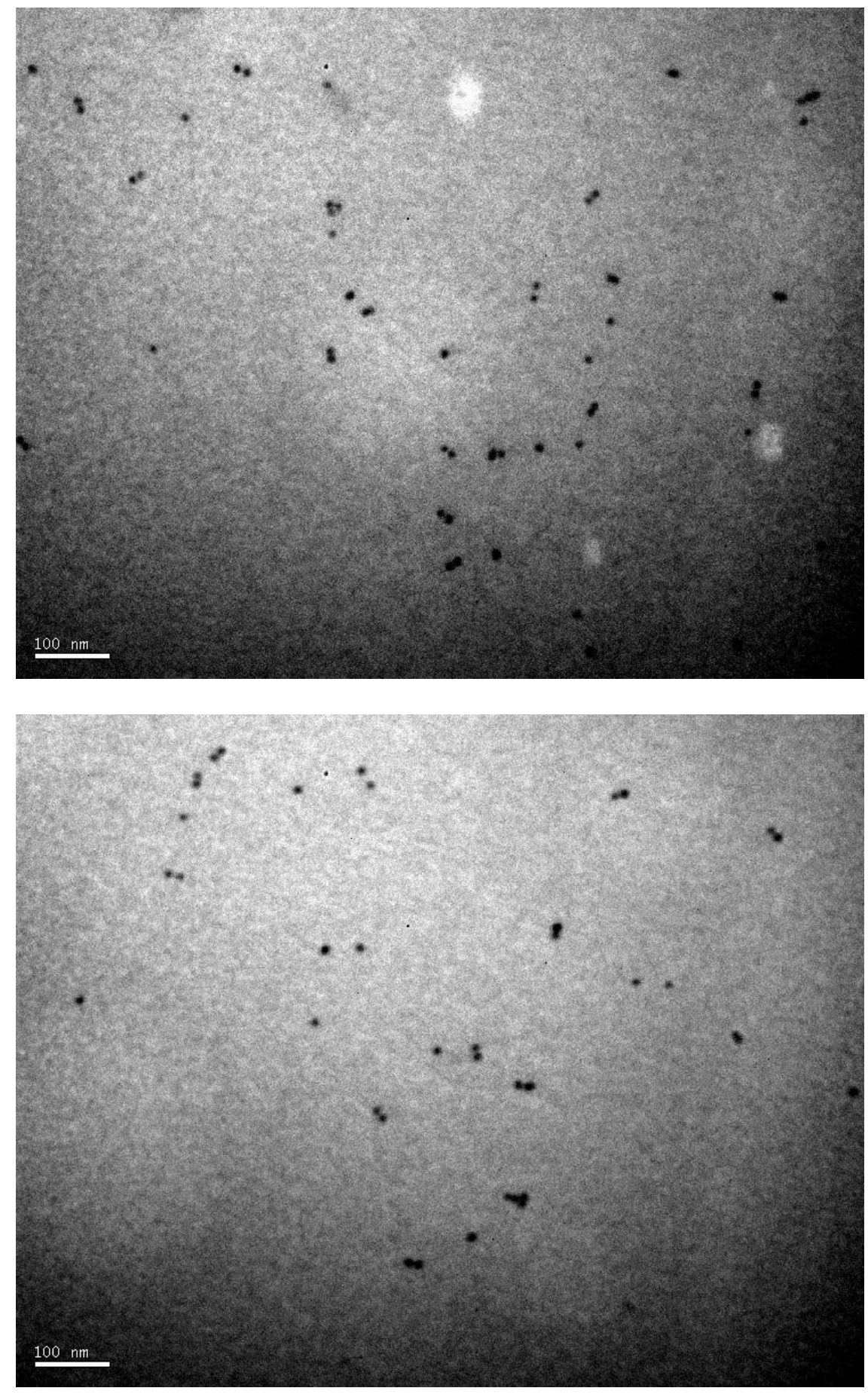

Figure S.A.4. Transmission electron micrograph for internal hairpin dimer structures 

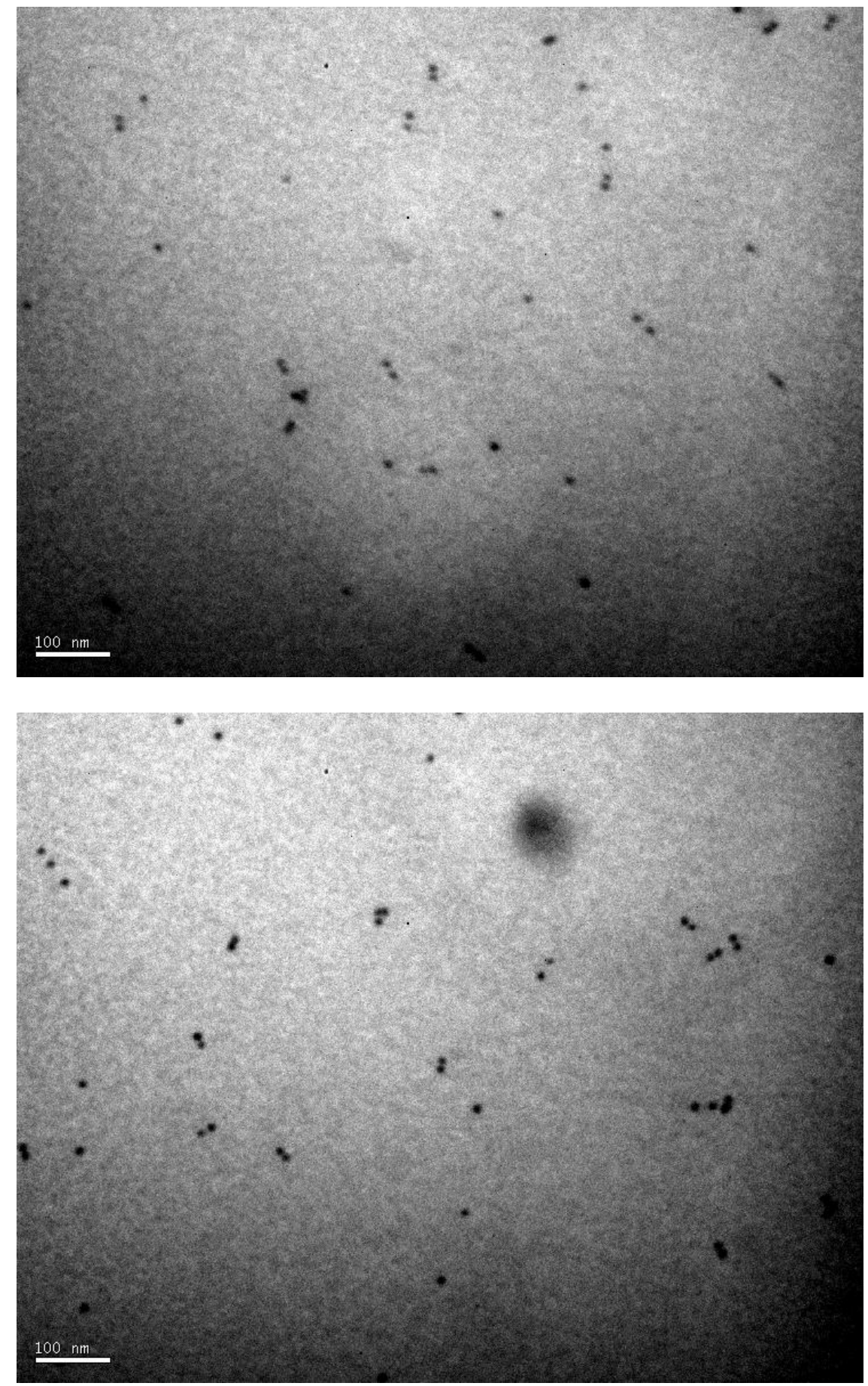

Figure S.A.5. Additional transmission electron micrograph for internal hairpin dimer structures 


\section{Appendix B: Supporting Information for Chapter 4}

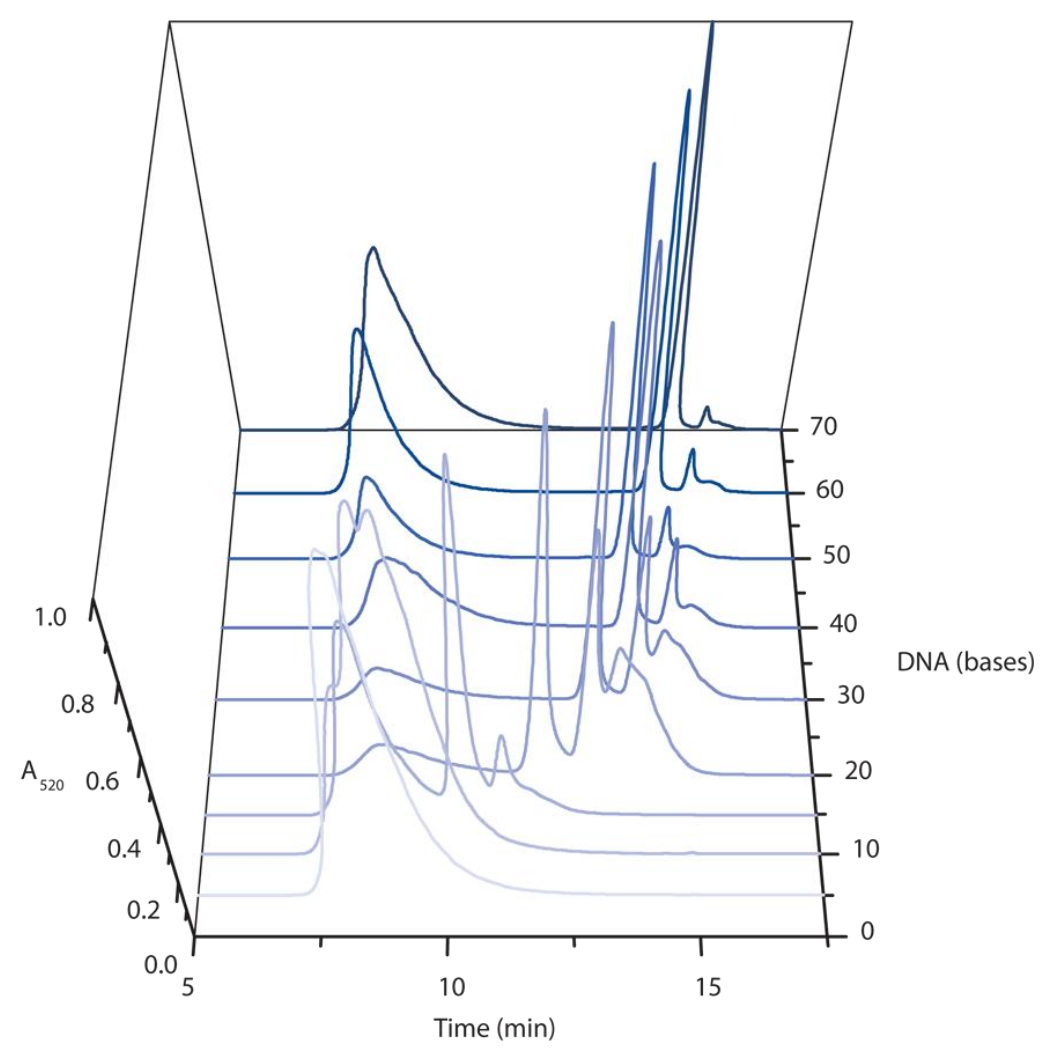

Figure S.B.1. Unnormalized HPLC traces showing retention behavior of $20 \mathrm{~nm}$ gold particles conjugated to varying lengths of polyT DNA.

Small variations are observed in the position of the unconjugated gold peak (first peak) from run to run. These are attributed to slight differences in the extent to which the neutral thiolated PEG ligands have replaced the charged phosphine ligands initially coating the surface of the particle. Longer ligand exchange times correlate with shorter peak retention times, consistent with fewer charged phosphines remaining on the particle surface. 


\section{Appendix C: Supporting Information for Chapter 5}

Raw SAXS Data. The difference between isolated gold nanoparticles and dimers is immediately apparent upon collection of raw SAXS data. The data for the bare gold is described by the scattering form factor for spheres convolved with the size distribution of the particles. The data for the dimers, however, is the product of this and a structure factor consisting of a sinc function with a frequency given by the center to center distance of the nanoparticles. The sharp drop at low q values is due to a beam stop which protects the detector face from the intense unscattered X-rays.

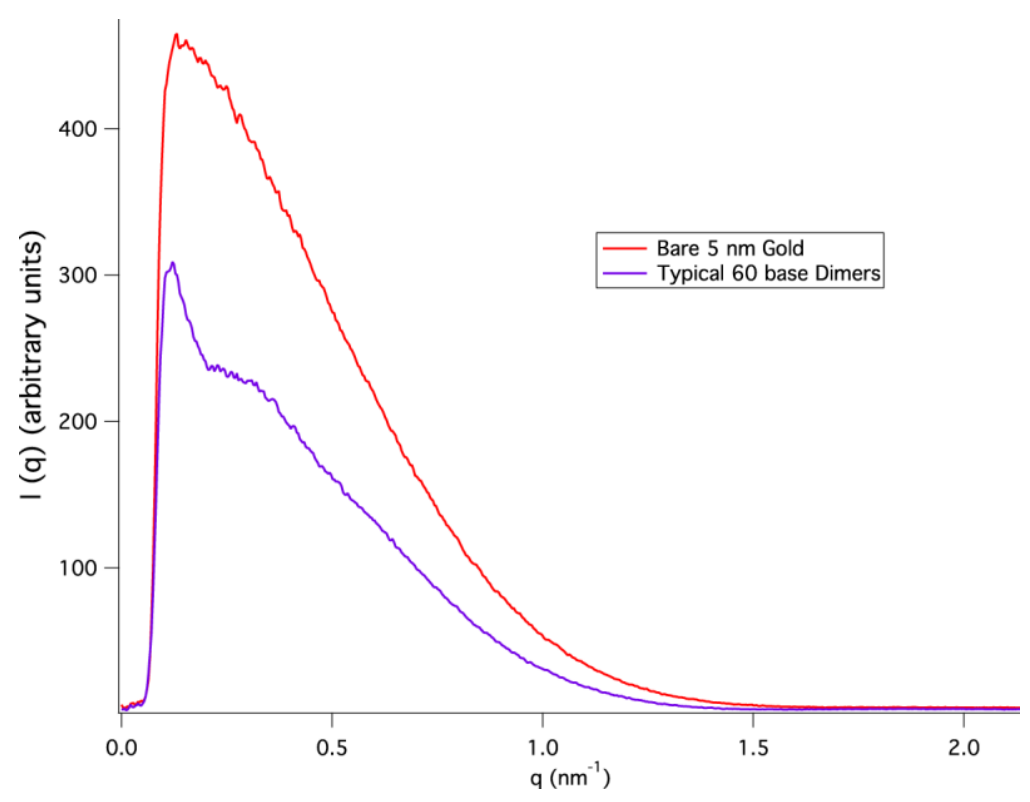

Figure S.C.1. Scattering distribution for bare $5 \mathrm{~nm}$ gold nanoparticles and 60-base dimers shows the introduction of a sinusoidal component corresponding to interference between X-rays scattered between pairs of nanoparticles in a dimer. 